AperTO - Archivio Istituzionale Open Access dell'Università di Torino

\title{
ERK inhibitor LY3214996-based treatment strategies for RAS-driven lung cancer
}

\section{This is the author's manuscript}

Original Citation:

Availability:

This version is available http://hdl.handle.net/2318/1771673

since 2021-02-07T14:12:35Z

Published version:

DOI:10.1158/1535-7163.MCT-20-0531

Terms of use:

Open Access

Anyone can freely access the full text of works made available as "Open Access". Works made available under a Creative Commons license can be used according to the terms and conditions of said license. Use of all other works requires consent of the right holder (author or publisher) if not exempted from copyright protection by the applicable law. 


\section{ERK inhibitor LY3214996-based treatment strategies for $R A S$-driven lung cancer}

Jens Köhler ${ }^{1, *}$, Yutong Zhao ${ }^{1, \#}$, Jiaqi Li ${ }^{1, \#}$, Prafulla C. Gokhale ${ }^{2}$, Hong L. Tiv ${ }^{2}$, Aine R. $\mathrm{Knott}^{2}$, Margaret K. Wilkens ${ }^{2}$, Kara M. Soroko ${ }^{2}$, Mika Lin ${ }^{1}$, Chiara Ambrogio ${ }^{1,3}$, Monica Musteanu $^{4,5}$, Atsuko Ogino ${ }^{1}$, Jihyun Choi ${ }^{1}$, Magda Bahcall ${ }^{1}$, Arrien A. Bertram ${ }^{1}$, Emily S. Chambers $^{1}$, Cloud P. Paweletz ${ }^{6}$, Shripad V. Bhagwat ${ }^{7}$, Jason R. Manro ${ }^{7}$, Ramon V. Tiu ${ }^{7}$, Pasi A. Jänne $e^{8, *}$

${ }^{1}$ Department of Medical Oncology, Dana-Farber Cancer Institute and Harvard Medical School, Boston, MA 02215, USA.

${ }^{2}$ Experimental Therapeutics Core and Belfer Center for Applied Cancer Science, DanaFarber Cancer Institute, Boston, MA 02210, USA.

${ }^{3}$ Department of Molecular Biotechnology and Health Science, Molecular Biotechnology Center, University of Torino, Torino, Italy.

${ }^{4}$ Experimental Oncology, Molecular Oncology Program, CNIO, Madrid, Spain.

${ }^{5}$ Biochemistry and Molecular Biology Department, Faculty of Pharmacy, Complutense University of Madrid, Spain.

${ }^{6}$ Department of Medical Oncology, Dana-Farber Cancer Institute and Harvard Medical School, Boston, MA 02215, USA; Belfer Center for Applied Cancer Science, Dana-Farber Cancer Institute, Boston, MA 02215, USA.

${ }^{7}$ Lilly Research Laboratories, Eli Lilly and Company, Indianapolis, IN 46285, USA.

${ }^{8}$ Department of Medical Oncology, Dana-Farber Cancer Institute and Harvard Medical School, Boston, MA 02215, USA; Belfer Center for Applied Cancer Science, Dana-Farber Cancer Institute, Boston, MA 02215, USA; Lowe Center for Thoracic Oncology, DanaFarber Cancer Institute, 450 Brookline Avenue, LC4114, Boston, MA 02215, USA.

\# contributed equally 
*Correspondence:

Pasi A. Jänne, MD/PhD

Director, Lowe Center for Thoracic Oncology

Dana-Farber Cancer Institute, LC-4114

450 Brookline Ave

Boston MA 02215, USA

Email: pasi_janne@dfci.harvard.edu

Jens Köhler, MD

Lowe Center for Thoracic Oncology

Dana-Farber Cancer Institute, LC-4053

450 Brookline Ave

Boston, MA 02215, USA

Email: jens_kohler@dfci.harvard.edu

Research support: This study was supported in part by Eli Lilly and Company, by the National Cancer Institute grant R35CA220497 (PAJ) and by a Mildred-Scheel postdoctoral research fellowship of the German Cancer Aid Foundation (70111755 to JK). 


\section{Conflicts of Interest:}

JK: received research support from Eli Lilly and Company and from the German Cancer Aid Foundation. He previously served as a consultant and on advisory boards for Boehringer Ingelheim.

YZ: None

JL: None

PCG: Sponsored research agreement with Elstar Therapeutics.

HLT: None

ARK: None

MKW: None

KMS: None

ML: None

CA: None

MM: None

AO: None

JC: None

MB: None

AAB: None

ESC: None

CPP: received honoraria from Bio-Rad, is a co-founder of XSphera Biosciences, and is on the scientific advisory board of Dropworks and XSphera Biosciences; sponsored research agreements with Daiichi Sankyo, Bicycle Therapeutics, Transcenta, Bicara Therapeutics, AstraZeneca, Intellia Therapeutics, and Constellation pharmaceuticals.

SVB: is an employee and stockholder of Eli Lilly and Company.

JRM: is an employee and stockholder of Eli Lilly and Company. 
RVT: was a Senior Medical Advisor at Eli Lilly and Company at the inception of this work. He has an ownership interest (stocks and patents) in Eli Lilly and Company and is currently employed as Senior Medical Director at Astellas US Pharma.

PAJ: reports consulting fees from AstraZeneca, Boehringer-Ingelheim, Pfizer, Roche/Genentech, Takeda Oncology, ACEA Biosciences, Eli Lilly and Company, Araxes Pharma, Ignyta, Mirati Therapeutics, Novartis, Loxo Oncology, Daiichi Sankyo, Sanofi Oncology, Voronoi, SFJ Pharmaceuticals and Biocartis; receiving post-marketing royalties from DFCI owned intellectual property on EGFR mutations licensed to Lab Corp; sponsored research agreements with AstraZeneca, DaichiSankyo, PUMA, Boehringer Ingelheim, Eli Lilly and Company, Revolution Medicines and Astellas Pharmaceuticals; and stock ownership in Loxo Oncology and Gatekeeper Pharmaceuticals. 


\begin{abstract}
$R A S$ gene mutations are the most frequent oncogenic event in lung cancer. They activate multiple RAS-centric signaling networks among them the MAPK, PI3K and RB pathways. Within the MAPK pathway ERK1/2 proteins exert a bottleneck function for transmitting mitogenic signals and activating cytoplasmic and nuclear targets. In view of disappointing anti-tumor activity and toxicity of continuously applied MEK inhibitors in patients with KRAS mutant lung cancer, research has recently focused on ERK1/2 proteins as therapeutic targets and on ERK inhibitors for their ability to prevent bypass and feedback pathway activation. Here we show that intermittent application of the novel and selective ATP-competitive ERK1/2 inhibitor LY3214996 exerts single-agent activity in patient-derived xenograft (PDX) models of $R A S$ mutant lung cancer. Combination treatments were well tolerated and resulted in synergistic (ERKi plus PI3K/mTORi LY3023414) and additive (ERKi plus CDK4/6i abemaciclib) tumor growth inhibition in PDX models. Future clinical trials are required to investigate if intermittent ERK inhibitor-based treatment schedules can overcome toxicities observed with continuous MEK inhibition and - equally important - to identify biomarkers for patient stratification.
\end{abstract}

Key words: RAS, ERK inhibitor, LY3214996, LY3023414, abemaciclib, FOXO3a, Bim, lung cancer, Bliss synergy, PDX model 


\section{Introduction}

Non-small cell lung cancers (NSCLC) with aberrations in the rat sarcoma oncogene family $(H-, N-, K R A S)$ represent $30 \%$ of all lung tumors (1). RAS mutations activate multiple downstream signaling pathways, among them MAPK and PI3K signaling both of which converge on the Cyclin D1/CDK4/6-RB axis (2,3). Besides this direct mechanistic link to mutant RAS, RB signaling is activated by co-occurring genetic events such as loss of CDKN2A (encoding for p16/p14ARF) or amplification of CDK4 or CCND1 (encoding for Cyclin D1) (4-6). These effector pathways play pivotal roles for cell cycle progression, proliferation and apoptotic resistance of cancer cells (7). Yet, abemaciclib - a CDK4/6 inhibitor - had only limited single-agent activity in clinical trials $(8,9)$ and MEK inhibitors administered on an uninterrupted schedule exhibited toxicity and poor anti-tumor activity in lung cancer patients $(10,11)$. Ultimately, MEK and PI3K inhibitor combinations caused significant toxicity in humans $(2,6,12,13)$.

Despite these setbacks, it remains an attractive strategy to inhibit RAS dependent effector pathways, since direct KRASG12C and immune checkpoint inhibitor (ICI) activity is limited to subgroups of patients with $R A S$ mutant cancers (14-16). ERK1/2 proteins exert a bottleneck function in activating cytoplasmic and nuclear targets and therefore, ERK inhibitors are considered to be more potent in preventing bypass and feedback activation than MEK inhibitors (17-19). So far, however, only few ERK inhibitors have been tested in clinical trials for solid tumors despite demonstrating efficacy in preclinical models of solid tumors and in BRAF and/or MEK inhibitor-refractory melanoma patients (20-24).

In the present study, we used models of $R A S$ mutant lung cancer derived from patients pretreated with multiple treatment modalities (including chemo+/-radiotherapy and ICIs) and from genetically engineered mouse models (GEMM) to investigate the efficacy of the novel ERK1/2 inhibitor LY3214996 alone and in combination with a PI3K/mTOR (LY3023414) (25) or CDK4/6 inhibitor (abemaciclib) (26). LY3214996 is effective in preclinical models across several cancer types $(27,28)$ and currently being evaluated in Phase I trials as monotherapy or in combination treatments for patients with advanced cancer (NCT02857270) (29). 


\section{Materials and Methods}

Detailed information is presented in Supplementary Materials and Methods.

Patient derived cell lines were generated from malignant pleural effusions or ascites collected under a Dana-Farber Cancer Institute IRB approved protocol. All patients provided written informed consent and the studies were conducted in accordance with the declaration of Helsinki. A targeted next-generation sequencing (NGS) cancer genomic assay ("Dana-Farber Cancer Institute (DFCI) OncoPanel”) was used to detect cell line specific somatic mutations, copy number variations and structural variants in tumor DNA. All cell lines were kept at $37{ }^{\circ} \mathrm{C}$ in complete media supplemented with $10 \%$ fetal bovine serum (FBS). DFCI168 (30), DFCI316, DFCI366, DFCI516 cells were grown in RPMI1640 media, DFCI24, DFCI298 and DFCI332 in ACL4 media. Murine cell lines were derived from previously described genetically engineered mouse models and grown in DMEM (GEMMs) (31,32). All cell lines tested negative for Mycoplasma throughout the study, were last tested on October $8^{\text {th }}, 2020$ and used until passage twenty-five for functional assays. LY3214996 (example \#1) (33), abemaciclib (example \#1) (34) and LY3023414 (example \#1) (35) were discovered at the Lilly Research Laboratories and synthesized as described in the respective patents. Selumetinib/AZD6244 (36), SCH772984 (37), afatinib/BIBW2992 (38) and linsitinib/OSI906 (39) were purchased from SelleckChem. Cells were lysed in RIPA buffer supplemented with protease and phosphatase inhibitors. The list of antibodies used can be found in Supplementary Materials and Methods. Western blot band intensities were quantified with ImageJ. All in vitro experiments were performed under adherent cell culture condition and live cell imaging was performed with an IncuCyte $\mathrm{ZOOM}^{\mathrm{TM}}$ real-time imaging system. Bliss synergy was determined and visualized with Combenefit (40). The Firefly-luciferase expressing FHRE-Luc reporter plasmid was a gift from Michael Greenberg (Addgene plasmid \#1789; http://n2t.net/addgene:1289 ; RRID:Addgene_1789). A renilla luciferase-expressing pRL-CMV control plasmid was used for normalization. Luciferase activities were quantified 
with the Dual-Glo® Luciferase Assay system. Nuclear-cytoplasmic fractionation was performed with the NE-PERTM Nuclear and Cytoplasmic Extraction Reagents. For patient-derived xenograft (PDX) models, female NSG (NOD SCID Gamma, Bar Harbor, Maine) and NCr nude mice (Taconic Biosciences, Rensselaer, NY), were housed and treated in accordance with protocols approved by the Dana-Farber Cancer Institute Animal Care and Use Committee. Tumor growth delay was calculated as previously described (41). MAPK pathway-dependent gene expression was quantified with a previously published 6-gene signature (DUSP4, DUSP6, ETV4, ETV5, SPRY2, PHLDA1) (42). A p-value less than 0.05 was considered statistically significant for all datasets. “*” indicates $p<0.05$, “**” $p<0.01$, “***” $p<0.001$ and “****” $p<0.0001$. Statistical analyses were performed with GraphPad Prism 8 and SAS (Version 9.3). 


\section{Results}

\section{Single agent activity of LY3214996 in $R A S$-mutant patient-derived lung cancer cell lines}

We sought to establish cancer cell lines reflecting the clinical distribution of $R A S$ mutations among lung cancer patients. In the TCGA Pan-Lung cancer dataset, about $30 \%$ of tumors exhibit aberrations in the $R A S$ gene family including activating gene mutations (Suppl. Fig. 1). KRAS is overall more frequently affected $(23 \%)$ than $N-(2.6 \%)$ or $\operatorname{HRAS}(1.7 \%)(43)$. Six out of seven cancer cell lines from patients who had previously undergone treatment for metastatic $R A S$ mutant lung cancer (Fig. 1A: bright-field microscopy images; Suppl. Fig. 2: patient histories) had KRAS mutations, one (DFCI168) had an NRAS mutation (30) and none had HRAS mutations. All patient-derived cell lines were genetically characterized by “OncoPanel” next-generation sequencing (NGS) at DFCI (44). We observed a high degree of concordance of genetic events between the available initial tumor biopsies and the established cell lines (Suppl. Table 1). Initially, we determined the absolute inhibitory concentrations $\left(\mathrm{IC}_{50}\right.$ values) of single-agent LY3214996 after $72 \mathrm{~h}$. DFCI168 $8^{\text {NRASQ61K }}(1.1 \mu \mathrm{M})$ and DFCI516 ${ }^{\text {KRASG12C }}(1.5 \mu \mathrm{M})$ exhibited the highest, DFCI316 ${ }^{\text {KRASQ61H }}(3.6 \mu \mathrm{M})$, DFCI2 $4^{\text {KRASG12C }}$ $(4.9 \mu \mathrm{M})$ and DFCI366 $6^{\text {KRASGI2D }}(9.1 \mu \mathrm{M})$ intermediate and DFCI298 $8^{\text {KRASGI2C }}$ and DFCI332 $2^{\text {KRASG12D }}$ the lowest sensitivity $(>10 \mu \mathrm{M})$ to LY3214996 (Fig. 1B). Despite a paradoxical dose-dependent increase in pERK $1 / 2^{\text {Thr202/Tyr204 and pMEK1/2 }}{ }^{\text {Ser217/221 }}$ following treatment with LY3214996, signaling downstream of pERK1/2 remained occluded as indicated by potent inhibition of phosphorylation of $\mathrm{p} 90 \mathrm{RSK}^{\mathrm{Thr} 359 / \mathrm{Ser} 363}$ and S6 ribosomal $\operatorname{protein}^{\text {Ser217/221 }}$ as well as reduction of c-MYC, DUSP4 and SPRY2 protein levels (Fig. 1C). We next established that compensatory ERK1/2 phosphorylation which was not induced in response to the structurally different ERK inhibitor SCH772984 (45) could be prevented by selumetinib (MEK inhibitor) pretreatment (Suppl. Fig. 3). Afatinib (pan-ErbB inhibitor) and linsitinib (IGFR inhibitor) had no effect on early ERK1/2 phosphorylation excluding a major involvement of these upstream RTKs in early ERK phosphorylation. Importantly, ERK target inhibition with LY3214996 $(1 \mu \mathrm{M})$ increased proportionally to treatment duration as 
evidenced by decreasing effector levels over 48 hours (Fig. 1D). Pathway inhibition was accompanied by stronger accumulation of pro-apoptotic BIM in sensitive (DFCI168 ${ }^{\text {NRASQ61K}}$ ) and intermediate sensitive cell lines (DFCI316 ${ }^{K R A S Q 61 H}$ ) which also exhibited more prominent PARP cleavage. LY3214996 treatment activated compensatory PI3K signaling (pAKT ${ }^{\text {Ser473) }}$ over baseline in all cell lines to varying extents (most evident in resistant cell lines and DFCI316 ${ }^{\text {KRASQ61H }}$ cells).

Subsequently, we quantified the expression of MAPK pathway-dependent effector genes during LY3214996 $(1 \mu \mathrm{M})$ treatment, using a previously published MAPK pathway activation gene set (42) and observed a decrease in mean pathway-dependent transcription in all cell lines over 48 hours (Fig. 1E). In DFCI24 and DFCI332 cells, mean expression levels increased slightly after 48 hours over levels observed at 24 hours but did not reach levels of untreated cells. Despite similar pathway suppression, dose-dependent inhibition of cancer cell proliferation with LY3214996 differed in cell lines over 72 hours and DFCI322 ${ }^{\text {KRASG12D }}$ cells were left unaffected with drug concentrations of up to $10 \mu \mathrm{M}$ (Fig. 1F). To investigate potential mechanisms of differential drug responses, we performed FOXO3a luciferase reporter assays since FOXO3a nuclear translocation and transcriptional activity has been shown to influence MEK inhibitor sensitivity (46). The more sensitive cell lines (DFCI168, DFCI24) exhibited increased FOXO3a reporter activity after 24 hours of LY3214996 (1 $\mu \mathrm{M})$ treatment, whereas reporter activity remained unchanged in resistant cell lines (DFCI366, DFCI298, DFCI332) and was reduced in intermediate sensitive DFCI316 cells (Fig. 1G). Cytoplasmic-nuclear fractionation experiments corroborated increased nuclear accumulation of FOXO3a in sensitive DFCI168 cells while FOXO3a levels were left unaffected in resistant DFCI332 cells (Fig. 1H).

\section{Single agent activity of LY3214996 in RAS mutant lung cancer PDX models}

To test the in vivo single agent activity, we treated DFCI168 $8^{\text {NRASQ61K }}$ tumor-bearing NSG mice with LY3214996 (100mg/kg, PO QD) and observed a significant reduction in tumor growth 
compared to tumors of vehicle treated animals (Fig. 2A, $\mathrm{n}=8$ animals/group, $p<0.0001$; Twoway Repeated Measures ANOVA with standard post hoc t-tests) which translated into a survival benefit despite treatment cessation after 21 days (median survival time: 49 days vs. 29.5, Fig. 2B, $p=0.0003$, Log-Rank test). Pharmacodynamic analyses (PD) demonstrated inhibition of ERK targets at 4 hours, including p90RSK ${ }^{\text {Thr359/Ser363 }}$ - a reliable PD biomarker for the extent of ERK inhibition (22) - of S6 ribosomal protein ${ }^{\text {Ser235/236 }}$ and reduction of total c-MYC, DUSP4 and SPRY2 protein levels (Fig. 2C). However, MAPK pathway activity recovered by 16 and 24 hours post-treatment. These pharmacodynamic effects correlated with plasma concentrations of LY3214996. At 4 hours, the LY3214996 plasma concentration was $3840 \pm 654 \mathrm{nM}$ resulting in $66 \%$ inhibition of pRSK. As the plasma concentrations declined at $16(189 \pm 267 \mathrm{nM})$ and 24 hours $(9 \mathrm{nM})$, pRSK inhibition declined to $33 \%$ and $34 \%$, respectively (Fig. 2D). AKT ${ }^{\text {Ser473 }}$ phosphorylation slightly increased at 4 hours indicating PI3K pathway activation and gradually decreased again over the next 20 hours. Consistent with strong MAPK pathway inhibition at 4 hours, we detected strong transcriptional suppression of individual genes within the 6-gene signature (60-80\%) (Suppl. Fig. 4A), and of the mean overall ERK transcriptional output $(\sim 60 \%)$, whereas gene expression increased slightly over baseline after 16 and 24 hours (Fig. 2E).

Despite good anti-tumor activity in DFCI168 tumors, LY3214996 did not affect growth of DFCI316 ${ }^{\text {KRASQ61H }}$ tumors when dosed once-daily $(100 \mathrm{mg} / \mathrm{kg}$, Fig. 2F, Two-way Repeated Measures ANOVA with standard post hoc t-tests) despite similar suppression of ERK-dependent gene expression as in DFCI168 ${ }^{\text {NRASQ61K }}$ tumors (Fig. 2G, Suppl. Fig. 4B). Interestingly, in contrast to LY3214996-sensitive DFCI168 ${ }^{\text {NRASQ61K }}$ tumors, LY3214996resistant DFCI316 ${ }^{\text {KRASQ61H }}$ tumors exhibited markedly increased ERK ${ }^{\text {Thr202/Tyr204 }}$ and AKT ${ }^{\text {Ser473 }}$ phosphorylation levels 4 hours after LY3214996 treatment compared to tumors of vehicle treated animals (Fig. 2H; DFCI316 vs. DFCI168, $p<0.05$, Student's t-test, Suppl. Fig. 5). $\mathrm{S6}^{\mathrm{Ser} 235 / 236}$ phosphorylation levels in DFCI316 tumors slightly increased over baseline compared to DFCI168 ${ }^{\text {NRASQ61K }}$ tumors (Fig. 2H, Suppl. Fig. 5, $p>0.05$, Student's t-test). 
Due to the lack of anti-proliferative activity in DFCI316 ${ }^{K R A S Q 61 H}$ tumors, the rapid MAPK pathway reactivation in two PDX models and the decrease of LY3214996 plasma levels with strong PK/PD relationship with once-daily drug dosing (Fig. 2C-H, Suppl. Fig. 4A,B), we subsequently tested if twice daily dosing at $50 \mathrm{mg} / \mathrm{kg}$ is superior to once daily dosing at $100 \mathrm{mg} / \mathrm{kg}$. Indeed, this was the case in the DFCI168 ${ }^{N R A S Q 61 K}$ PDX model (Fig. 2I, $\mathrm{n}=8$ animals/group, $p<0.0001$, Two-way Repeated Measures ANOVA with standard post hoc t-tests). Twice daily application of LY3214996 was well tolerated by NSG mice over 21 days (Suppl. Fig. 6).

\section{In vitro efficacy of combined ERK and PI3K/mTOR inhibition}

Since LY3214996-induced FOXO3a reporter activities differed substantially in the patientderived cancer cell lines (Fig. 1G), suggestive of differences in PI3K pathway activity, we next investigated the baseline characteristics of these cell lines. We observed that resistant cell lines (DFCI366, DFCI298, DFCI332) exhibited a more mesenchymal phenotype (AXL ${ }^{\text {high }}$, $\mathrm{ERBB}^{\text {low }}, \mathrm{BIM}^{\mathrm{low}}$ ) than sensitive cell lines (DFCI168, DFCI316 and DFCI24; Fig. 3A, Suppl. Fig 7). Since mesenchymal cells also exhibited increased PI3K pathway activation $\left(\mathrm{pAKT}^{\mathrm{S} 473}, \mathrm{pS}^{\mathrm{S} 235 / 236}\right)$, we next tested the effect of combined ERK1/2 and PI3K/mTOR inhibition with LY3214996 and LY3023414. First, we determined Bliss synergy after 72 hours in all patient-derived cell lines and observed mostly additive effects (color-coded in green) with some synergy (color-coded in blue) in DFCI366 ${ }^{\text {KRASG12A }}$ and DFCI516 ${ }^{\text {KRASGI2C }}$ cells (Fig. 3B). Western blot analyses of DFCI24 $4^{\text {KRASGI2C }}$ and DFCI316 ${ }^{\text {KRASQ61H }}$ protein lysates indicated, that PI3K inhibition with $1 \mu \mathrm{M}$ of LY3023414 slightly increased protein levels of ERK targets c-MYC, DUSP4 and SPRY2 compared to DMSO treated cells, whereas $1 \mu \mathrm{M}$ of LY3214996 and the combination of both drugs (both $1 \mu \mathrm{M}$ ) reduced ERK target levels over 72 hours, respectively (Fig. 3C). In both models, combined ERK plus PI3K inhibition also reduced $\mathrm{S}^{\mathrm{Ser} 235 / 236}$ phosphorylation more profoundly than either drug alone. 
Levels of pro-apoptotic BIM increased slightly in both cell lines and PARP cleavage was detectable after 48 and 72 hours in DFCI316 cells with combined drug treatment.

Next, we quantified transcriptional changes during simultaneous ERK1/2 and PI3K/mTOR inhibition. While LY3023414 $(1 \mu \mathrm{M})$ significantly increased mean overall MAPK pathway-dependent gene expression over 72 hours in both models compared to DMSO-treated cells (Fig. 3D; $\mathrm{p}<0.001$ for DFCI24 and $\mathrm{p}<0.01$ for DFCI316; Unpaired tTest), LY3214996 alone $(1 \mu \mathrm{M})$ or the combination of PI3K/mTOR and ERK1/2 inhibitor reduced the expression $(\mathrm{p}<0.0001$; Unpaired $\mathrm{t}-\mathrm{Test})$. The reduction of overall gene expression in cells treated with single-agent LY3214996 and with the drug combination was comparable ( $p=0.83$ for DFCI24 and $p=0.068$ for DFCI316; Unpaired t-Test). Stronger transcriptional pathway suppression with the drug combination was accompanied by increased FOXO3a reporter activity in DFCI24 and DFCI316 cells compared to LY3214996 treatment alone (Fig. 3E) and resulted in increased nuclear FOXO3a accumulation in DFCI24 cells (Fig. 3F).

To determine the effect of co-occurring $T p 53$ or $L k b 1$ mutations (47) on efficacy of combined ERK1/2 and PI3K/mTOR inhibition, we determined Bliss synergy in cell lines derived from genetically engineered mouse models $($ GEMM $)\left(\right.$ Kras $^{G 12 V}=$ "K"-genotype: CHA14.1 and CHA14.2 (48); $\operatorname{Kras}^{G 12 V} ; \operatorname{Tp}^{53^{f l f l}=}$ "KP"-genotype: CHA9.1 and CHA9.3; $\operatorname{Kras}^{G 12 V} ; T p 53^{\text {fllfl }} ;$ Lkb $^{f l l f l}=$ "KPL"-genotype: CHA487 and CHA496) after 72 hours (Fig. 3G). We observed mostly additive effects (color-coded in green), increased synergy (color-coded in blue) was detected in the presence of $T p 53$ and $L k b 1 / S t k 11$ co-mutations. Overall, the surface area indicating synergy was increased in GEMM-derived cell lines across genotypes compared to human-derived cancer cell lines (Fig. 3B).

\section{Anti-tumor effect of combined ERK and PI3K/mTOR inhibition in PDX models}

To test the in vivo efficacy of combined ERK1/2 and PI3K inhibition, we treated NSG mice with xenotransplanted DFCI24 ${ }^{\text {KRASGI2C }}$ tumors for 4 weeks with vehicle, high-dose continuous LY3214996 (150mg/kg, PO QD), intermittent split-dose LY3214996 (75mg/kg, PO BID, 4d 
ON, 3d OFF), intermittent split-dose LY3023414 (15mg/kg, PO BID, 4d ON, 3d OFF) or a combination of both drugs. Anti-tumor effects of single agent treatments were comparably modest, whereas the inhibitor combination had a relatively robust anti-tumor effect (Fig. 4A and Suppl. Fig. 8A; p<0.0001; Two-way Repeated Measures ANOVA with standard post hoc t-tests). We also treated the DFCI316 ${ }^{K R A S Q 61 H}$ PDX model with the same treatment schedules. We observed significant tumor growth inhibition in all treatment groups after 4-weeks, but tumor regressions were only achieved in the combination group (Fig. 4B and Suppl. Fig. 8B; $\mathrm{p}<0.0001$; Two-way Repeated Measures ANOVA with standard post hoc t-tests). All treatment schedules were well tolerated (Suppl. Fig. 9) and no differences in plasma drug concentrations from day $1 / 2$ to day $14 / 15$ were observed thus excluding changes in drug metabolism over time (Suppl. Fig. 10). With most animals for both PDX models having progressive disease with single agent treatment, nearly half of the animals with DFCI24 ${ }^{\text {KRASG12C }}$ tumors and all animals with DFCI316 ${ }^{\text {KRASQ61H }}$ tumors achieved at least stable disease after 4-weeks of treatment in the combination group. Partial responses (PR) were observed in 3/8 animals (DFCI24) and 5/9 animals (DFCI316) in the combination group, respectively. Overall, treatment effects were synergistic in both PDX models (Bliss Independence method; Suppl. Fig. 11A,B) and translated into a stronger tumor growth delay in mice treated with the drug combination compared (Fig. 4C; DFCI24: 15.8 (combination) vs. 2.3 (LY3214996 BID) vs. 0.9 days (LY3023414); DFCI316: 26.8 (combination) vs. 12.2 (LY3214996 BID) vs. 17.5 days (LY3023414) compared to vehicle control).

Lysates of DFCI24 ${ }^{\text {KRASG12C }}$ tumors which had been treated with vehicle, LY3214996 $(75 \mathrm{mg} / \mathrm{kg})$, LY3023414 $(15 \mathrm{mg} / \mathrm{kg})$ or a combination of both drugs for 4,8 and 24 hours showed reduced levels of DUSP4, SPRY2, c-MYC and phosphorylation of p90RSK ${ }^{\text {Thr359/Ser363 }}$ as early as 4 hours after the application of LY3214996 or of the drug combination. Contrariwise, phosphorylation and total levels of these proteins were increased in tumors treated with single agent LY3023414 (Fig. 4D). Whereas signaling parameters (phosphop90RSK and phospho-S6) returned to baseline after 24 hours with single-agent treatment, the 
ERK/PI3K inhibitor combination induced continuous suppression of MAPK and PI3K downstream targets. ERK1/2 ${ }^{\text {Thr202/Tyr204 }}$ phosphorylation was increased in LY3214996-treated tumors at all time points and slightly increased in tumors of LY3023414-treated mice. More potent pathway inhibition with the drug combination coincided with stronger BIM accumulation and PARP cleavage at all time points. Analysis of MAPK pathway-dependent gene expression from the same tumors showed good overall pathway suppression with single agent LY3214996 4 and 8 hours after the last drug application, whereas PI3K/mTOR inhibition alone induced pathway hyperactivation at 4 hours (Fig. 4E). The drug combination not only prevented the early $\mathrm{PI} 3 \mathrm{~K} / \mathrm{mTOR}$ inhibitor-induced transcriptional pathway hyperactivation but was also more efficacious in counteracting pathway reactivation with single agent ERK1/2 inhibition at 24 hours (Fig. 4E, dotted red line, $p<0.05$, Unpaired t-Test).

\section{In vitro efficacy of combined ERK and CDK4/6 inhibition}

Since inputs from the MAPK and PI3K signaling pathways promote G1/S cell cycle transition via the cyclin D1-CDK4/6-RB pathway (3), we also tested the combination of LY3214996 and abemaciclib (LY2835219), a specific cyclin-dependent kinase (CDK) 4/6 inhibitor. First, we determined Bliss synergy by treating all patient-derived cell lines for 72 hours with different concentrations of both drugs. We observed mostly additive effects (color-coded in green) across the tested dose range with some synergy (color-coded in blue) in DFCI316 ${ }^{\text {KRASQ61H }}$, DFCI332 $2^{\text {KRASG12D }}$ and DFCI516 ${ }^{\text {KRASGI2C }}$ cells (Fig. 5A). Treatment effects were independent of the drug sequence (Suppl. Fig. 12) and of the used ERK inhibitor as combination partner (SCH772984 in Suppl. Fig. 13). Lysates of DFCI24 ${ }^{\text {RRASGI2C }}$ and DFCI332 ${ }^{\text {KRASGI2D }}$ cells which had been treated for up to 72 hours with DMSO, LY3214996 $(1 \mu \mathrm{M})$, abemaciclib $(1 \mu \mathrm{M})$ or the combination of both drugs showed more profound suppression of RB, ERK1/2 and S6 phosphorylation as well as of c-MYC protein levels than with either drug alone (Fig. 5B). DUSP4 and SPRY2 protein levels were equally suppressed with LY3214996 and the drug combination. Single agent abemaciclib suppressed S6 
phosphorylation which is due to inhibition of CDK4-activated mTOR activity (49). Neither treatment led to PARP cleavage and BIM accumulation in response to LY3214996 was counteracted by the addition of abemaciclib.

To determine the impact of co-occurring Tp53 and Lkb1 mutations (47) on the efficacy of combined ERK1/2 and CDK4/6 inhibition, we determined drug synergy in GEMM-derived KRASG12V mutant lung cancer cell lines with $\mathrm{K}, \mathrm{KP}$ and KPL genotype after 72 hours and observed some drug synergy (color-coded in blue) across genotypes which was increased in the presence of co-mutations in Tp53 and STK11/Lkb1 (Fig. 5C). Overall, the synergy of combined ERK1/2 and CDK4/6 inhibition was more pronounced in GEMM-derived cell lines across genotypes compared to patient-derived cell lines (Fig. 5A).

\section{Anti-tumor effect of combined ERK1/2 and CDK4/6 inhibition in PDX models}

To test the in vivo efficacy of combined ERK1/2 and CDK4/6 inhibition, we treated the DFCI168 ${ }^{\text {NRASQ61K }}$ (Fig. 6A) and DFCI24 ${ }^{\text {KRASG12C }}$ PDX models (Fig. 6B) for 28 days with vehicle, LY3214996 (100mg/kg, PO QD), abemaciclib (50mg/kg, PO QD) or the combination of both drugs. We established, that the well-tolerated split-dose intermittent application of LY3214996 (50mg/kg, PO BID, 4d ON 3d OFF) in combination with abemaciclib $(50 \mathrm{mg} / \mathrm{kg}$, PO QD) was not superior over once-daily drug application (Suppl. Fig. 14). Therefore, we chose a continuous once-daily dosing schedule for the efficacy studies. We observed tumor growth inhibition in both PDX models with LY3214996, whereas abemaciclib itself was ineffective ( $p<0.001$, Two-way Repeated Measures ANOVA with standard post hoc t-tests). The strongest anti-tumor effect was observed in animals which received both drugs (DFCI168: Fig. 6A and Suppl. Fig. 15A; DFCI24: Fig. 6B and Suppl. Fig. 15B; $p<0.0001$, Two-way Repeated Measures ANOVA with standard post hoc t-tests). The effect of combining LY3214996 and abemaciclib was additive in the DFCI168 ${ }^{\text {NRASQ61K }}$ and less than additive in the DFCI24 ${ }^{\text {KRASGI2C }}$ model (Bliss Independence method; Suppl. Fig. 16A, B) but translated into a longer tumor growth delay compared to single agent treatment (Fig. 6C; 
DFCI168: 24.8 (combination) vs. 15.7 (LY3214996) vs. 2.9 days (abemaciclib); DFCI24: 7.2 (combination) vs. 3.2 (LY3214996) vs. 3.1 days (abemaciclib) compared to vehicle control). In tumor lysates we observed inhibition of RB phosphorylation with LY3214996 or abemaciclib at early timepoints (4 and 8 hours) but partial pathway reactivation after 24 hours (DFCI168: Fig. 6D; DFCI24: Suppl. Fig. 17). This rebound was effectively reduced by the addition of LY3214996 to abemaciclib. Single-agent abemaciclib increased phosphorylation of p90RSK (which is in contrast to p-p90RSK inhibition which we observed in vitro (Fig. 5B)) and AKT as well as protein levels of Cyclin D1 compared to vehicle which was pronounced at 24 hours in both models, suggesting compensatory MAPK and PI3K pathway hyperactivation. MAPK pathway hyperactivation could be counteracted by adding LY3214996 to abemaciclib. While BIM protein levels increased in LY3214996-treated DFCI168 $8^{\text {NRASQ61K }}$ tumors, treatment with abemaciclib or the drug combination had the opposite effect on BIM overall and neither treatment increased PARP cleavage. Analysis of MAPK pathway-dependent gene expression from the same tumors showed good overall pathway suppression with single agent LY3214996 4 and 8 hours after the last drug application, whereas abemaciclib induced early (4 and 8 hours) pathway hyperactivation which could be prevented by the drug combination (Fig. 6E).

\section{Discussion}

Activating mutations in RAS proteins occur in about 30\% of lung cancers (Suppl. Fig. 1) (1). Advances have been made in the clinical development of direct KRAS and immune checkpoint inhibitors (ICB) but these strategies are so far restricted to lung cancers with KRASG12C mutations and to immunologically "hot" tumors, respectively $(14-16,50)$. Therefore, inhibiting RAS effector pathways which promote malignant behavior of cancer cells remains an attractive alternative. Unfortunately, single agent treatment approaches have had no (MEK inhibitors) or only limited (CDK4/6 inhibitor) anti-tumor activity in clinical trials $(8,10,11)$. Based on high cancer cell plasticity and pathway redundancy, potential 
resistance mechanisms include the loss of ERK-mediated negative feedback inhibition and PI3K pathway activation via receptor tyrosine kinases (RTKs) for MEK $(51,52)$ and compensatory MAPK pathway activation for CDK4/6 inhibitors (53). Additionally, cooccurring loss of function mutations of tumor suppressor genes (e.g. TP53 and STK11) increase the genetic heterogeneity of $R A S$ mutant tumors and impede therapeutic interventions (47). The major obstacle, however, is the toxicity observed with continuous blockade of MAPK pathway activity alone or in combination with other pathways (e.g. MEK plus PI3K inhibition) hence strongly indicating an unmet need to develop alternative combination strategies $(2,6,10,11,13)$.

Since ERK1/2 inhibitors are more potent in preventing feedback and bypass activation compared to MEK1/2 inhibitors, toxicities intrinsic to continuous MEK inhibition could potentially be overcome by intermittent application (i.e. to include drug-free periods) of ERK inhibitors without compromising on anti-tumor efficacy $(17,18)$. Therefore, in the present study, we investigated the efficacy of the ATP-competitive ERK1/2 inhibitor LY3214996 as single agent and in combination with a PI3K/mTOR (LY3023414) inhibitor (25) or CDK4/6 inhibitor (abemaciclib) (26). LY3214996 has anti-neoplastic activity in commercially available cell lines and tumor models with MAPK pathway aberrations - many of them with KRAS mutations (27). Since for these models no or only very limited clinical annotation is available, we sought to study genetically well-characterized cell lines established from tumors of pre-treated patients which are more reflective of the clinical setting in which an ERK inhibitor or ERK inhibitor-based drug combination would be initially clinically evaluated.

We established seven $R A S$ mutant cancer cell lines (n=6 KRAS, $\mathrm{n}=1$ NRAS, Fig. 1A, Suppl. Table 1) from malignant effusions of in part heavily pre-treated patients (Suppl. Fig. 2), in which single agent LY3214996 treatment profoundly suppressed MAPK pathway activity (Fig. 1C-E). With the exception of DFCI332 cells, this translated into growth inhibition in all cell lines including those with STK11/LKB1 co-mutations (Fig. 1F), a genotype with relative intrinsic insensitivity to MEK inhibition (54), hence supporting pre- 
clinical data indicating, that ERK inhibitors may have the potential to overcome this limitation of MEK inhibitors (55). LY3214996 also exhibited good anti-tumor activity in various PDX models (Fig. 2A; Fig. 4A and B, Fig. 6A and B) in which - similar to other ERK inhibitors - we observed a strong PK/PD relationship with once-daily drug application due to rapid plasma elimination (Fig. 2D). This pharmacokinetic trait led to an early recovery of MAPK pathway activity (Fig. 2C-E, 2G-H; Suppl. Fig. 4A, B) and consequently, the antitumor potency of LY3214996 increased with a split-dose approach without affecting the plasma drug clearance over longer treatment periods (Fig. 2I; Fig. 4B versus Fig. 2F, Suppl. Fig. 6 and 10).

Across various cell lines and PDX models, however, the anti-neoplastic effect of LY3214996 differed substantially (Fig. 1B and F, Fig. 2A and F) despite comparable suppression of MAPK pathway activity (Fig. 1C-E; Fig. 2E and G). LY3214996 increased pro-apoptotic BIM in sensitive and intermediate sensitive cell lines in vitro (Fig. 1D), but failed to do so in resistant cell lines and - despite reducing tumor growth in various PDX models - tumor regressions were not observed (Fig. 2A; Fig. 4A and B; Fig. 6A and B). This possibly indicated compensatory mechanisms counteracting full execution of apoptosis. We subsequently established that cancer cell lines with reduced LY3214996 sensitivity exhibit a more mesenchymal phenotype with PI3K pathway activation and BIM suppression at baseline (DFCI298, DFCI332) (Fig. 3A, Suppl. Fig. 7) or activate PI3K signaling in response to LY3214996 (DFCI316, Fig. 1C and D, Fig. 2H, Suppl. Fig. 5). PI3K pathway activation is known to prevent nuclear translocation of FOXO3a upon MEK inhibition thus preventing BIM induction and apoptosis execution $(46,56)$. Consistently, we observed a lack of FOXO3a nuclear translocation and transcriptional activation in resistant (DFCI298, DFCI332, DFCI366) versus sensitive (DFCI168) cell lines upon LY3214996 treatment (Fig. 1G, H).

We subsequently show that PI3K pathway-mediated LY3214996 resistance can be overcome by combined ERK1/2 plus $\mathrm{PI} 3 \mathrm{~K} / \mathrm{mTOR}$ inhibition. The combination with LY3023414 increased downstream pathway suppression, BIM induction and anti-proliferative 
activity in human and GEMM-derived cancer cell lines (Fig. 3B-D, G) by promoting nuclear FOXO3a accumulation and transcriptional activition (Fig. 3D,E). This translated into synergistic growth inhibition and stronger tumor growth delay in PDX models with actual tumor regressions indicating an in vivo apoptotic response (Fig. 4A-D; Suppl. Fig. 8, Suppl. Fig. 11A and B). Tumor growth delay is a critically important measure of antitumor efficacy since it most closely mimics clinical endpoints that required observation of mice through the time of disease progression (41). Intermittent dosing of both drugs (i.e. 4 days treatment followed by a 3 day treatment-free period) was well tolerated by NSG mice (Suppl. Fig. 9) and did not compromise treatment efficacy which is important for the transfer into clinical applications even though toxicity profiles of ERK plus PI3K inhibitor combinations in humans remain unknown today. In light of significant toxicity observed with MEK or BRAF plus PI3K inhibitor combinations on uninterrupted schedules $(6,57)$, future clinical trials are therefore required to investigate if the LY3214996 plus LY3023414 drug combination is better tolerated. Compared to MEK inhibitors, ERK inhibitors lack a subset of toxicities (e.g. retinopathy) (58) and LY3023414 differentiates from other PI3K pathway inhibitors in showing a short half-life of approximately two hours in clinical PK studies (59) thus potentially making the LY3214996 plus LY3023414 combination more applicable to humans to overcome overlapping toxicities such as nausea, vomiting, diarrhea, fatigue or rash. The pronounced drug synergy that we observed in GEMM-derived cell lines with subtypedefining Tp53 and Stk11/Lkb1 co-mutations (Fig. 3G) may hold promise for this drug combination also in these otherwise hard to treat lung cancer subtypes $(47,54)$.

Whereas tumor regressions were observed with the ERK/PI3K inhibitor combination, combining LY3214996 with the CDK4/6 inhibitor abemaciclib (26) - a concept supported by mechanistic studies which showed synthetic lethality between KRAS and CDK4 and identified MAPK pathway activation as a CDK4/6 inhibitor resistance mechanism $(5,60)$ lacked the potential to induce an apoptotic response in PDX models despite more sustained pathway inhibition and anti-neoplastic activity in vitro and in vivo (Fig. 5B and C; Fig. 6A-E, 
Suppl. Fig. S12A and B, Suppl. Fig. 13). This is not unexpected since a key feature of CDK4/6 inhibition is the induction of a cell cycle inhibitory response that mimics the intrinsic senescence phenotype (5). Failure to induce cancer cell death, however, could compromise treatment efficacy, especially if rapid tumor shrinkage is required in symptomatic patients with high tumor burden.

Therefore, one major aspect that needs to be addressed in future pre-clinical and clinical studies is a survey to identify predictive biomarkers to aid patient stratification especially for the ERK plus CDK4/6 inhibitor combination. Here, we identify epithelial differentiation as a correlative marker for LY3214996 sensitivity. We hypothesize that apart from epithelial-to-mesenchymal transition, mutations affecting PI3K signalling (e.g. loss of PTEN or PIK3CA mutations) may exert similar effects. Interestingly, resistant DFCI332 cells which harbor a Noonan syndrome-associated SHP2/PTPN11 (c.923A>G, p.N308S) missense mutation exhibited the highest level of baseline PI3K pathway activation of all cell lines (Fig. 3A). SHP2 controls PI3K (and MAPK) pathway activity (61) and the PTPN11 c.923A>G mutation is considered pathogenic (FATHMM prediction score 1.0) in COSMIC. Furthermore of interest, DFCI168 cells with the highest LY3214996 single agent sensitivity harbor a $N R A S^{Q 61 K}$ mutation. Zhou et al. reported recently, that KRASQ61H preferentially signals through the MAPK pathway conferring MEK inhibitor sensitivity (62). Even though our study is limited to draw general conclusions, certain $R A S$ mutations may also predict increased LY3214996 sensitivity. Of note, single agent abemaciclib was ineffective in both PDX models (Fig. 6A and B), even though both cell lines harbor non-functional p16 proteins which have been associated with CDK4/6 inhibitor sensitivity (63). DFCI168 cells present with a p16INK4A R80* mutation predicted to be pathogenic (FATHMM prediction score 0.88 in COSMIC) and reported to produce a truncated, non-functional p16 protein (64); DFCI24 cells exhibit a two-copy deletion of CDKN2A conferring loss of p16 (Suppl. Table 1). The predictive value of p16 loss, however, remains unclear (65) and in DFCI24 cells, mesenchymal differentiation with associated PI3K pathway activation (Fig. 3A) may have 
prevented abemaciclib from being effective (66). Overall, our experimental findings in combination with the available clinical data $(8,9)$ suggest that isolated CDK4/6 inhibition may be insufficient to achieve satisfactory anti-tumor activity in $R A S$ mutant lung cancer and that combined CDK4/6 plus ERK1/2 inhibition has the potential to overcome this limitation to a certain extent especially in tumors with TP53 and STK11/LKB1 co-mutations (Fig. 3E; Fig. 5C) $(47,54)$.

In summary, we demonstrate the efficacy of LY3214996-based drug combinations in PDX models of RAS mutant lung cancer (Fig. 6F summarizes the therapeutic approaches). Intermittent ERK inhibition on a "4-days-On-3-days-OFF" schedule is well tolerated in mice without compromising on anti-tumor activity. Currently ongoing (NCT02857270, NCT03454035) and future clinical trials should aim to determine whether intermittent ERK inhibitor-based drug combinations can overcome toxicities associated with continuous MEK inhibition and to validate treatment predictors.

\section{Acknowledgements:}

This study was funded by Eli Lilly and Company. We thank Johannes Köster for supporting this project scientifically. 


\section{References}

1. Prior IA, Hood FE, Hartley JL. The frequency of Ras mutations in cancer. Cancer Res 2020

2. Hoeflich KP, Merchant M, Orr C, Chan J, Den Otter D, Berry L, et al. Intermittent administration of MEK inhibitor GDC-0973 plus PI3K inhibitor GDC-0941 triggers robust apoptosis and tumor growth inhibition. Cancer Res 2012;72:210-9

3. Topacio BR, Zatulovskiy E, Cristea S, Xie S, Tambo CS, Rubin SM, et al. Cyclin DCdk4,6 Drives Cell-Cycle Progression via the Retinoblastoma Protein's C-Terminal Helix. Mol Cell 2019;74:758-70 e4

4. Aktas H, Cai H, Cooper GM. Ras links growth factor signaling to the cell cycle machinery via regulation of cyclin D1 and the Cdk inhibitor p27KIP1. Mol Cell Biol 1997; $17: 3850-7$

5. Puyol M, Martin A, Dubus P, Mulero F, Pizcueta P, Khan G, et al. A synthetic lethal interaction between K-Ras oncogenes and Cdk4 unveils a therapeutic strategy for nonsmall cell lung carcinoma. Cancer Cell 2010;18:63-73

6. Shapiro GI, LoRusso P, Kwak E, Pandya S, Rudin CM, Kurkjian C, et al. Phase Ib study of the MEK inhibitor cobimetinib (GDC-0973) in combination with the PI3K inhibitor pictilisib (GDC-0941) in patients with advanced solid tumors. Invest New Drugs 2020;38:419-32

7. Simanshu DK, Nissley DV, McCormick F. RAS Proteins and Their Regulators in Human Disease. Cell 2017;170:17-33

8. Goldman JW, Mazieres J, Barlesi F, Koczywas M, Dragnev KH, Göksel T, et al. A randomized phase 3 study of abemaciclib versus erlotinib in previously treated patients with stage IV NSCLC with KRAS mutation: JUNIPER. Journal of Clinical Oncology 2018;36:9025-

9. Patnaik A, Rosen LS, Tolaney SM, Tolcher AW, Goldman JW, Gandhi L, et al. Efficacy and Safety of Abemaciclib, an Inhibitor of CDK4 and CDK6, for Patients with Breast Cancer, Non-Small Cell Lung Cancer, and Other Solid Tumors. Cancer Discov 2016;6:740-53

10. Blumenschein GR, Jr., Smit EF, Planchard D, Kim DW, Cadranel J, De Pas T, et al. A randomized phase II study of the MEK1/MEK2 inhibitor trametinib (GSK1120212) compared with docetaxel in KRAS-mutant advanced non-small-cell lung cancer (NSCLC). Ann Oncol 2015;26:894-901

11. Janne PA, van den Heuvel MM, Barlesi F, Cobo M, Mazieres J, Crino L, et al. Selumetinib Plus Docetaxel Compared With Docetaxel Alone and Progression-Free 
Survival in Patients With KRAS-Mutant Advanced Non-Small Cell Lung Cancer: The SELECT-1 Randomized Clinical Trial. JAMA 2017;317:1844-53

12. Engelman JA, Chen L, Tan X, Crosby K, Guimaraes AR, Upadhyay R, et al. Effective use of PI3K and MEK inhibitors to treat mutant Kras G12D and PIK3CA H1047R murine lung cancers. Nat Med 2008;14:1351-6

13. Ramanathan RK, Von Hoff DD, Eskens F, Blumenschein G, Jr., Richards D, Genvresse I, et al. Phase Ib Trial of the PI3K Inhibitor Copanlisib Combined with the Allosteric MEK Inhibitor Refametinib in Patients with Advanced Cancer. Target Oncol 2020; $15: 163-74$

14. Canon J, Rex K, Saiki AY, Mohr C, Cooke K, Bagal D, et al. The clinical KRAS(G12C) inhibitor AMG 510 drives anti-tumour immunity. Nature 2019;575:21723

15. Hallin J, Engstrom LD, Hargis L, Calinisan A, Aranda R, Briere DM, et al. The KRAS(G12C) Inhibitor MRTX849 Provides Insight toward Therapeutic Susceptibility of KRAS-Mutant Cancers in Mouse Models and Patients. Cancer Discov 2020;10:54-71

16. Borghaei H, Paz-Ares L, Horn L, Spigel DR, Steins M, Ready NE, et al. Nivolumab versus Docetaxel in Advanced Nonsquamous Non-Small-Cell Lung Cancer. N Engl J Med 2015;373:1627-39

17. Nissan MH, Rosen N, Solit DB. ERK pathway inhibitors: how low should we go? Cancer Discov 2013;3:719-21

18. Xue Y, Martelotto L, Baslan T, Vides A, Solomon M, Mai TT, et al. An approach to suppress the evolution of resistance in BRAF(V600E)-mutant cancer. Nat Med 2017;23:929-37

19. Hatzivassiliou G, Liu B, O'Brien C, Spoerke JM, Hoeflich KP, Haverty PM, et al. ERK inhibition overcomes acquired resistance to MEK inhibitors. Mol Cancer Ther 2012; $11: 1143-54$

20. Blake JF, Burkard M, Chan J, Chen H, Chou KJ, Diaz D, et al. Discovery of (S)-1-(1(4-Chloro-3-fluorophenyl)-2-hydroxyethyl)-4-(2-((1-methyl-1H-pyrazol-5-y

1)amino)pyrimidin-4-yl)pyridin-2(1H)-one (GDC-0994), an Extracellular SignalRegulated Kinase 1/2 (ERK1/2) Inhibitor in Early Clinical Development. J Med Chem 2016;59:5650-60

21. Germann UA, Furey BF, Markland W, Hoover RR, Aronov AM, Roix JJ, et al. Targeting the MAPK Signaling Pathway in Cancer: Promising Preclinical Activity with the Novel Selective ERK1/2 Inhibitor BVD-523 (Ulixertinib). Mol Cancer Ther 2017; 16:2351-63 
22. Morris EJ, Jha S, Restaino CR, Dayananth P, Zhu H, Cooper A, et al. Discovery of a novel ERK inhibitor with activity in models of acquired resistance to BRAF and MEK inhibitors. Cancer Discov 2013;3:742-50

23. Moschos SJ, Sullivan RJ, Hwu WJ, Ramanathan RK, Adjei AA, Fong PC, et al. Development of MK-8353, an orally administered ERK1/2 inhibitor, in patients with advanced solid tumors. JCI Insight 2018;3

24. Sullivan RJ, Infante JR, Janku F, Wong DJL, Sosman JA, Keedy V, et al. First-in-Class ERK1/2 Inhibitor Ulixertinib (BVD-523) in Patients with MAPK Mutant Advanced Solid Tumors: Results of a Phase I Dose-Escalation and Expansion Study. Cancer Discov 2018;8:184-95

25. Smith MC, Mader MM, Cook JA, Iversen $\mathrm{P}$, Ajamie R, Perkins E, et al. Characterization of LY3023414, a Novel PI3K/mTOR Dual Inhibitor Eliciting Transient Target Modulation to Impede Tumor Growth. Mol Cancer Ther 2016; $15: 2344-56$

26. Gelbert LM, Cai S, Lin X, Sanchez-Martinez C, Del Prado M, Lallena MJ, et al. Preclinical characterization of the CDK4/6 inhibitor LY2835219: in-vivo cell cycledependent/independent anti-tumor activities alone/in combination with gemcitabine. Invest New Drugs 2014;32:825-37

27. Bhagwat SV, McMillen WT, Cai S, Zhao B, Whitesell M, Shen W, et al. ERK Inhibitor LY3214996 Targets ERK Pathway-Driven Cancers: A Therapeutic Approach Toward Precision Medicine. Mol Cancer Ther 2020;19:325-36

28. Weisberg E, Meng C, Case A, Sattler M, Tiv HL, Gokhale PC, et al. Evaluation of ERK as a therapeutic target in acute myelogenous leukemia. Leukemia 2020;34:625-9

29. Pant S, Bendell JC, Sullivan RJ, Shapiro G, Millward M, Mi G, et al. A phase I dose escalation (DE) study of ERK inhibitor, LY3214996, in advanced (adv) cancer (CA) patients (pts). Journal of Clinical Oncology 2019;37:3001-

30. Ogino A, Choi J, Lin M, Wilkens MK, Calles A, Xu M, et al. Genomic and pathological heterogeneity in clinically diagnosed small cell lung cancer in never/light smokers identifies therapeutically targetable alterations. Mol Oncol 2020

31. Ambrogio C, Carmona FJ, Vidal A, Falcone M, Nieto P, Romero OA, et al. Modeling lung cancer evolution and preclinical response by orthotopic mouse allografts. Cancer Res 2014;74:5978-88

32. Ambrogio C, Gomez-Lopez G, Falcone M, Vidal A, Nadal E, Crosetto N, et al. Combined inhibition of DDR1 and Notch signaling is a therapeutic strategy for KRASdriven lung adenocarcinoma. Nat Med 2016;22:270-7 
33. Cortez GS, Joseph S, McLean JA, McMillen WT, Rodriguez MJ, Zhao G. Erk inhibitors. United States Patent US 9,469,652 B2. 2016 Oct 18.

34. Coates DA, Gelbert LM, Knobeloch JM, De Dios Magana A, De Prado Gonzalez A, Del Prado Catalina MF, et al. Protein Kinase Inhibitors. United States Patent US 7,855,211 B2 2010 Dec 21.

35. Barda DA, Mader MM. PI3 Kinase/mTor Dual Inhibitor. United States Patent US $8,658,668$ B2 2014 Feb 25.

36. Yeh TC, Marsh V, Bernat BA, Ballard J, Colwell H, Evans RJ, et al. Biological characterization of ARRY-142886 (AZD6244), a potent, highly selective mitogenactivated protein kinase kinase 1/2 inhibitor. Clin Cancer Res 2007;13:1576-83

37. Chaikuad A, Tacconi EM, Zimmer J, Liang Y, Gray NS, Tarsounas M, et al. A unique inhibitor binding site in ERK1/2 is associated with slow binding kinetics. Nat Chem Biol 2014;10:853-60

38. Eskens FA, Mom CH, Planting AS, Gietema JA, Amelsberg A, Huisman H, et al. A phase I dose escalation study of BIBW 2992, an irreversible dual inhibitor of epidermal growth factor receptor 1 (EGFR) and 2 (HER2) tyrosine kinase in a 2-week on, 2-week off schedule in patients with advanced solid tumours. Br J Cancer 2008;98:80-5

39. Ji QS, Mulvihill MJ, Rosenfeld-Franklin M, Cooke A, Feng L, Mak G, et al. A novel, potent, and selective insulin-like growth factor-I receptor kinase inhibitor blocks insulin-like growth factor-I receptor signaling in vitro and inhibits insulin-like growth factor-I receptor dependent tumor growth in vivo. Mol Cancer Ther 2007;6:2158-67

40. Di Veroli GY, Fornari C, Wang D, Mollard S, Bramhall JL, Richards FM, et al. Combenefit: an interactive platform for the analysis and visualization of drug combinations. Bioinformatics 2016;32:2866-8

41. Teicher BA. Tumor models for efficacy determination. Mol Cancer Ther 2006;5:243543

42. Brant R, Sharpe A, Liptrot T, Dry JR, Harrington EA, Barrett JC, et al. Clinically Viable Gene Expression Assays with Potential for Predicting Benefit from MEK Inhibitors. Clin Cancer Res 2017;23:1471-80

43. Campbell JD, Alexandrov A, Kim J, Wala J, Berger AH, Pedamallu CS, et al. Distinct patterns of somatic genome alterations in lung adenocarcinomas and squamous cell carcinomas. Nat Genet 2016;48:607-16

44. Sholl LM, Do K, Shivdasani P, Cerami E, Dubuc AM, Kuo FC, et al. Institutional implementation of clinical tumor profiling on an unselected cancer population. JCI Insight 2016; $1: \mathrm{e} 87062$ 
45. Kidger AM, Munck JM, Saini HK, Balmanno K, Minihane E, Courtin A, et al. DualMechanism ERK1/2 Inhibitors Exploit a Distinct Binding Mode to Block Phosphorylation and Nuclear Accumulation of ERK1/2. Mol Cancer Ther 2020;19:52539

46. Yang JY, Chang CJ, Xia W, Wang Y, Wong KK, Engelman JA, et al. Activation of FOXO3a is sufficient to reverse mitogen-activated protein/extracellular signal-regulated kinase kinase inhibitor chemoresistance in human cancer. Cancer Res 2010;70:4709-18

47. Skoulidis F, Byers LA, Diao L, Papadimitrakopoulou VA, Tong P, Izzo J, et al. Cooccurring genomic alterations define major subsets of KRAS-mutant lung adenocarcinoma with distinct biology, immune profiles, and therapeutic vulnerabilities. Cancer Discov 2015;5:860-77

48. Guerra C, Mijimolle N, Dhawahir A, Dubus P, Barradas M, Serrano M, et al. Tumor induction by an endogenous K-ras oncogene is highly dependent on cellular context. Cancer Cell 2003;4:111-20

49. Litchfield LM, Boehnke K, Brahmachary M, Mur C, Bi C, Stephens JR, et al. Combined inhibition of PIM and CDK4/6 suppresses both mTOR signaling and Rb phosphorylation and potentiates PI3K inhibition in cancer cells. Oncotarget 2020; $11: 1478-92$

50. Hong DS, Fakih MG, Strickler JH, Desai J, Durm GA, Shapiro GI, et al. KRAS(G12C) Inhibition with Sotorasib in Advanced Solid Tumors. N Engl J Med 2020;383:1207-17

51. Kruspig B, Monteverde T, Neidler S, Hock A, Kerr E, Nixon C, et al. The ERBB network facilitates KRAS-driven lung tumorigenesis. Sci Transl Med 2018;10

52. Lito P, Saborowski A, Yue J, Solomon M, Joseph E, Gadal S, et al. Disruption of CRAF-mediated MEK activation is required for effective MEK inhibition in KRAS mutant tumors. Cancer Cell 2014;25:697-710

53. de Leeuw R, McNair C, Schiewer MJ, Neupane NP, Brand LJ, Augello MA, et al. MAPK Reliance via Acquired CDK4/6 Inhibitor Resistance in Cancer. Clin Cancer Res 2018; $24: 4201-14$

54. Chen Z, Cheng K, Walton Z, Wang Y, Ebi H, Shimamura T, et al. A murine lung cancer co-clinical trial identifies genetic modifiers of therapeutic response. Nature 2012;483:613-7

55. Caiola E, Iezzi A, Tomanelli M, Bonaldi E, Scagliotti A, Colombo M, et al. LKB1 Deficiency Renders NSCLC Cells Sensitive to ERK Inhibitors. J Thorac Oncol 2020; $15: 360-70$ 
56. Meng J, Fang B, Liao Y, Chresta CM, Smith PD, Roth JA. Apoptosis induction by MEK inhibition in human lung cancer cells is mediated by Bim. PLoS One 2010;5:e13026

57. Yam C, Xu X, Davies MA, Gimotty PA, Morrissette JJD, Tetzlaff MT, et al. A Multicenter Phase I Study Evaluating Dual PI3K and BRAF Inhibition with PX-866 and Vemurafenib in Patients with Advanced BRAF V600-Mutant Solid Tumors. Clin Cancer Res 2018;24:22-32

58. de la Cruz-Merino L, Di Guardo L, Grob JJ, Venosa A, Larkin J, McArthur GA, et al. Clinical features of serous retinopathy observed with cobimetinib in patients with BRAF-mutated melanoma treated in the randomized coBRIM study. J Transl Med 2017; $15: 146$

59. Bendell JC, Varghese AM, Hyman DM, Bauer TM, Pant S, Callies S, et al. A First-inHuman Phase 1 Study of LY3023414, an Oral PI3K/mTOR Dual Inhibitor, in Patients with Advanced Cancer. Clin Cancer Res 2018;24:3253-62

60. Tao Z, Le Blanc JM, Wang C, Zhan T, Zhuang H, Wang P, et al. Coadministration of Trametinib and Palbociclib Radiosensitizes KRAS-Mutant Non-Small Cell Lung Cancers In Vitro and In Vivo. Clin Cancer Res 2016;22:122-33

61. Zhang SQ, Tsiaras WG, Araki T, Wen G, Minichiello L, Klein R, et al. Receptorspecific regulation of phosphatidylinositol 3'-kinase activation by the protein tyrosine phosphatase Shp2. Mol Cell Biol 2002;22:4062-72

62. Zhou ZW, Ambrogio C, Bera AK, Li Q, Li XX, Li L, et al. KRAS(Q61H) Preferentially Signals through MAPK in a RAF Dimer-Dependent Manner in Non-Small Cell Lung Cancer. Cancer Res 2020;80:3719-31

63. Young RJ, Waldeck K, Martin C, Foo JH, Cameron DP, Kirby L, et al. Loss of CDKN2A expression is a frequent event in primary invasive melanoma and correlates with sensitivity to the CDK4/6 inhibitor PD0332991 in melanoma cell lines. Pigment Cell Melanoma Res 2014;27:590-600

64. Horn S, Leonardelli S, Sucker A, Schadendorf D, Griewank KG, Paschen A. Tumor CDKN2A-Associated JAK2 Loss and Susceptibility to Immunotherapy Resistance. J Natl Cancer Inst 2018; 110:677-81

65. Gopalan PK, Villegas AG, Cao C, Pinder-Schenck M, Chiappori A, Hou W, et al. CDK4/6 inhibition stabilizes disease in patients with p16-null non-small cell lung cancer and is synergistic with mTOR inhibition. Oncotarget 2018;9:37352-66

66. Pandey K, An HJ, Kim SK, Lee SA, Kim S, Lim SM, et al. Molecular mechanisms of resistance to CDK4/6 inhibitors in breast cancer: A review. Int J Cancer 2019;145:117988 


\section{Figures}

\section{Figure 1: LY3214996 single agent activity in vitro.}

(A) Bright-field microscopy images of the seven patient-derived $R A S$ mutant lung cancer cell lines used in this study (scale bar $=150 \mu \mathrm{M}$ ). (B) Absolute $\mathrm{IC}_{50}$ values for LY3214996 (in $\mu \mathrm{M})$ in patient-derived cell lines after $72 \mathrm{~h}$. (C) Western blot analysis of cell lysates from patient-derived cell lines treated for $24 \mathrm{~h}$ with increasing doses of LY3214996 (dose range 1010,000nM). (D) Western blot analysis of lysates from patient-derived cell lines treated for up to $48 \mathrm{~h}$ with $1 \mu \mathrm{M}$ of LY3214996. (E) Overall ERK-dependent transcriptional output (6-gene signature) of cell lines treated for up to $48 \mathrm{~h}$ with $1 \mu \mathrm{M}$ of LY3214996. (F) Growth kinetics of patient-derived cell lines treated with increasing doses of LY3214996 over 72 h. (G) FOXO3a reporter activity in transiently transfected patient-derived cancer cell lines after $24 \mathrm{~h}$ of LY3214996 $(1 \mu \mathrm{M})$ treatment. (H) Western blot analysis of cytoplasmic and nuclear protein fractions of LY3214996-sensitive DFCI168 and -resistant DFCI332 cells after $24 \mathrm{~h}$ of treatment with $1 \mu \mathrm{M}$ of LY3214996.

\section{Figure 2: LY3214996 single agent activity in $R A S$ mutant lung cancer PDX models.}

(A) Growth kinetics of DFCI168 ${ }^{\text {NRASQ61K }}$ tumors treated with vehicle or LY3214996 (100mg/kg, QD) for 21 days $(\mathrm{n}=8$ in vehicle group, $\mathrm{n}=7$ in LY3214996 group; $p<0.0001$, Two-way Repeated Measures ANOVA with standard post hoc t-tests). (B) Kaplan-Meier survival curves of vehicle- and LY3214996-treated NSG mice with xenotransplanted DFCI168 $8^{\text {NRASQ61K }}$ tumors $(p=0.0003$, Log-rank test). (C) Western blot analysis of lysates of xenotransplanted DFCI168 ${ }^{\text {NRASQ61K }}$ tumors treated with vehicle or LY3214996 (100mg/kg) for 4, 16 and $24 \mathrm{~h}$ (n=3 tumors/time point). (D) Time course of LY3214996 plasma concentrations (in $\mathrm{nM}$, left y-axis) and of relative p-p90RSK levels (in \%, right y-axis) 4, 16 and $24 \mathrm{~h}$ after the last drug application $(100 \mathrm{mg} / \mathrm{kg}, \mathrm{QD} ; \mathrm{n}=3$ animals/group; $p=0.0013$; Unpaired t-Test). In the $24 \mathrm{~h}$ group, two plasma samples were not analyzable for technical reasons. (E) Mean relative expression of ERK-dependent target genes in DFCI168 ${ }^{\text {NRASQ61K }}$ tumors 4, 16 and $24 \mathrm{~h}$ after the last LY3214996 dose $(100 \mathrm{mg} / \mathrm{kg}$, pooled data of $\mathrm{n}=3$ tumors/group). PHLDA1 transcripts were undetectable. (F) Growth kinetics of 
DFCI316 ${ }^{\text {KRASQ61H }}$ tumors treated with vehicle or LY3214996 (100mg/kg, PO QD) for 21 days ( $\mathrm{n}=8 /$ group, $p=0.9$, Two-way Repeated Measures ANOVA with standard post hoc t-tests).

(G) Mean relative expression of ERK-dependent target genes in DFCI316 ${ }^{\text {RASQ61H }}$ tumors 4 , 16 and $24 \mathrm{~h}$ after the last LY3214996 dose (100mg/kg) (pooled data of $\mathrm{n}=3$ tumors/group). (H) Western blot analysis of lysates of xenotransplanted DFCI316 ${ }^{K R A S Q 61 H}$ tumors treated with vehicle or with LY3214996 (100mg/kg) for 4, 16 and $24 \mathrm{~h} \mathrm{(n=3} \mathrm{tumors/group).} \mathrm{(I)} \mathrm{Growth}$ kinetics of DFCI168 ${ }^{N R A S Q 61 K}$ tumors treated for 21 days with once- $(100 \mathrm{mg} / \mathrm{kg}$, PO QD) or twice-daily (50mg/kg, PO BID) LY3214996 ( $\mathrm{n}=8$ NSG mice/group, $p=0.0102$, Two-way Repeated Measures ANOVA with standard post hoc t-tests).

Figure 3: Anti-proliferative activity of combined ERK1/2 and PI3K/mTOR inhibition in vitro.

(A) Western blot analysis of signaling (MAPK and PI3K pathway) and EMT baseline characteristics of serum starved (0.1\% FBS) RAS-mutant patient-derived cancer cell lines. (B) Bliss synergy between LY3214996 and LY3023414 (dose range for each drug 2-10,000nM) in patient-derived cancer cell lines after $72 \mathrm{~h}$ of treatment. Synergism: blue, antagonism: red ( $\mathrm{n}=6$ replicates/dose combination). (C) Western blot analysis of lysates of DFCI24 ${ }^{\text {KRASGI2C }}$ (left panel) and DFCI316 ${ }^{\text {KRASQ61H }}$ (right panel) cells treated for up to $72 \mathrm{~h}$ with DMSO, LY3214996 $(1 \mu \mathrm{M})$, LY3023414 $(100 \mathrm{nM})$ or a combination of both drugs. (D) Relative (compared to DMSO control) pooled ERK-dependent gene expression in DFCI24 ${ }^{\text {KRASGI2C }}$ (left graph) and DFCI316 ${ }^{\text {KRASQ61H }}$ (right graph) cells treated for up to $72 \mathrm{~h}$ with LY3214996 $(1 \mu \mathrm{M})$, LY3023414 $(100 \mathrm{nM})$ or a combination of both (Student's t-Test). (E) Relative FOXO3a reporter activity in transiently transfected DFCI24 (left) and DFCI316 (right) cells after $24 \mathrm{~h}$ of treatment with LY3214996 $(1 \mu \mathrm{M})$, LY3023414 (100nM) or a combination of both drugs (Student's t-test). (F) Western blot analysis of cytoplasmic and nuclear protein fractions of DFCI24 cells treated for $24 \mathrm{~h}$ with $1 \mu \mathrm{M}$ of LY3214996, LY3023414 (100nM) or a combination of both drugs. (G) BLISS synergy between LY3214996 and LY3023414 (dose range 40-10,000nM) in GEMM-derived cancer cell lines with $\operatorname{Kras}^{G 12 V}(\mathrm{~K}), \operatorname{Kras}^{G 12 V}$;Tp5 $3^{f l f l}$ (KP) and $\operatorname{Kras}^{G 12 V} ; T_{p} 53^{f l f l} ; L k b 1^{f l f l}$ (KPL) genotype after $72 \mathrm{~h}$ (n=6 replicates/dose 
combination). Western blots show the loss of Lkb1 and TP53 in GEMM-derived cancer cell lines. "*” indicates treatment of cell lines for $24 \mathrm{~h}$ with $5 \mu \mathrm{M}$ of cisplatin to induce TP53.

\section{Figure 4: Anti-tumor activity of combined ERK1/2 and PI3K inhibition in PDX models.}

Growth kinetics of DFCI24 $4^{\text {RASGI2C }}$ (A) and DFCI316 ${ }^{\text {KRASQ61H }}$ (B) tumors treated with vehicle, LY3214996 (75mg/kg BID, 4d ON 3d OFF), LY3214996 (150mg/kg, PO QD), LY3023414 $(15 \mathrm{mg} / \mathrm{kg}$, PO BID, 4d ON 3d OFF) or a combination of both drugs for 28 days ( $\mathrm{n}=8-9 /$ group, Two-way Repeated Measures ANOVA with standard post hoc t-tests). Waterfall plots of individual tumor responses are depicted for day 24 (DFCI24) and day 28 (DFCI316), respectively (PD - progressive disease (solid columns); SD - stable disease (pattern columns); PR - partial response (open columns)). (C) Tumor growth delay (in days) in mice xenotransplanted with DFCI24 and DFCI316 tumors by treatment regimen compared to vehicle treated animals. (TGI - Tumor Growth Inhibition) (D) Western blot analysis of lysates of DFCI24 ${ }^{\text {KRASGI2C }}$ tumors treated with vehicle, LY3214996 (75mg/kg, BID), LY3023414 $(15 \mathrm{mg} / \mathrm{kg}$, BID) or a combination of both 4,8 and $24 \mathrm{~h}$ after the last drug application. (E) Pooled mean ERK-dependent gene expression (compared to vehicle) in DFCI24 ${ }^{\text {KRASG12C }}$ tumors treated for 4,8 and $24 \mathrm{~h}$ with LY3214996 $(75 \mathrm{mg} / \mathrm{kg}), \mathrm{LY} 3023414$ $(15 \mathrm{mg} / \mathrm{kg})$ or a combination of both drugs ( $\mathrm{n}=3$ tumors/group, Student's t-Test).

\section{Figure 5: Anti-proliferative activity of combined ERK1/2 and CDK4/6 inhibition in} vitro.

(A) Bliss synergy between LY3214996 and abemaciclib (dose range 40-10,000nM) in patientderived $R A S$-mutant cancer cell lines after $72 \mathrm{~h}$ ( $\mathrm{n}=6$ replicates/dose combination). Synergism: blue, antagonism: red. (B) Western blot analysis of DFCI24 ${ }^{\text {KRASG12C }}$ (left panel) and DFCI332 ${ }^{\text {KRASG12D }}$ (right panel) cells treated with DMSO, LY3214996 $(1 \mu \mathrm{M})$, abemaciclib $(1 \mu \mathrm{M})$ or a combination of both drugs for up to $72 \mathrm{~h}$. (C) BLISS synergy between LY3214996 and LY30323414 (dose range 40-10,000nM) in GEMM-derived cancer cell lines

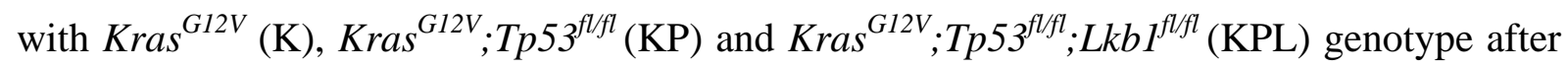
$72 \mathrm{~h}$ ( $\mathrm{n}=6$ replicates/dose combination). 
Figure 6: Anti-tumor activity of combined ERK1/2 and CDK4/6 inhibition in PDX models.

Growth kinetics of DFCI168 ${ }^{\text {NRASQ61K }}(\mathbf{A})$ and DFCI24 $4^{\text {KRASGI2C }}(\mathbf{B})$ tumors treated with vehicle, LY3214996 (100mg/kg, PO QD), abemaciclib (50mg/kg, PO QD) or a combination of both drugs for 28 days (n=8-10/group; Two-way Repeated Measures ANOVA with standard post hoc t-tests). Waterfall plots of individual tumor responses are depicted for day 29 (DFCI168) and day 15 (DFCI24), respectively (PD - progressive disease (solid columns); SD - stable disease (pattern columns); PR - partial response (open colums); CR - complete response (pink column)). (C) Tumor growth delay (in days) in mice xenotransplanted with DFCI168 ${ }^{\text {NRASQ61K }}$ and DFCI24 tumors by treatment regimen compared to vehicle treated animals. (TGI - Tumor Growth Inhibition) (D) Western blot analysis of lysates of DFCI168 $8^{N R A S Q 61 K}$ tumors treated with vehicle, LY3214996 (100mg/kg, QD), abemaciclib (50mg/kg, QD) or a combination of both drugs 4, 8 and $24 \mathrm{~h}$ after the last drug application. (E) Pooled mean expression of MAPK pathway-dependent genes (compared to vehicle) in DFCI168 $8^{\text {NRASQ61K }}$ tumors treated for 4, 8 and $24 \mathrm{~h}$ with LY3214996 $(100 \mathrm{mg} / \mathrm{kg})$, abemaciclib $(50 \mathrm{mg} / \mathrm{kg})$ or a combination of both drugs ( $\mathrm{n}=3$ tumors/group, Student's t-Test). (F) Schematic summary of the different treatment approaches investigated in this study: single agent LY3214996 treatment for ERK inhibitor sensitive cell lines, combined ERK plus PI3K inhibitor treatment for PI3K pathway-activated ERK inhibitor-resistant cell lines and combined ERK plus CDK4/6 inhibition. The figure was created with BioRender.com. 


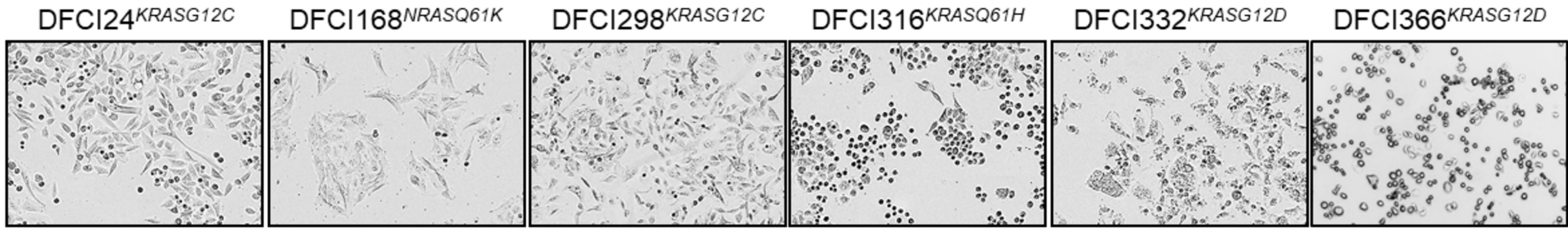

B

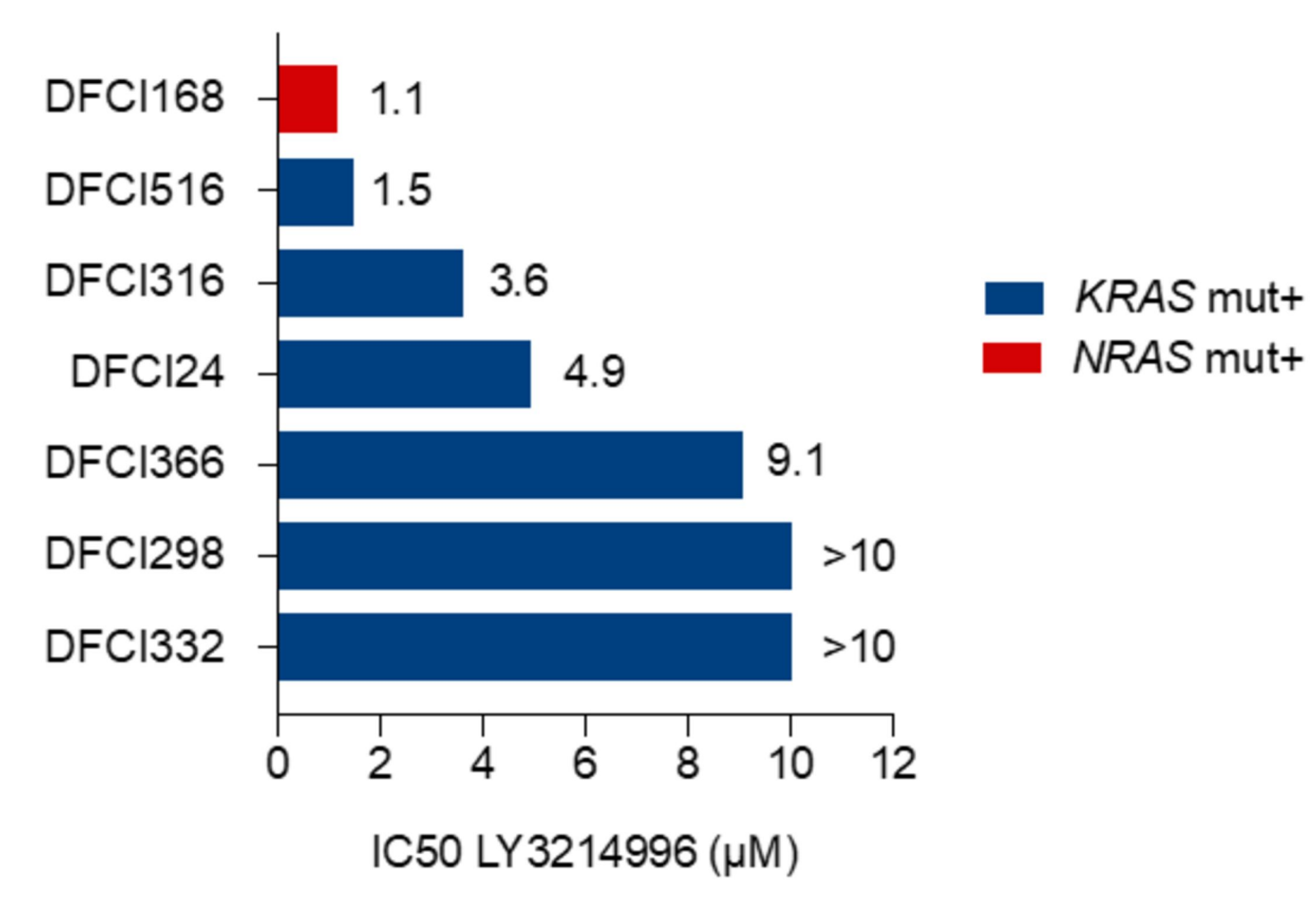

$\mathrm{D}$

DFCl168 $\quad$ DFCl316 $\quad$ DFCl24 $\quad$ DFCl298 $\quad$ DFCl332

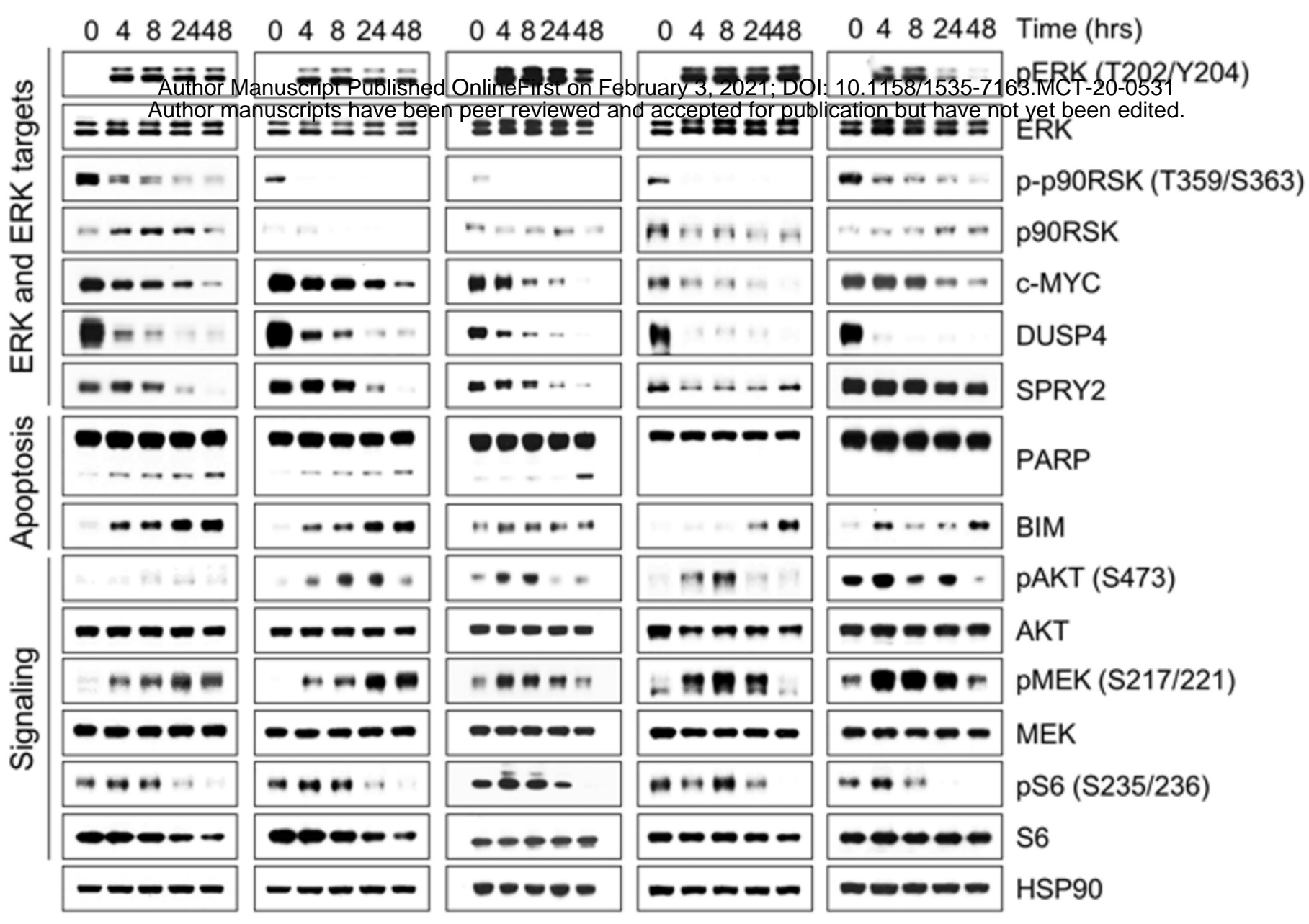

E

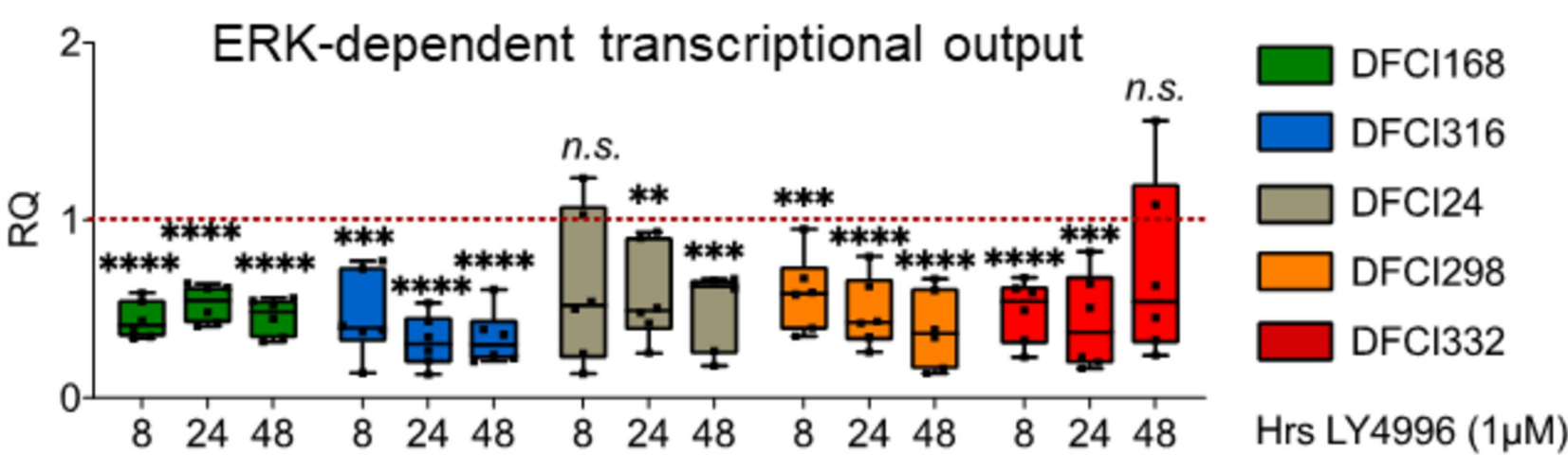

G

FOXO3a reporter activity

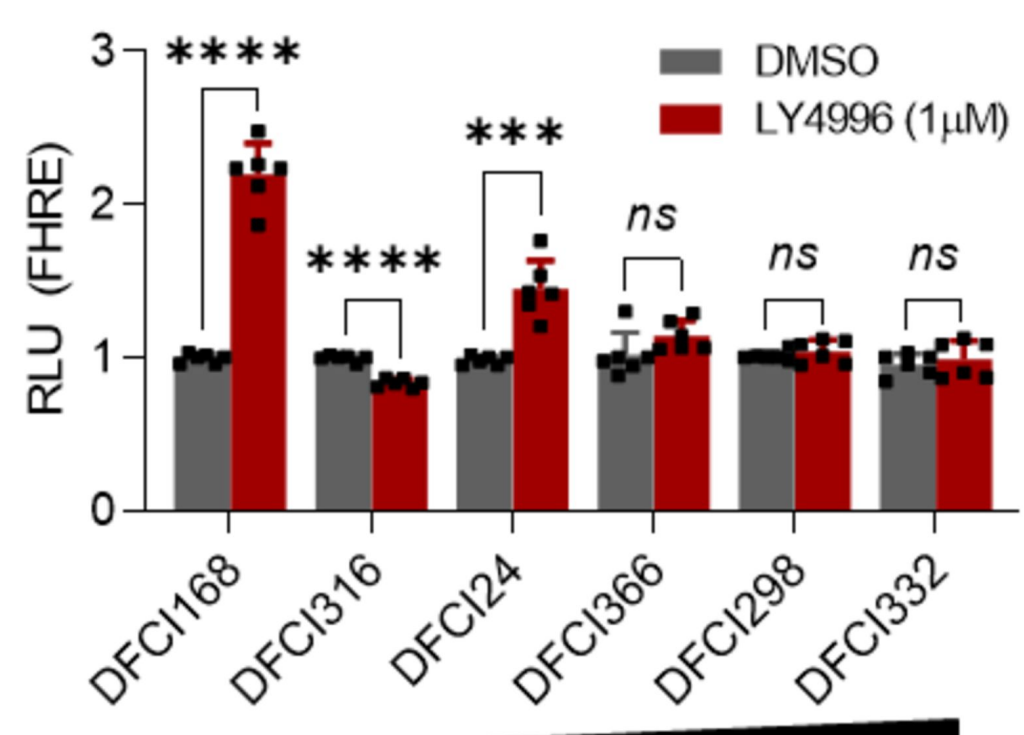

\section{C}

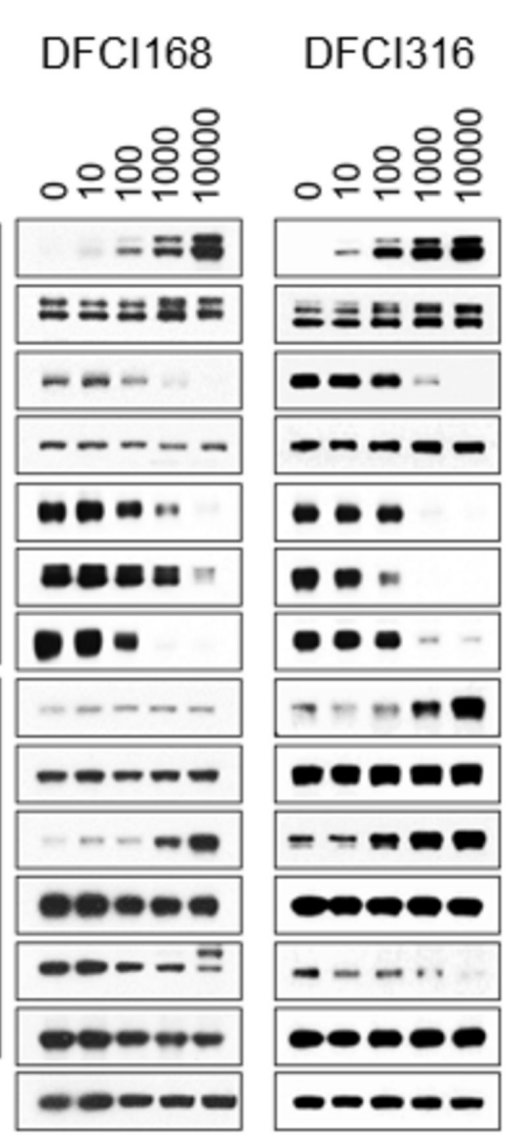

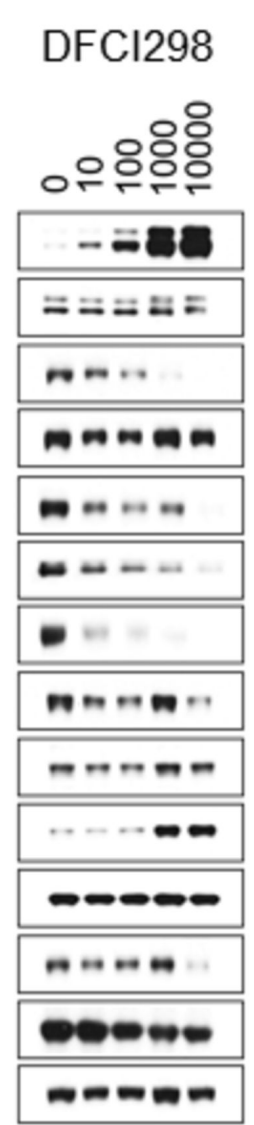

DFCl332

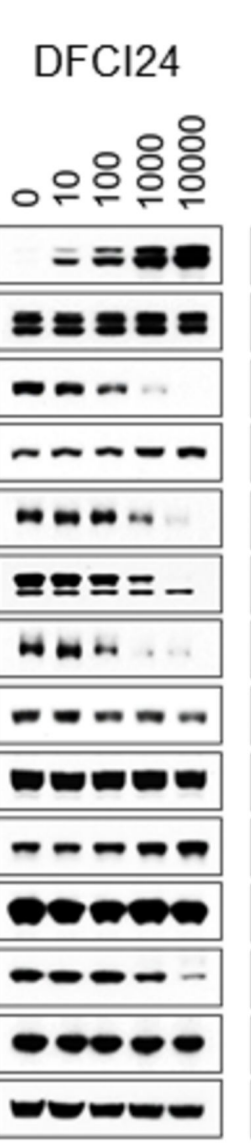

$\mathrm{F}$
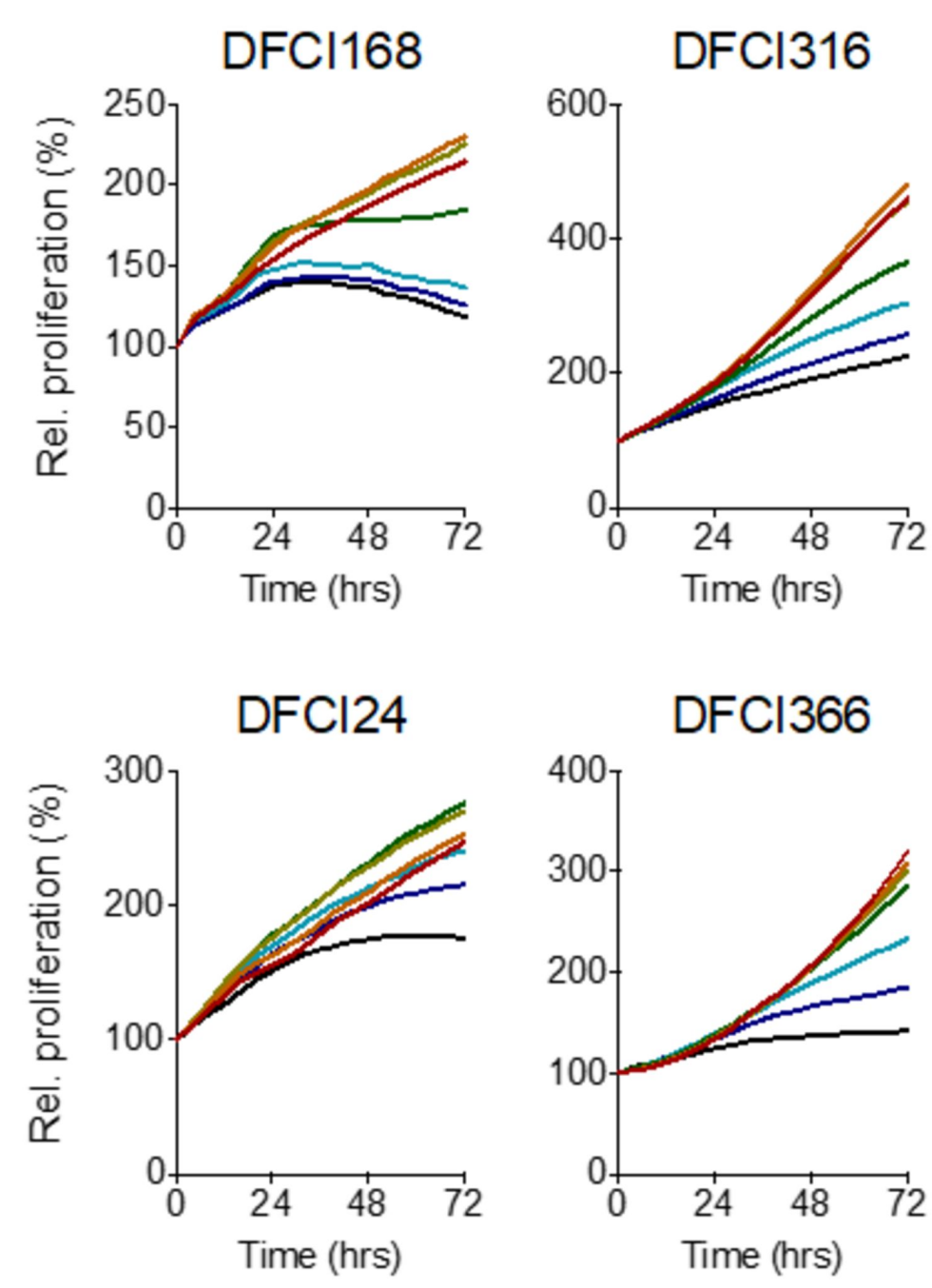

$\mathrm{DFCl} 332$

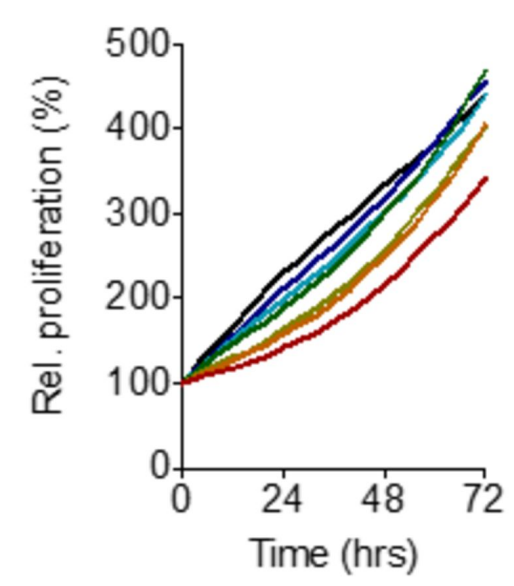

$\mathrm{H}$

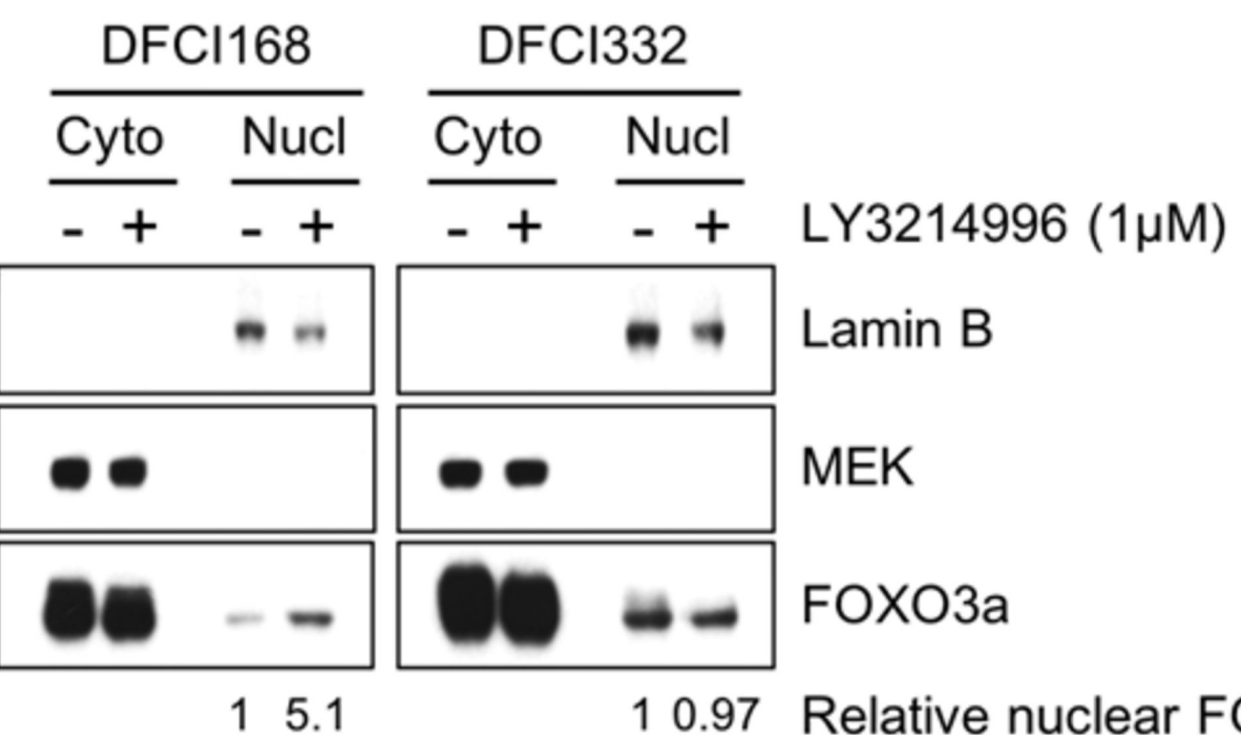

$150 \mu \mathrm{M}$
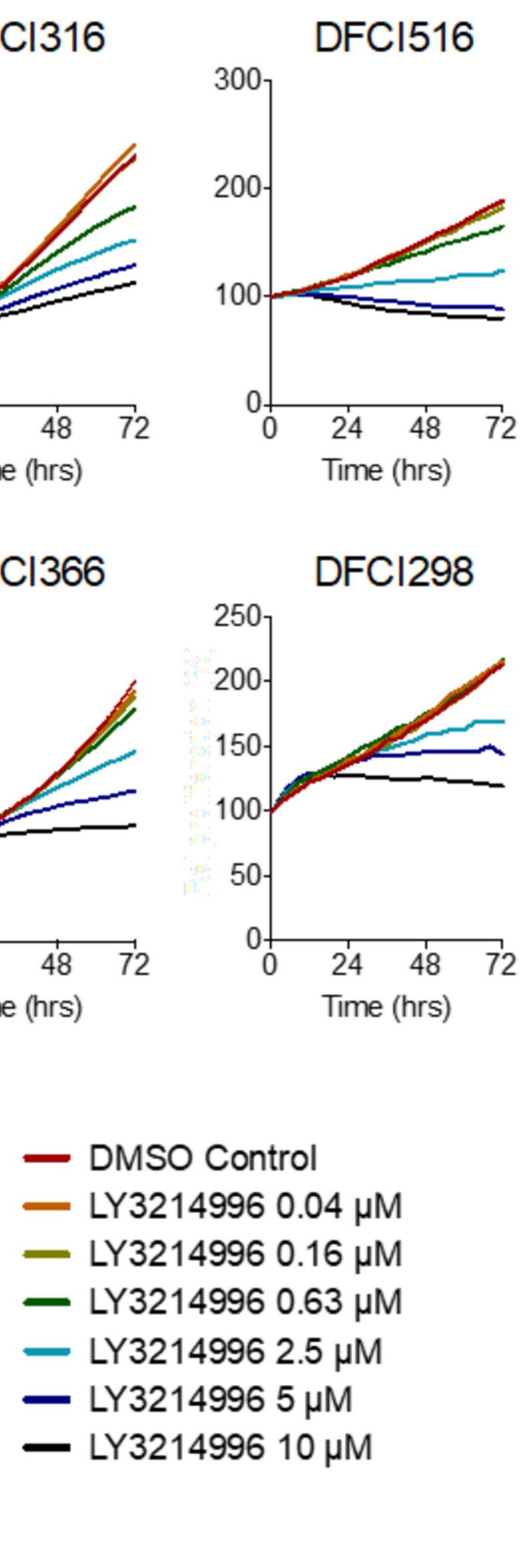

10.97 Relative nuclear FOXO3a (x-fold, normalized to Lamin B) 
DFCl168NRASQ61K (PDX)

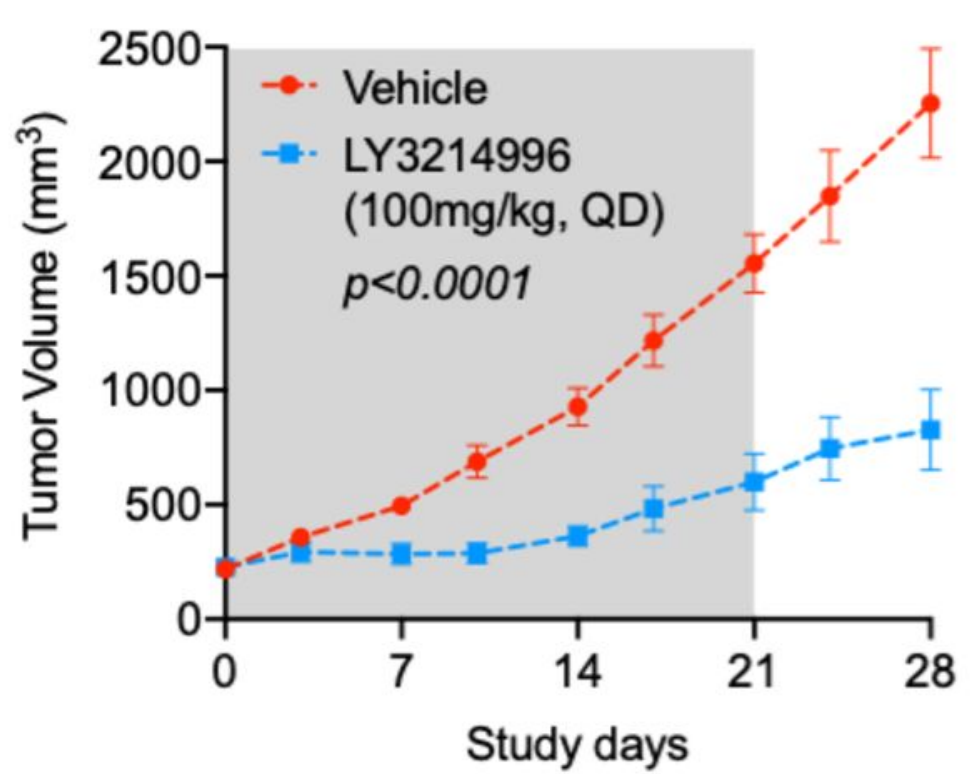

B

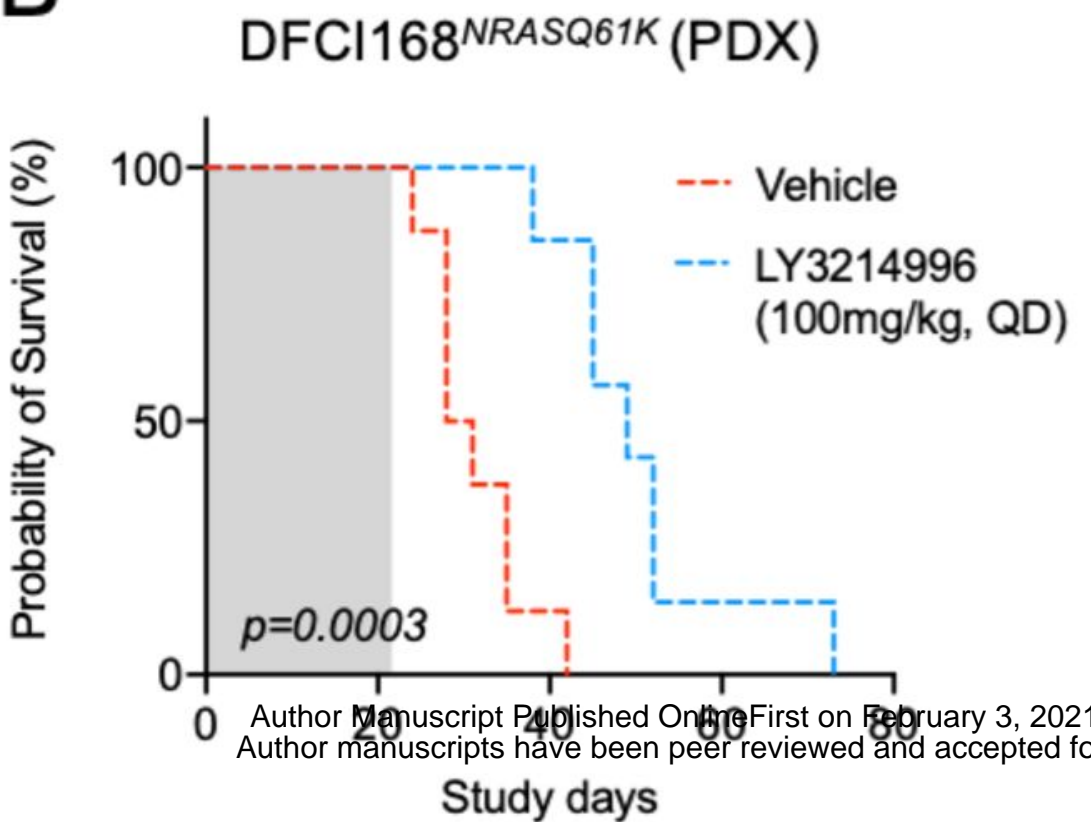

$F$

DFCI316 KRASQ61H (PDX)

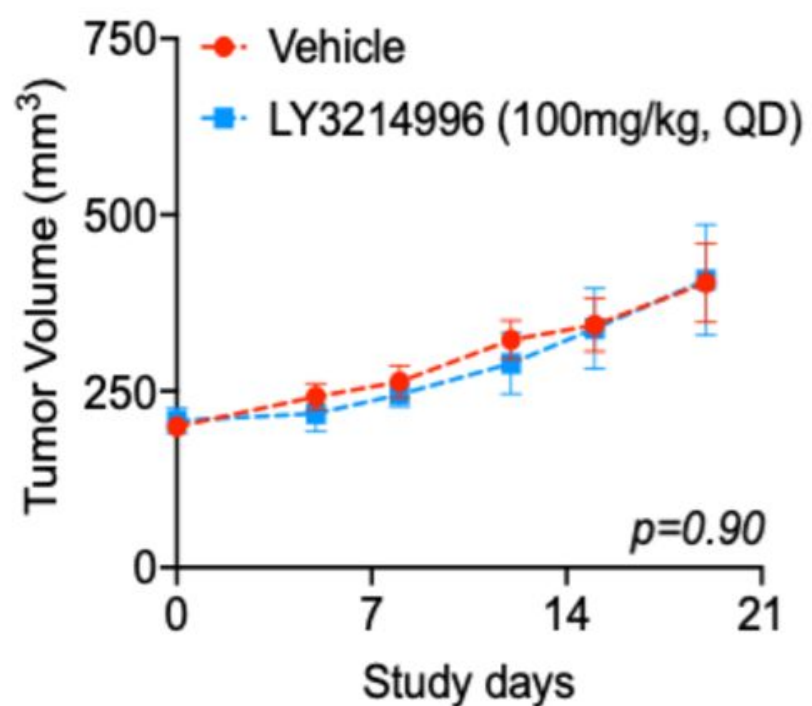

G

ERK-dependent transcriptional output (DFCl316 PDX)

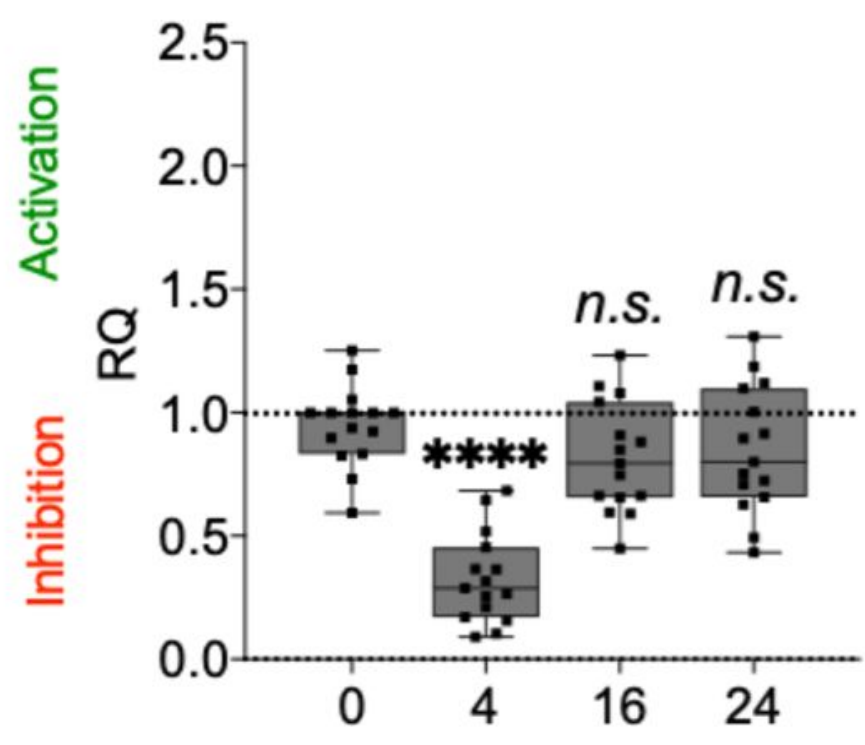

Hrs post last LY4996 dose
DFCI168NRASQ61K (PDX)

LY3214996 (100mg/kg)

\begin{tabular}{l|l|l|l}
0 & 4 & 16 & 24 \\
\hline
\end{tabular}

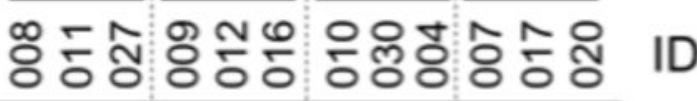

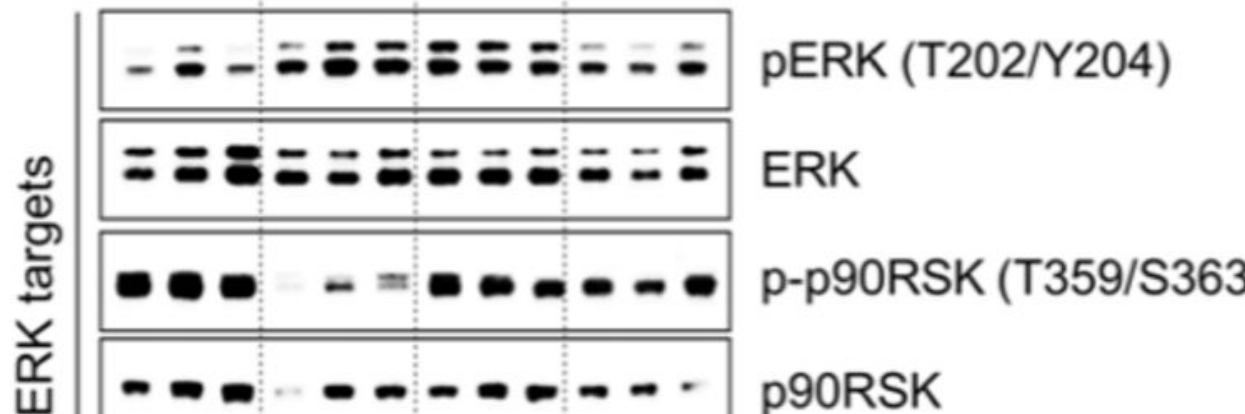

- - - - - - - - p90RSK

営

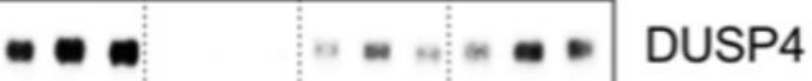

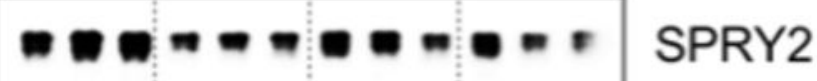
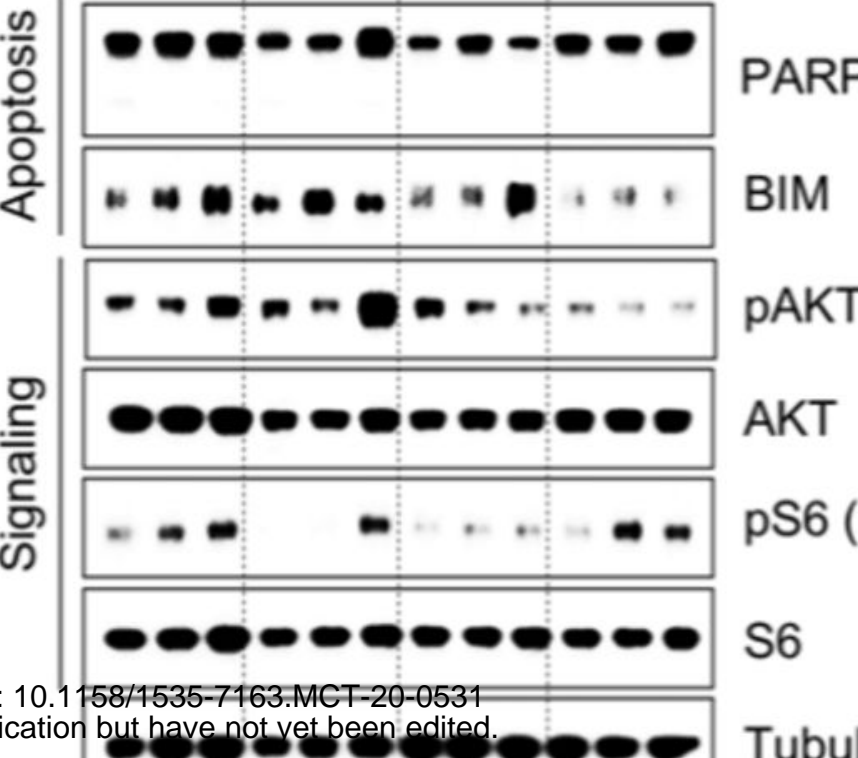

but have notyet been edited.00- Tubulin $--n-\ldots-n-m$ c-MYC

LY3214996

(100mg/kg, NSG mice)

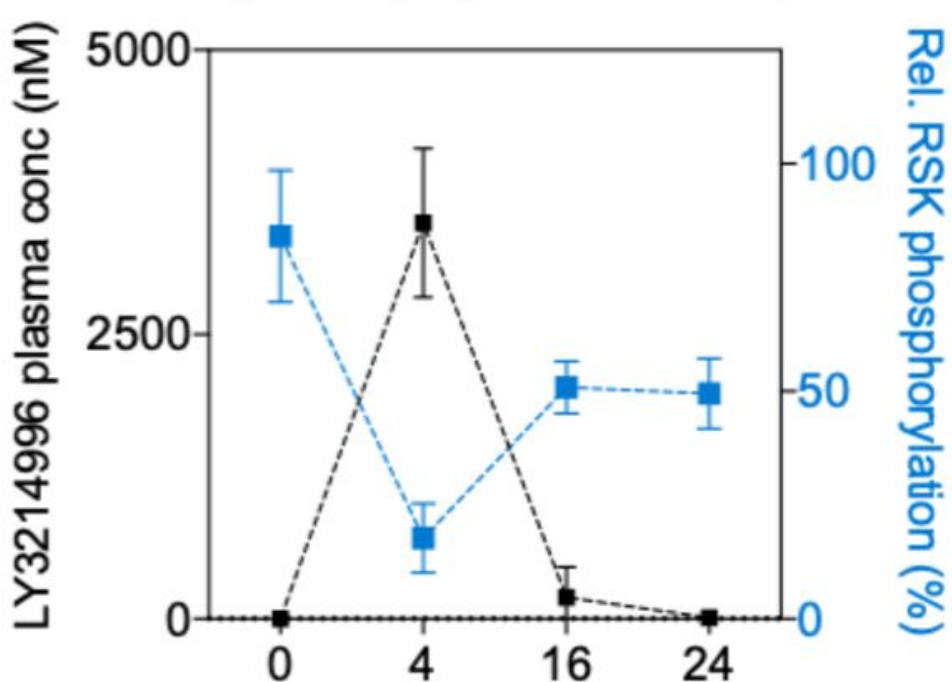

Hrs post last LY4996 dose

E ERK-dependent transcriptional output (DFCl168 PDX)

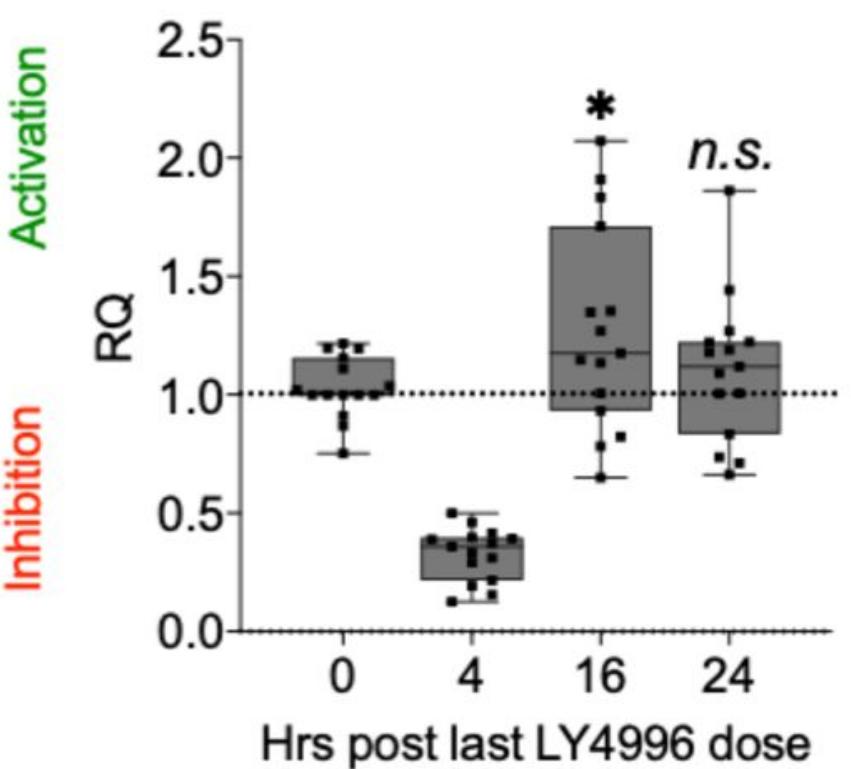

DFCl168NRASQ61K $(P D X)$

LY3214996 (100mg/kg) \begin{tabular}{l|l|l|l}
0 & 4 & 16 & 24 \\
$\mathrm{Hrs}$
\end{tabular}

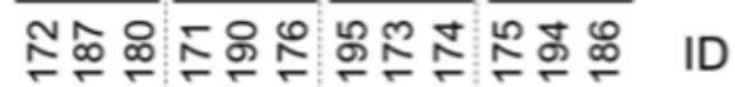

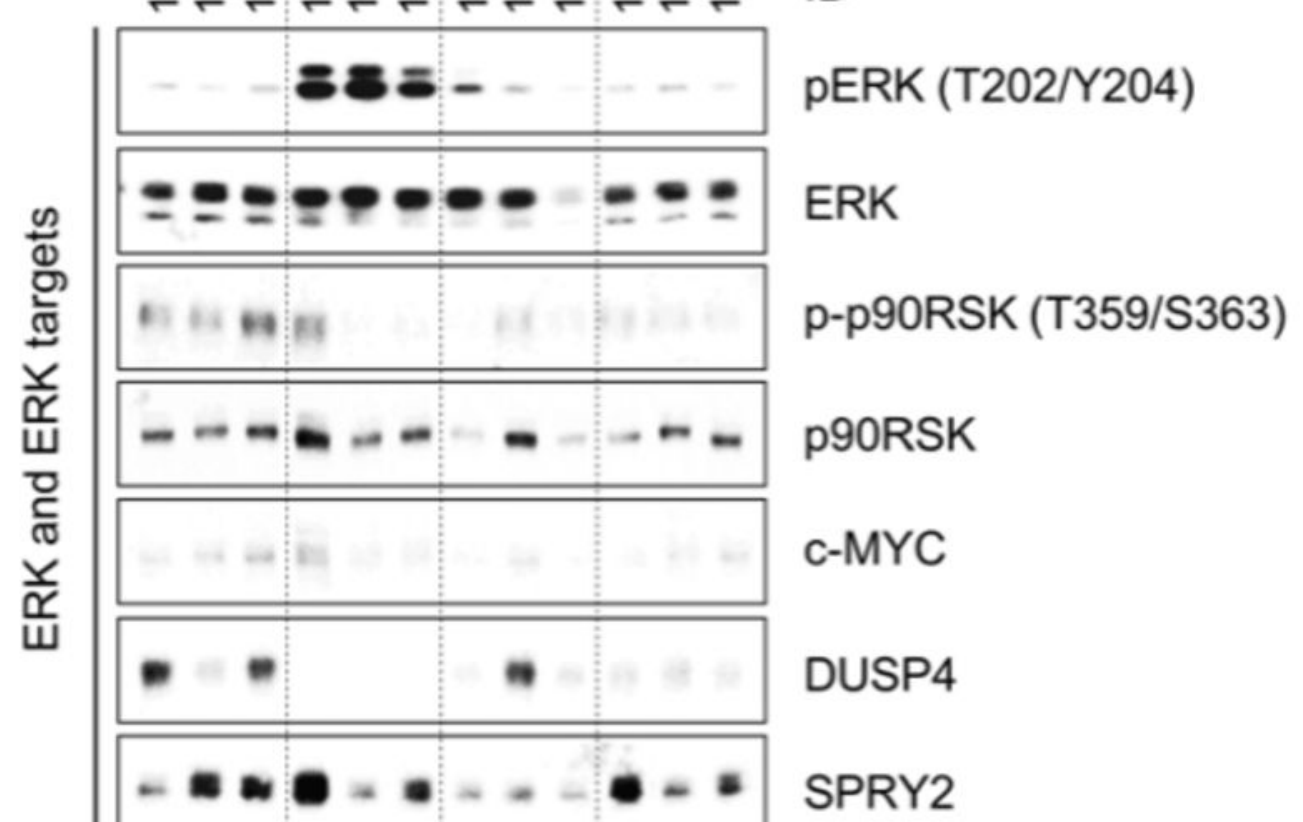

- Vehicle

- LY3214996 (100mg/kg, QD)

-*. LY3214996 (50mg/kg, BID)

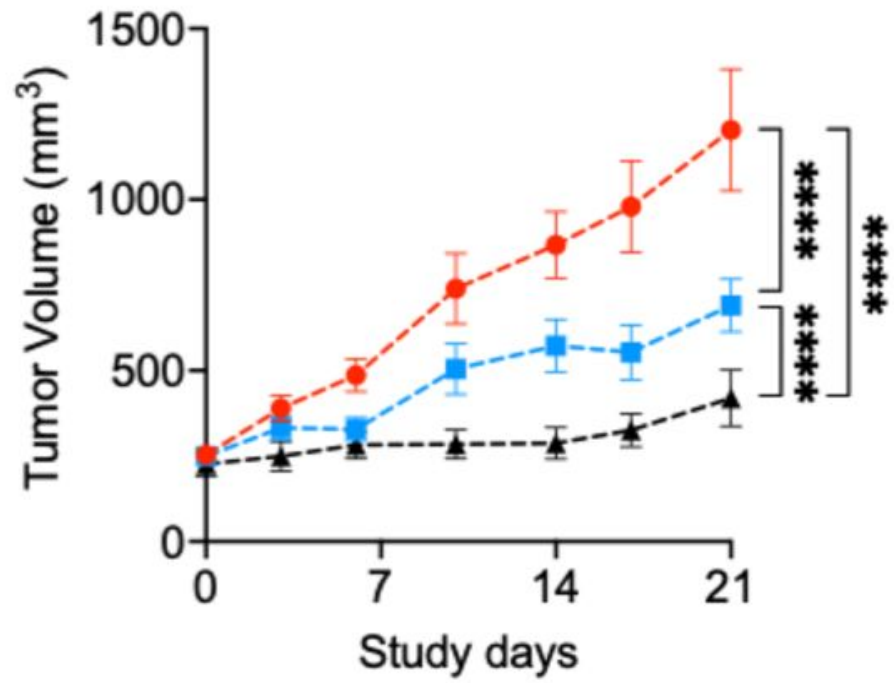

$\frac{\infty}{0}$
$\frac{0}{0}$
$\frac{0}{0}$
$\frac{2}{<}$

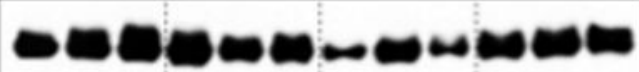

$\because \cdots \bullet \bullet-\cdots \cdots \cdots \mathrm{BIM}$

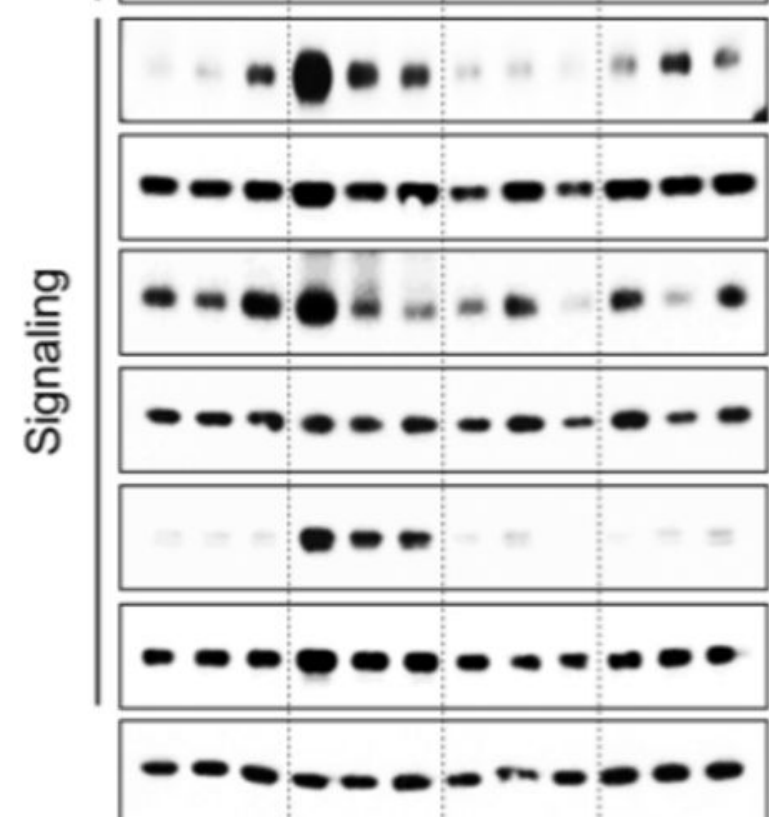

PARP

pAKT (S473)

AKT

pS6 (S235/S236)

S6

pMEK (S217/221)

MEK

Hsp90 


\section{A}

\begin{tabular}{|c|c|}
\hline - & AXL \\
\hline - - - & HER3 \\
\hline - $\quad-0$ & p-AKT (S473) \\
\hline - & AKT \\
\hline$-\quad-\quad-=$ & p-ERK (T202/Y204) \\
\hline$-=-= \pm$ & ERK \\
\hline טم-の-ー & p-S6 (S235/236) \\
\hline$---0-\infty$ & S6 \\
\hline$\bullet \bullet \bullet$ & BIM \\
\hline$-0-0-0$ & Tubulin \\
\hline & LY4996 IC50 \\
\hline
\end{tabular}

epithelial mesenchymal

DFCl24

DFCl168

DFCl298

Figure 3

C

DFCl24KRASG12C

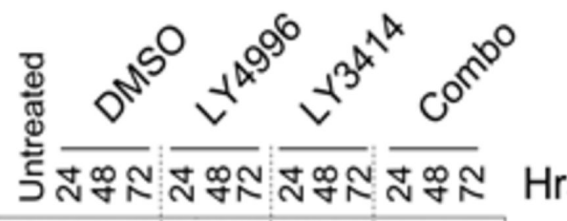

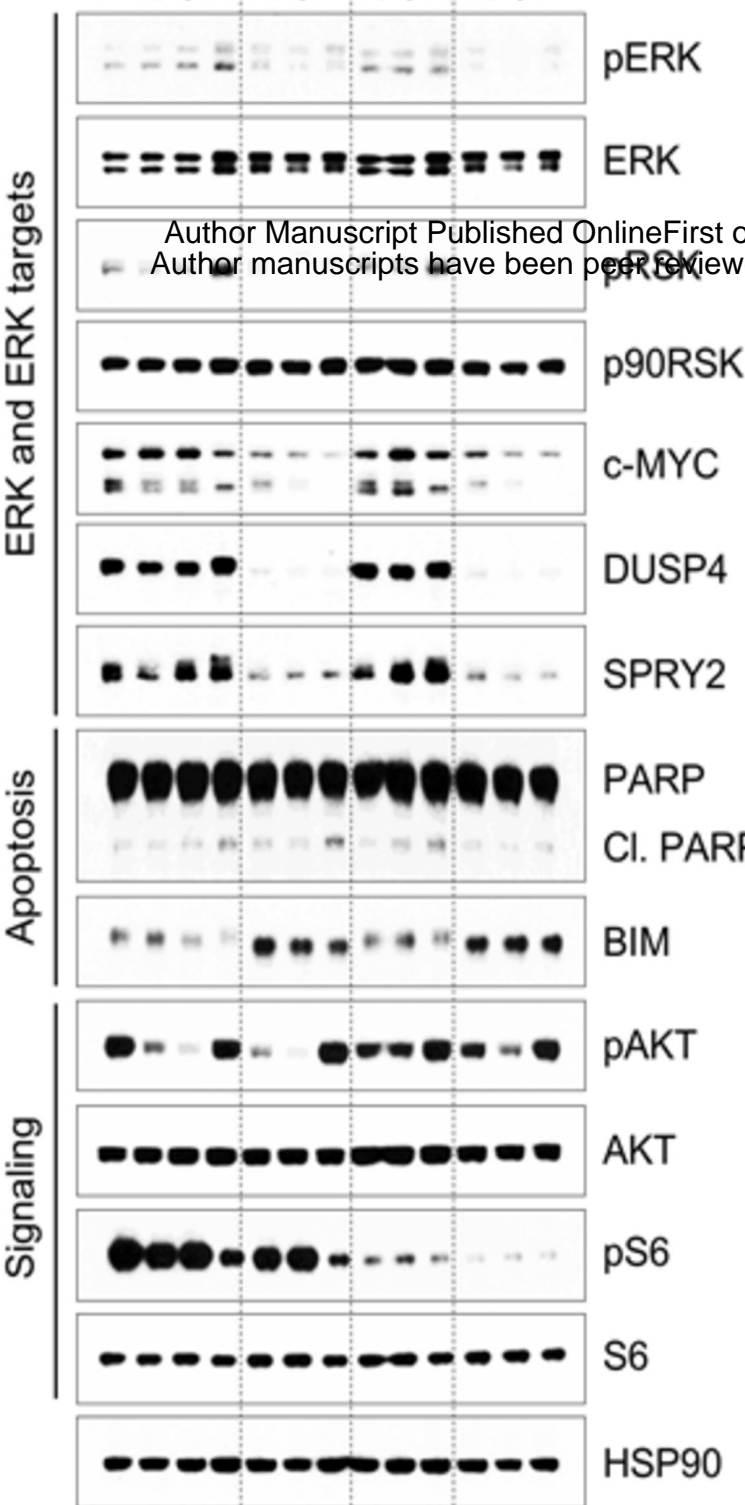

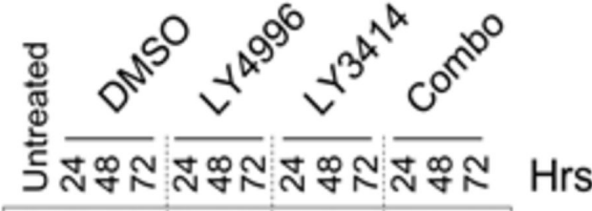

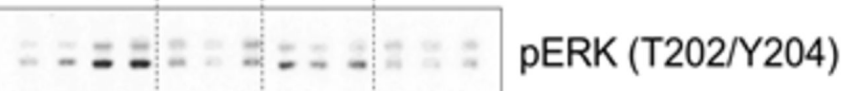

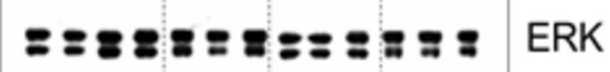

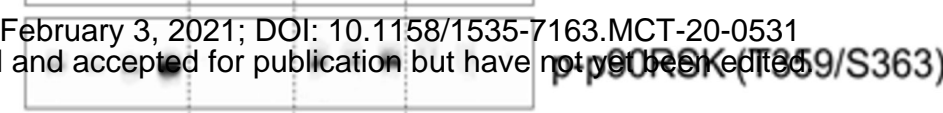

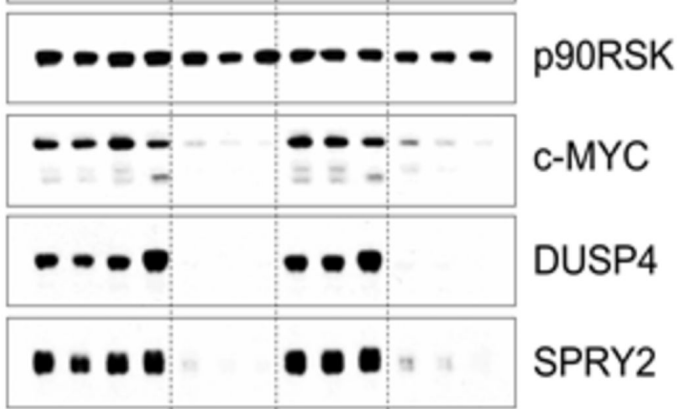

$\bullet \bullet \bullet \bullet \bullet \bullet \bullet \bullet \bullet \bullet \bullet ~ P A R P$

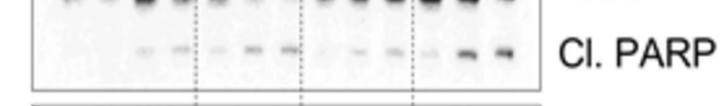

......... BIM

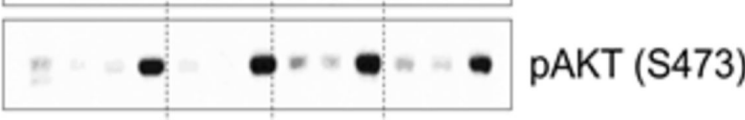

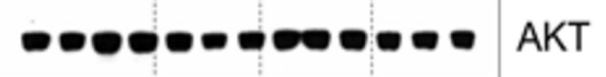

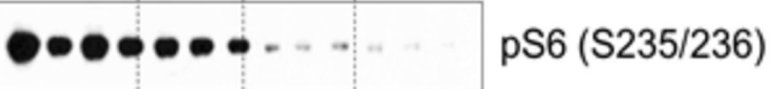

מ...........

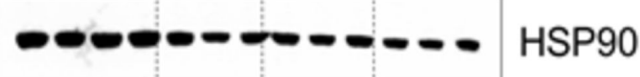

G

Kras $^{\mathrm{G} 12 \mathrm{~V}}$

(K)

CHA14.1

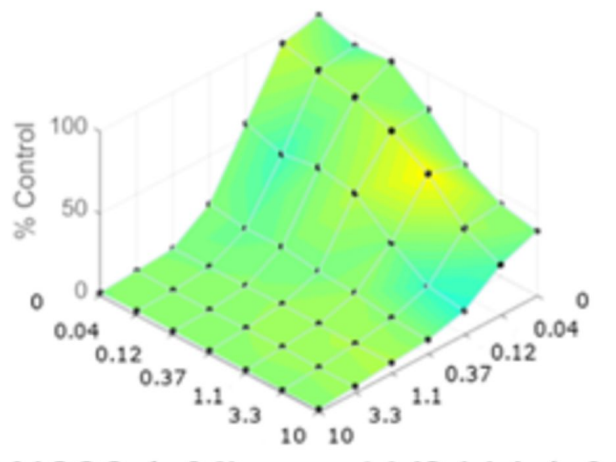

LY4996 ( $\mu \mathrm{M})$

LY3414 ( $\mu \mathrm{M})$

CHA14.2

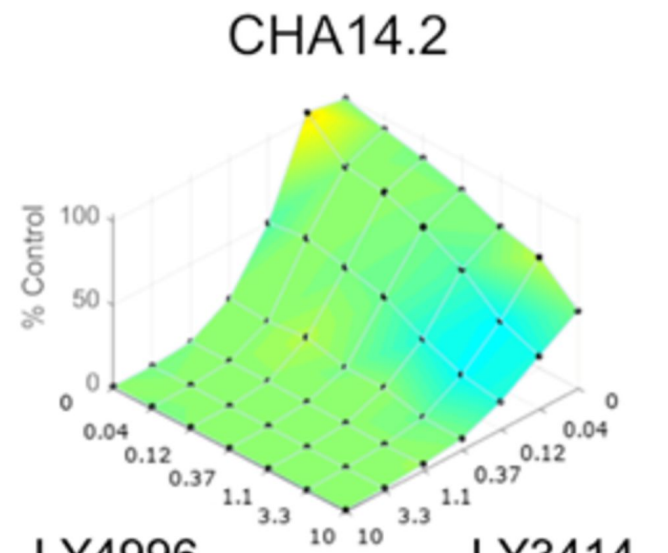

LY4996

LY3414
Kras $^{G 12 V} ; \operatorname{Tp5} 3^{f / t t}$

(KP)

CHA9.1

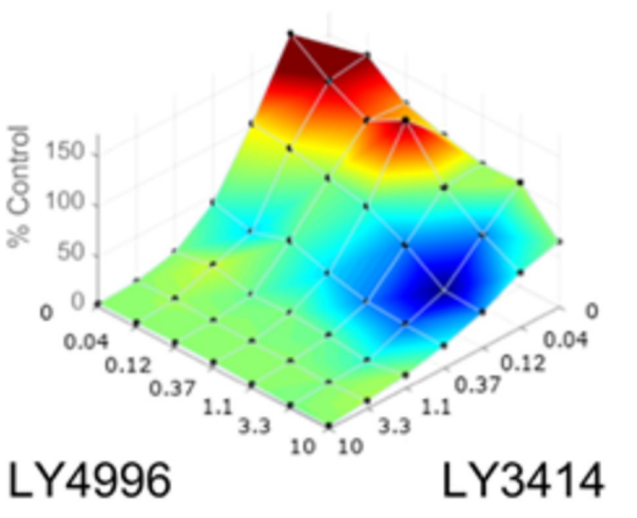

LY3414

LY4996

$\mathrm{Kras}^{\mathrm{G} 12 \mathrm{~V}} ; \mathrm{Tp} 53^{\mathrm{fl} / \mathrm{f} \text {; }}$

$L k b 1^{f / / f l}$ (KPL)

CHA487

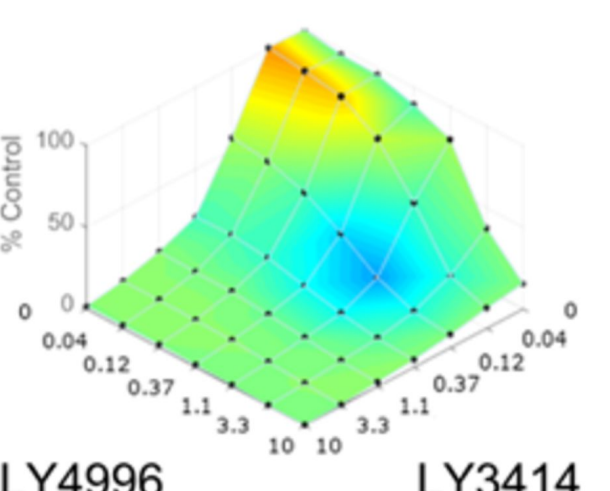

LY3414

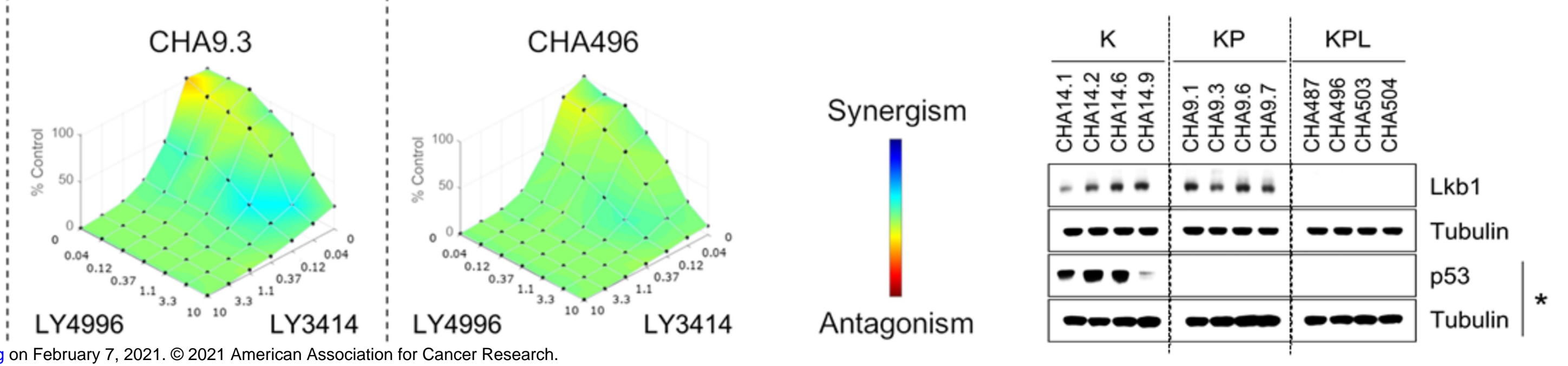

D

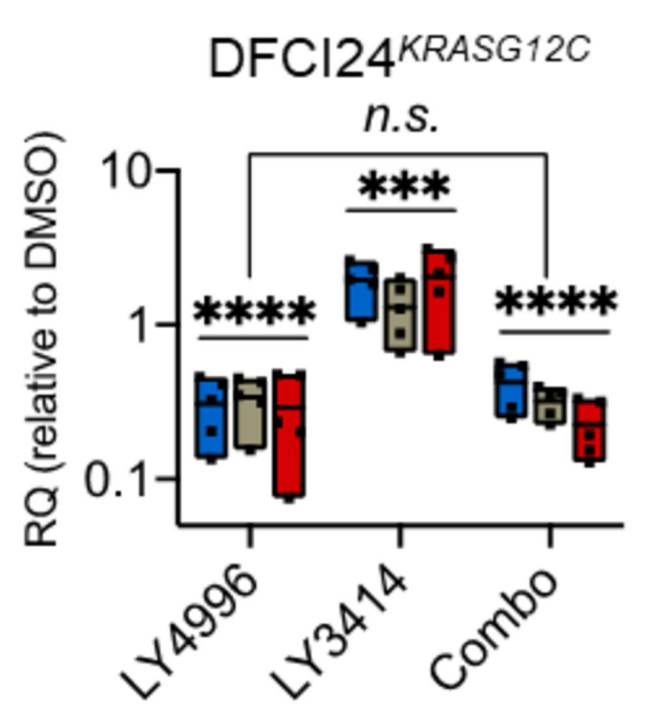

$E$

FOXO3a reporter activity
DFCI24KRASG12C

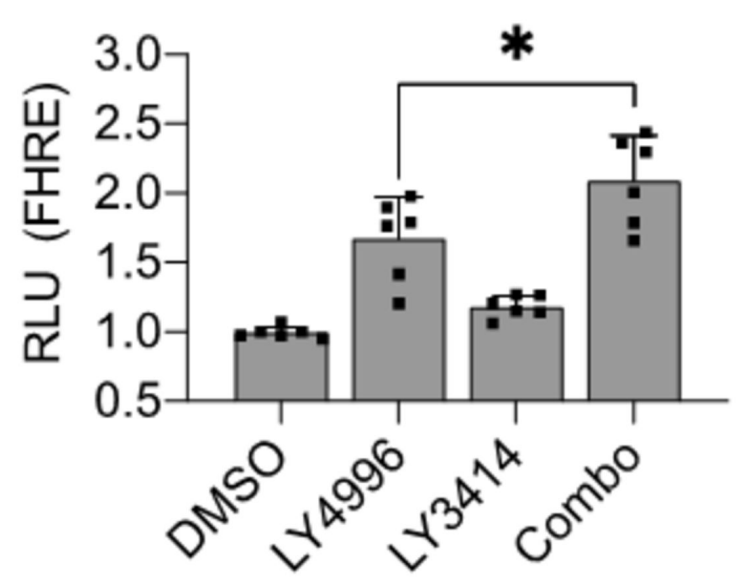

F

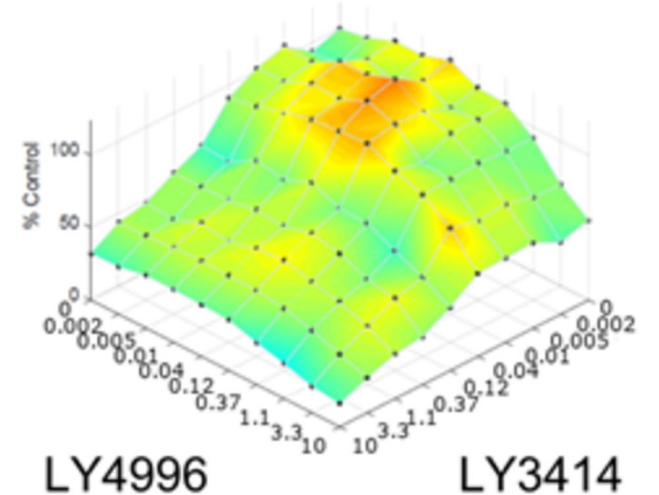

DFCl366
Synergism

DFCl516

Antagonism

LY3414 LY4996 10 10 10 LY3414 LY4996

LY3414

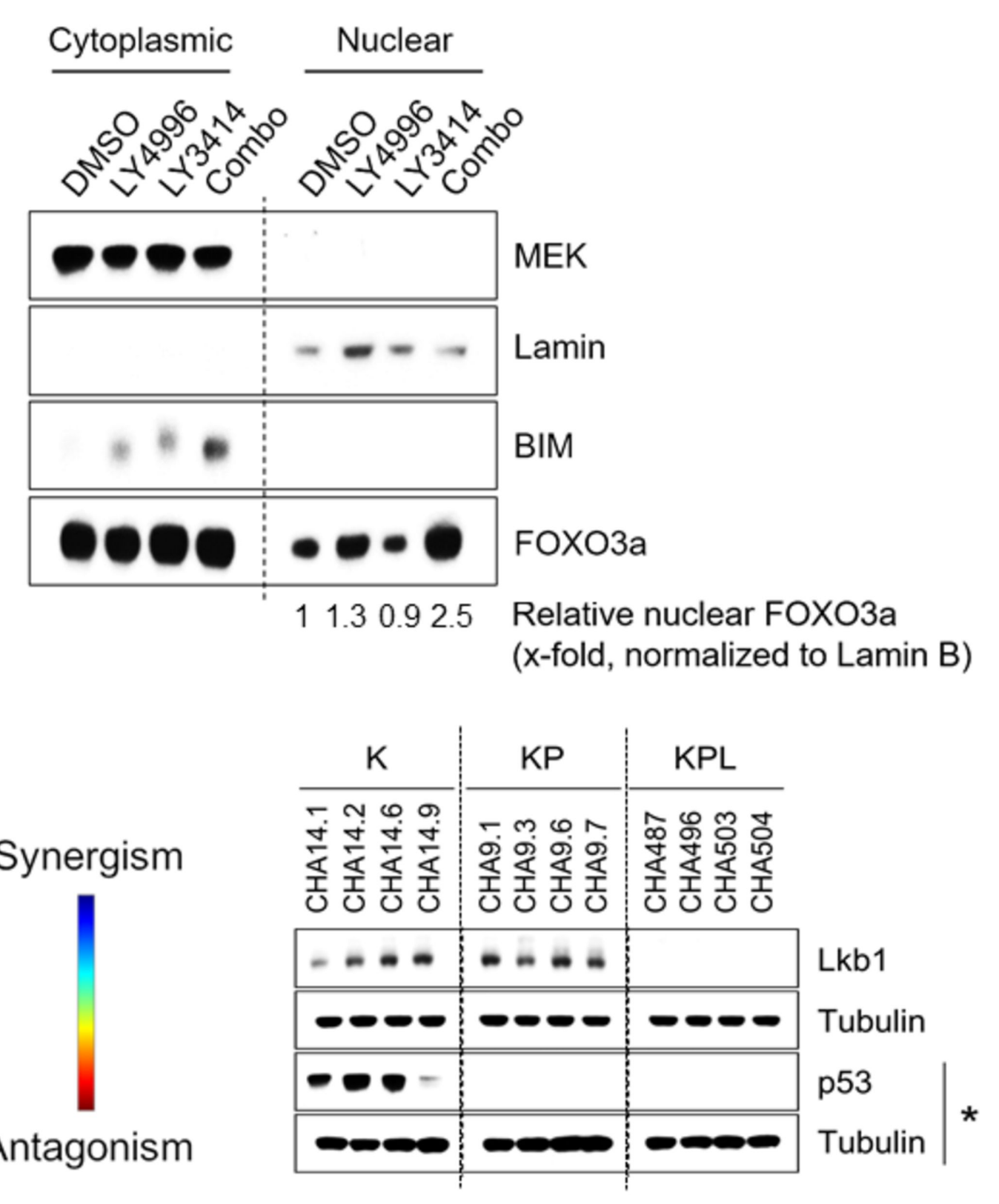


A

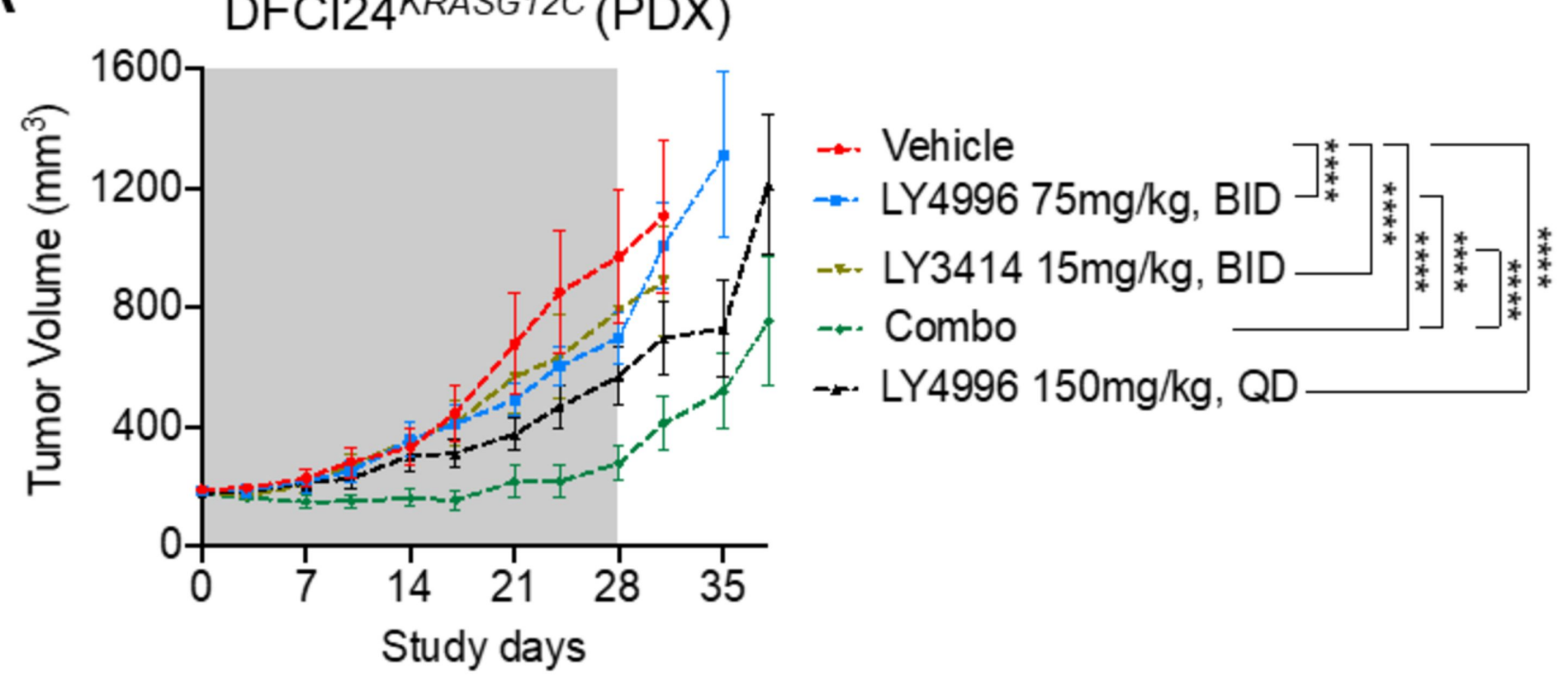

B
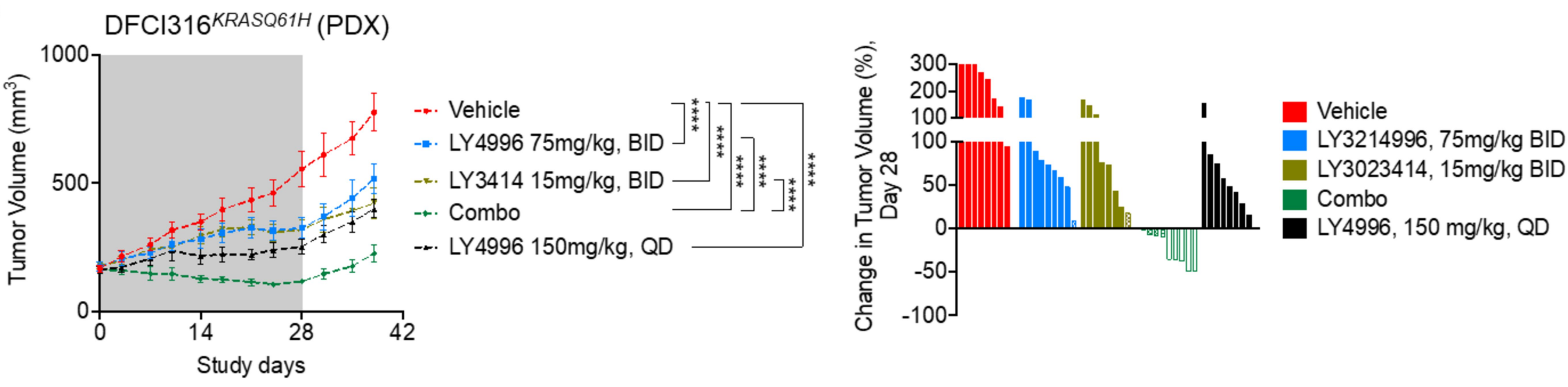

C

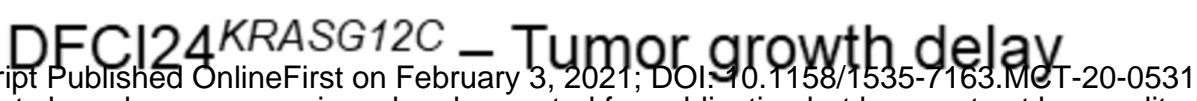

\begin{tabular}{|c|c|c|c|c|}
\hline Compound & $\begin{array}{l}\% \text { TGI } \\
\text { (Day 24) }\end{array}$ & $\begin{array}{l}\text { \% Maximum } \\
\text { Regression }\end{array}$ & $\begin{array}{c}\text { Days to } 300 \% \text { Target } \\
\text { Tumor Volume }\end{array}$ & $\begin{array}{l}T-C \\
\text { (Days) }\end{array}$ \\
\hline Vehicle & - & - & 20.8 & - \\
\hline $\begin{array}{l}\text { LY3214996, } \\
75 \mathrm{mg} / \mathrm{kg}, \text { BID }\end{array}$ & 36.7 & 0.0 & 23.1 & 2.3 \\
\hline $\begin{array}{c}\text { LY3023414 } \\
15 \mathrm{mg} / \mathrm{kg}, \mathrm{BID}\end{array}$ & 31.5 & 7.1 & 21.7 & 0.9 \\
\hline Combo & 94.4 & 16.7 & 36.6 & 15.8 \\
\hline $\begin{array}{c}\text { LY3214996 } \\
150 \mathrm{mg} / \mathrm{kg}, Q D\end{array}$ & 56.0 & 0.0 & 26.3 & 5.5 \\
\hline
\end{tabular}

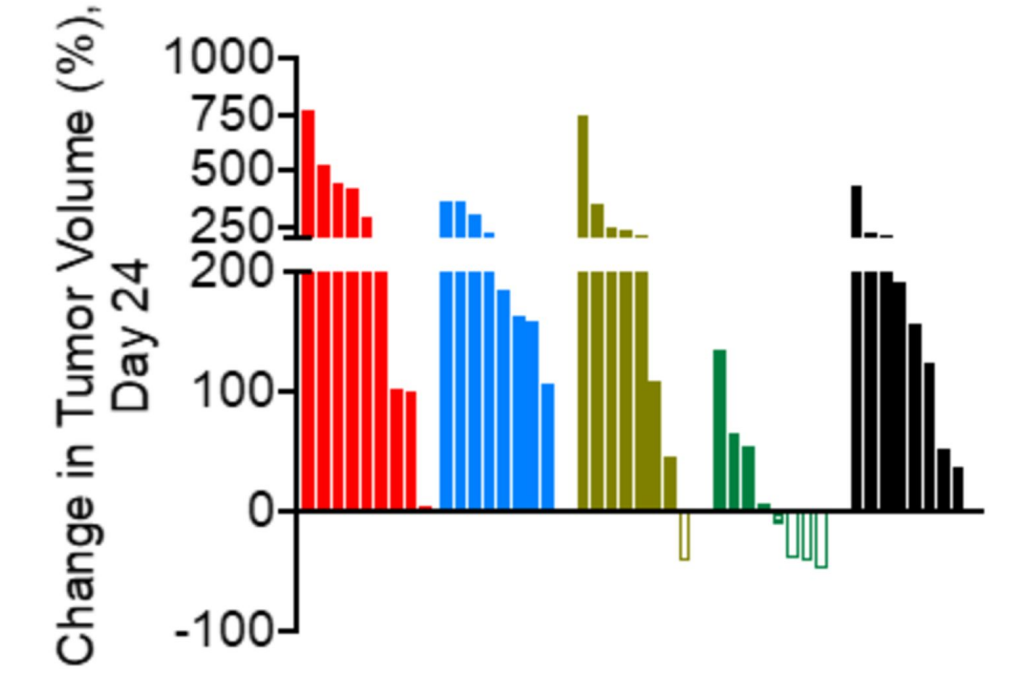

Vehicle

LY3214996, 75mg/kg, BID

LY3023414, 15mg/kg, BID

Combo

LY4996, $150 \mathrm{mg} / \mathrm{kg}, \mathrm{QD}$

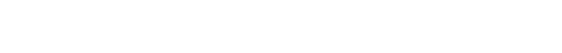

$$
\text { (1) }
$$

DFCI316KRASQ61H - Tumor growth delay
\begin{tabular}{|c|c|c|c|c|}
\hline Compound & $\begin{array}{c}\% \text { TGI } \\
(\text { Day 28) }\end{array}$ & $\begin{array}{c}\text { \% Maximum } \\
\text { Regression }\end{array}$ & $\begin{array}{c}\text { Days to 400\% Target } \\
\text { Tumor Volume }\end{array}$ & $\begin{array}{c}\text { T - C } \\
\text { (Days) }\end{array}$ \\
\hline Vehicle & - & - & 34.2 & - \\
\hline $\begin{array}{c}\text { LY3214996 } \\
75 \mathrm{mg} / \mathrm{kg}, \mathrm{BID}\end{array}$ & 61.4 & 0.0 & 46.4 & 12.2 \\
\hline $\begin{array}{c}\mathrm{LY} 3023414 \\
15 \mathrm{mg} / \mathrm{kg}, \mathrm{BID}\end{array}$ & 63.6 & 0.0 & 51.7 & 17.5 \\
\hline $\begin{array}{c}\text { Combo } \\
\text { LY3214996 } \\
150 \mathrm{mg} / \mathrm{kg}, \text { QD }\end{array}$ & 100.0 & 35.6 & 61.0 & 26.8 \\
\hline
\end{tabular}

D

DFCI24KRASG12C PDX

4hrs $\quad 8 \mathrm{hrs} 24 \mathrm{hrs}$

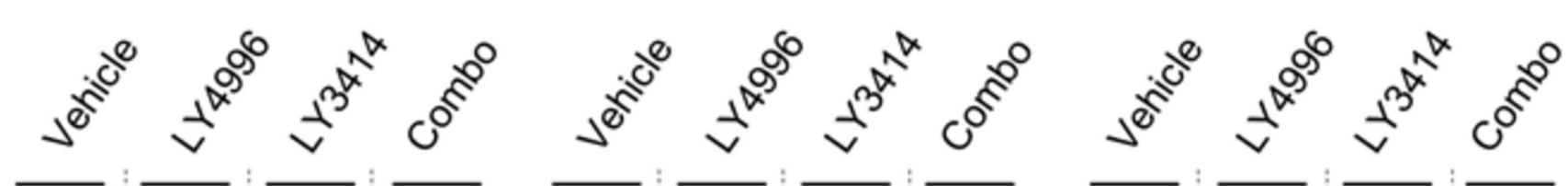

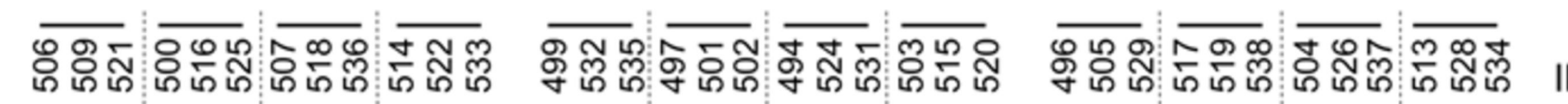

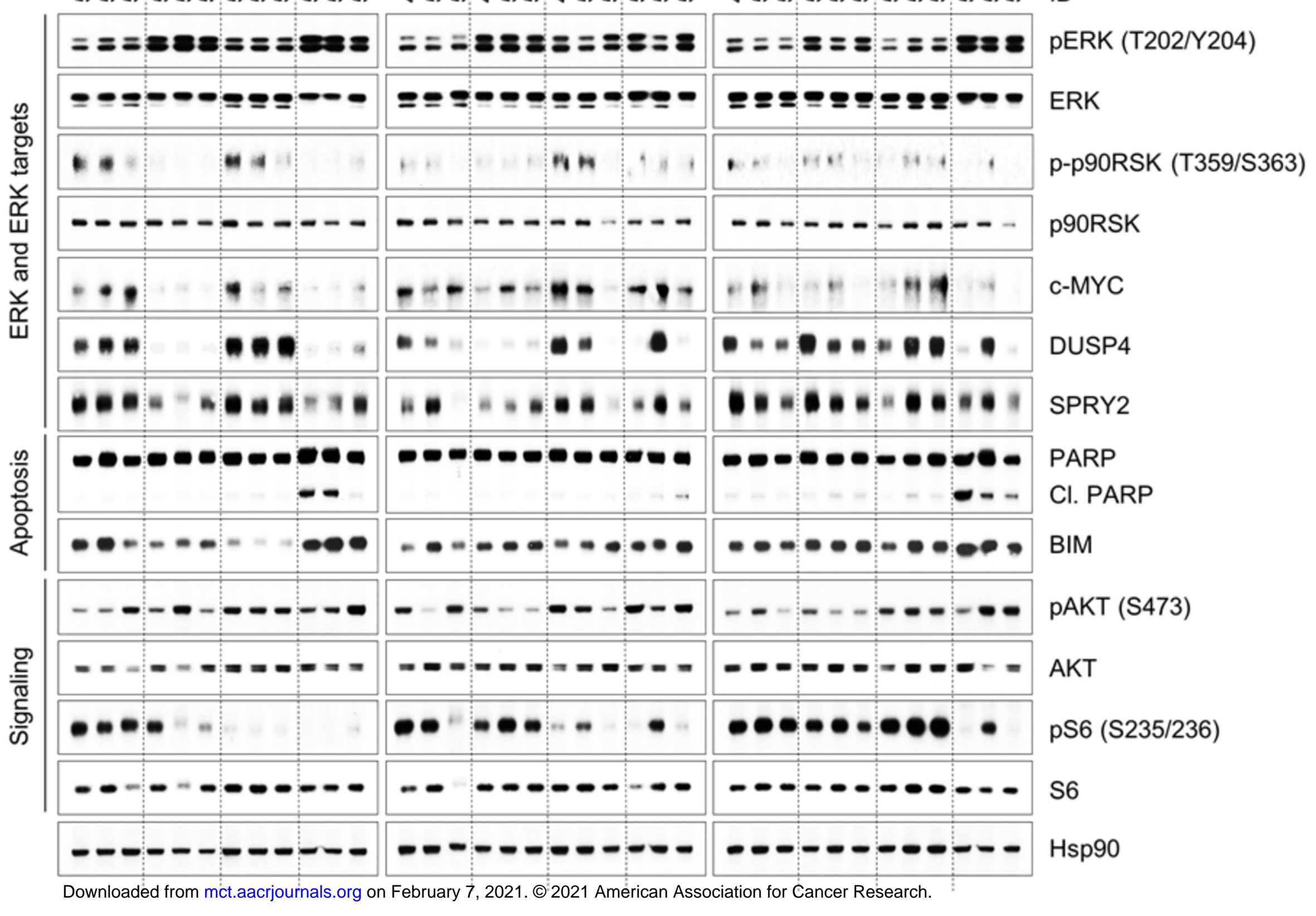

E $\quad$ ERK-dependent transcriptional output (DFCl24 PDX)

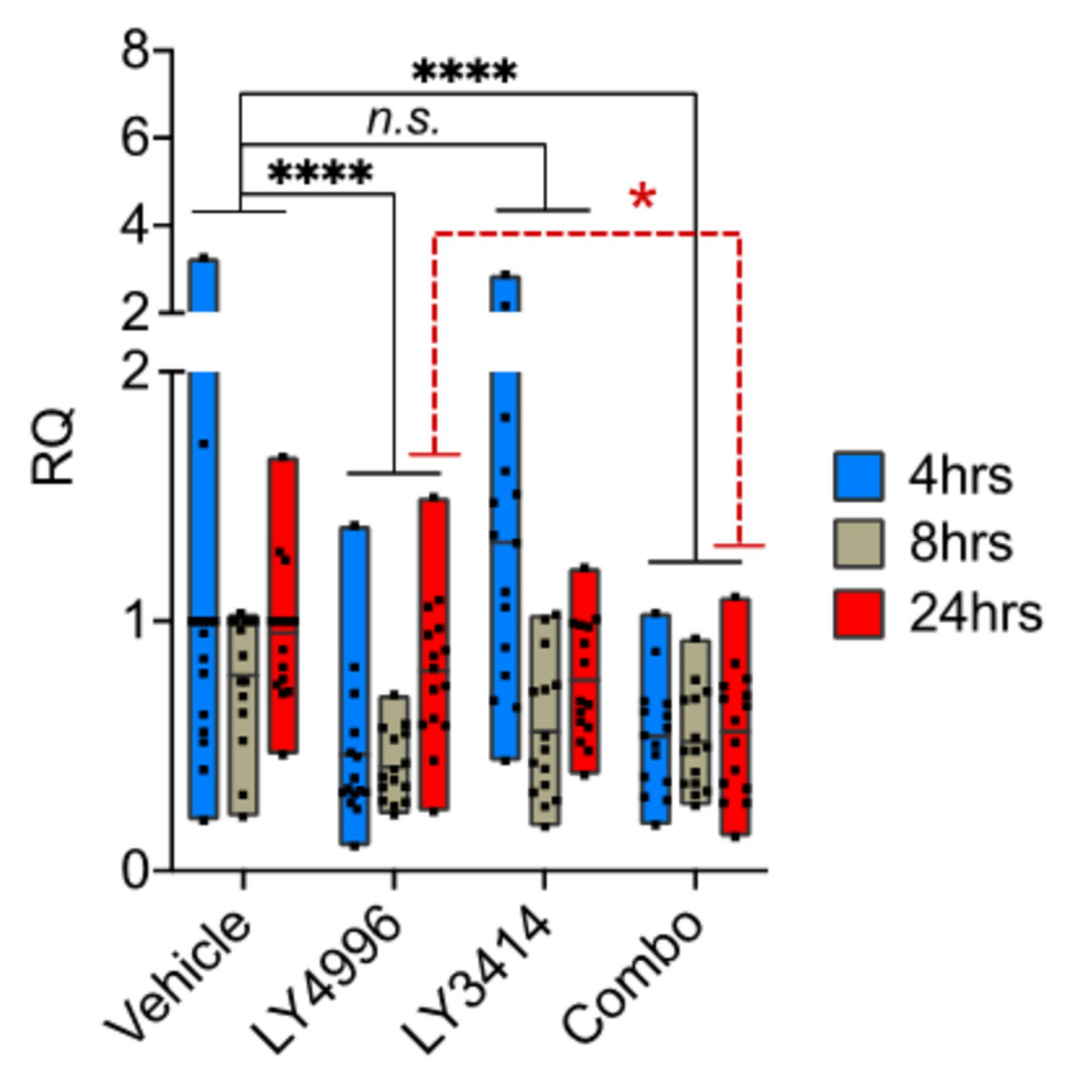




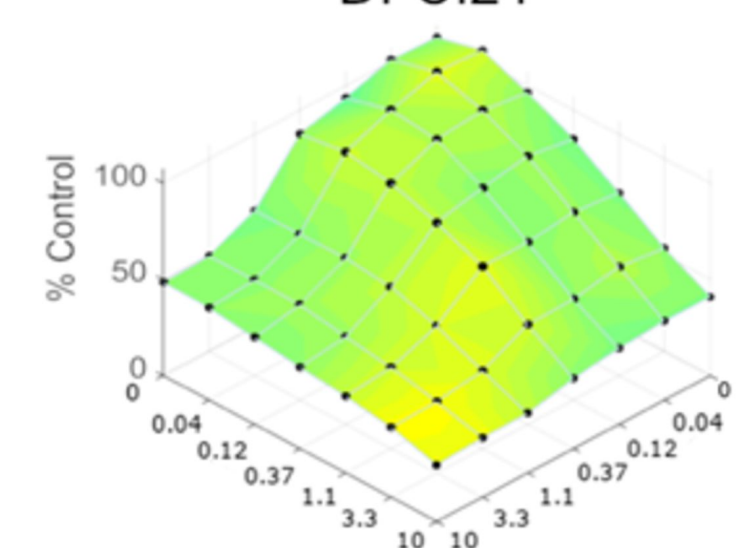

LY4996 ( $\mu \mathrm{M})$

Abema $(\mu \mathrm{M})$

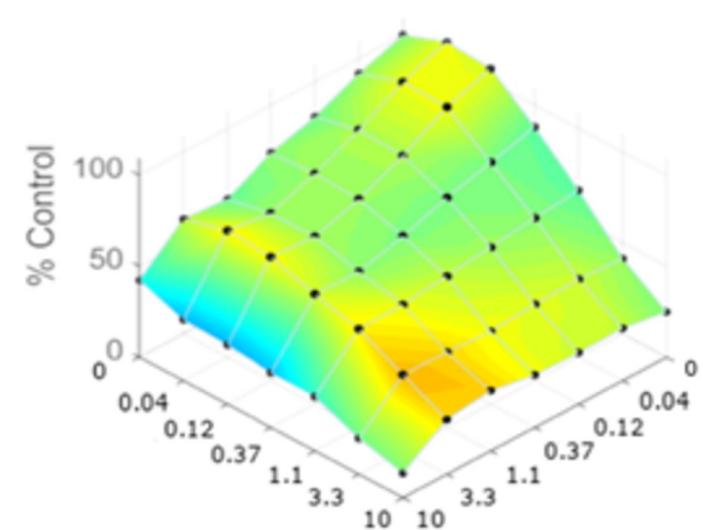

LY4996
Abema

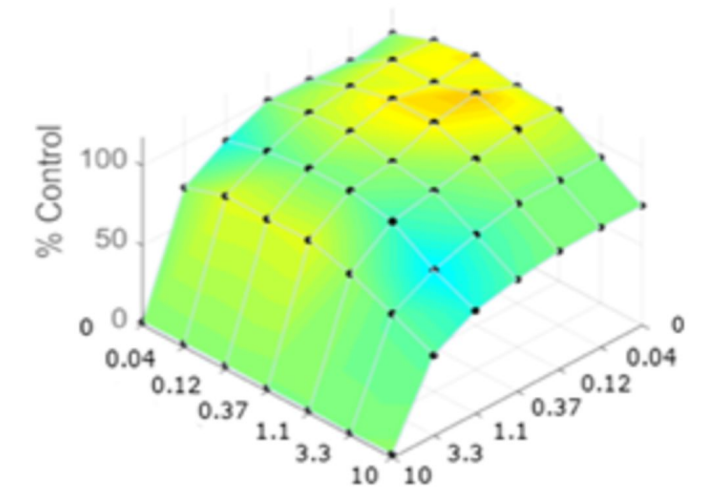

LY4996

Abema

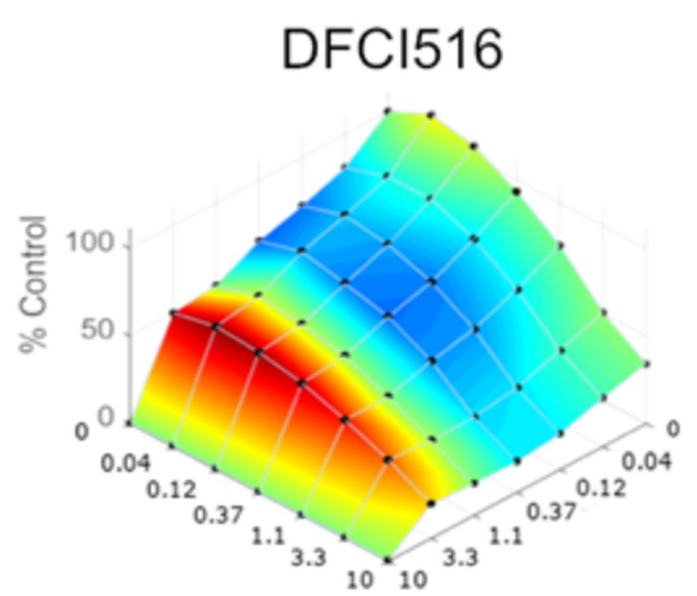

LY4996
Synergism

Antagonism

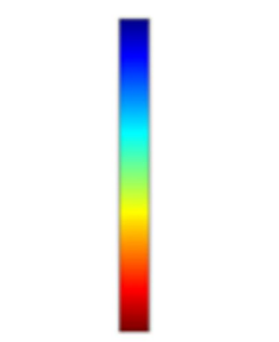

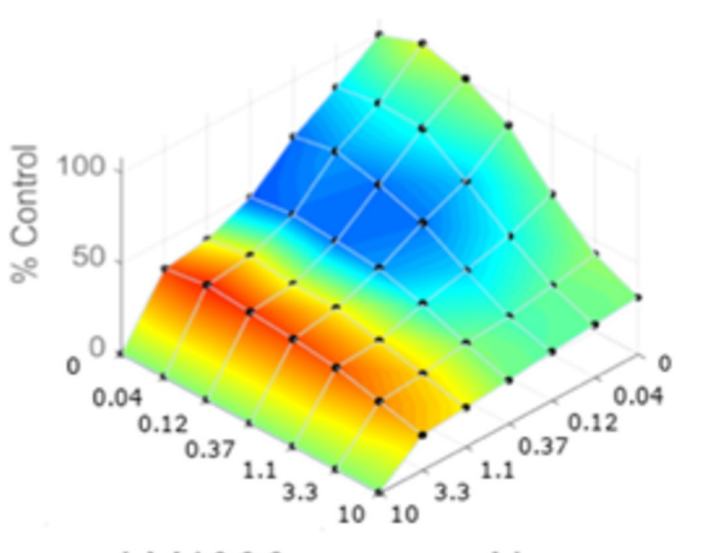

LY4996

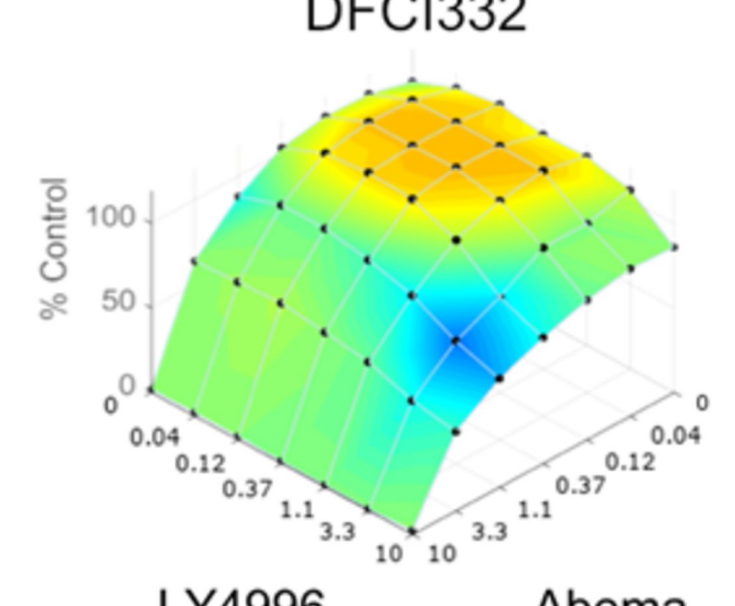

LY4996

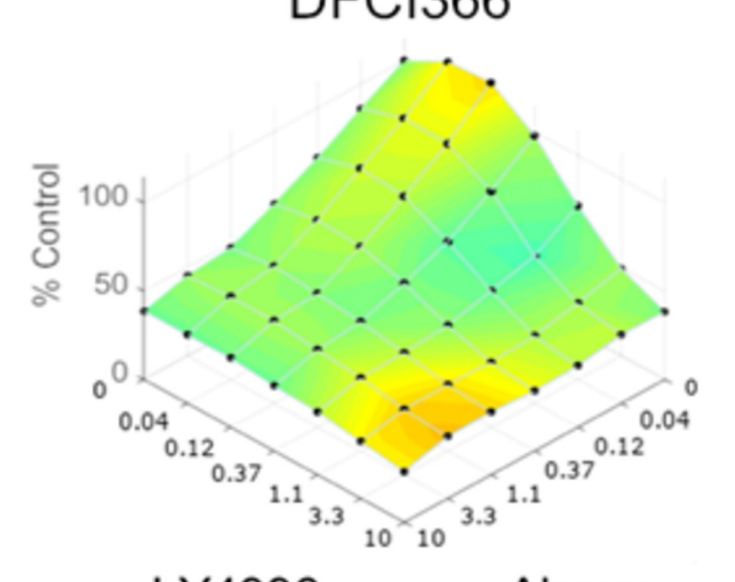

LY4996 Abema

B

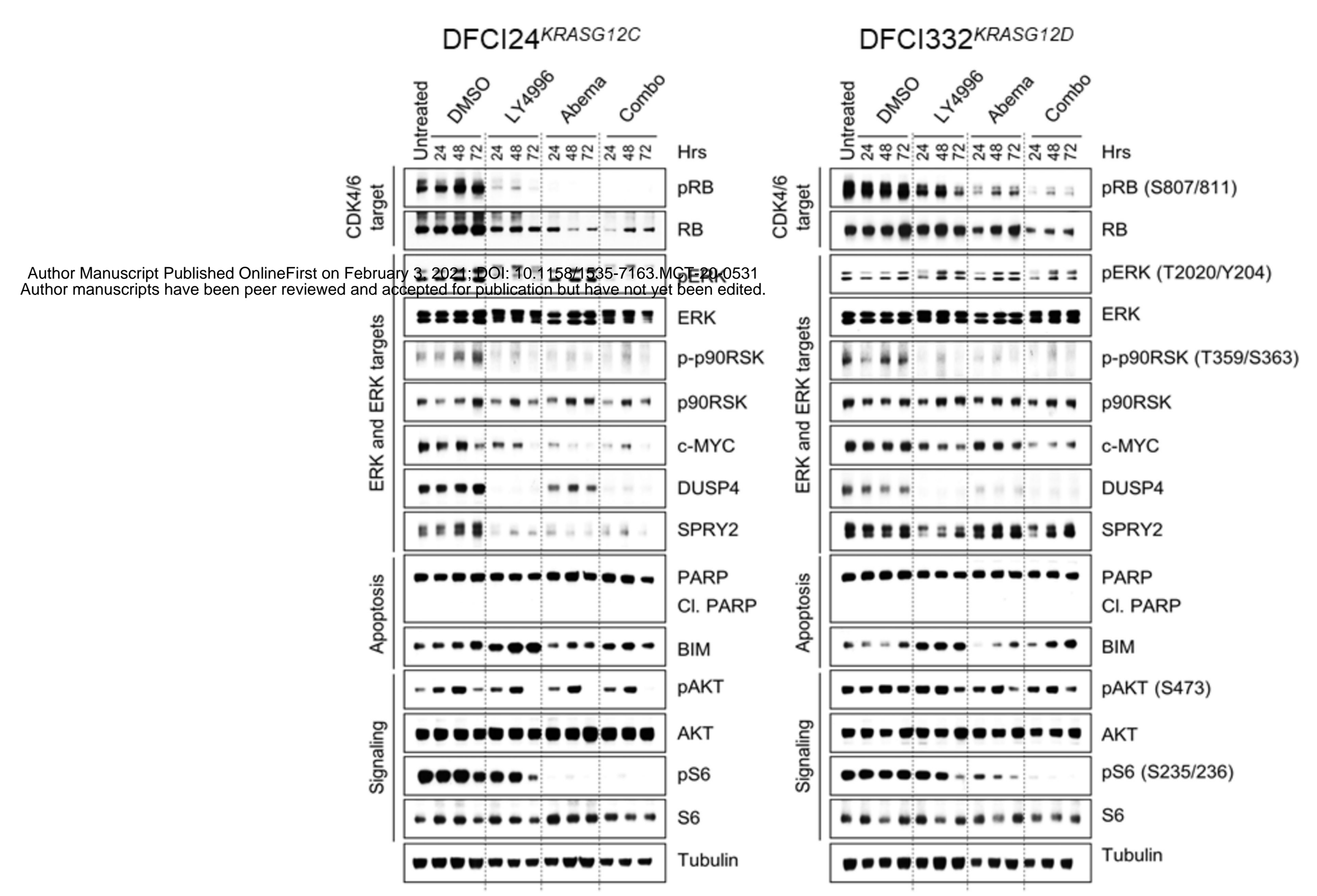

C

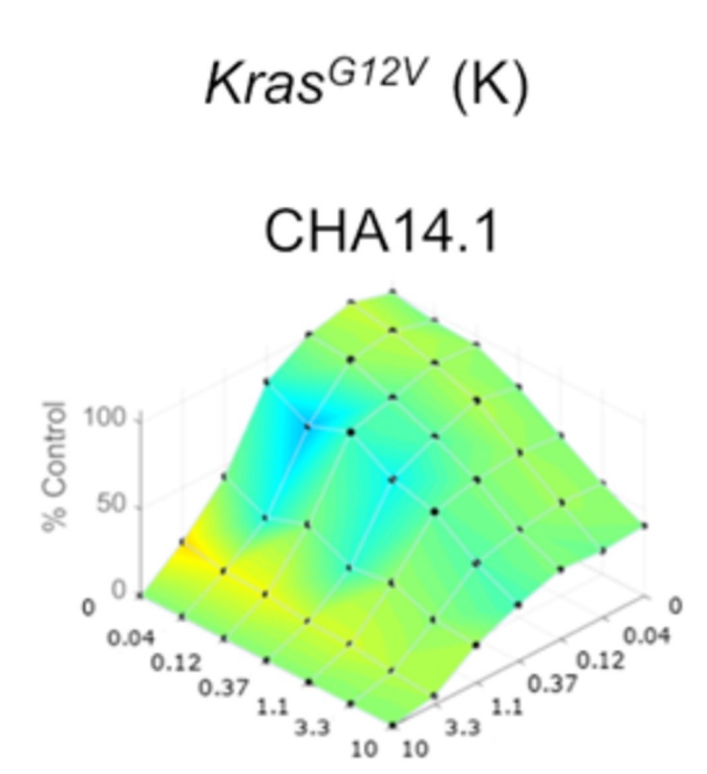

LY4996 $(\mu \mathrm{M}) \quad$ Abema $(\mu \mathrm{M})$

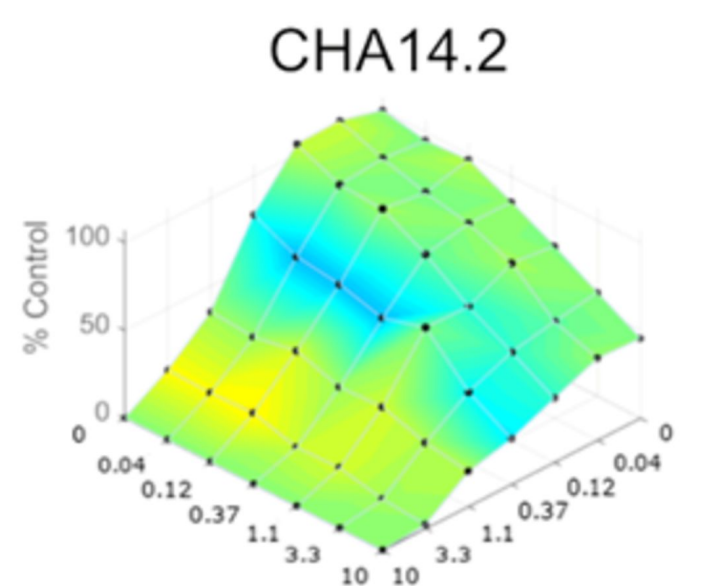

LY4996

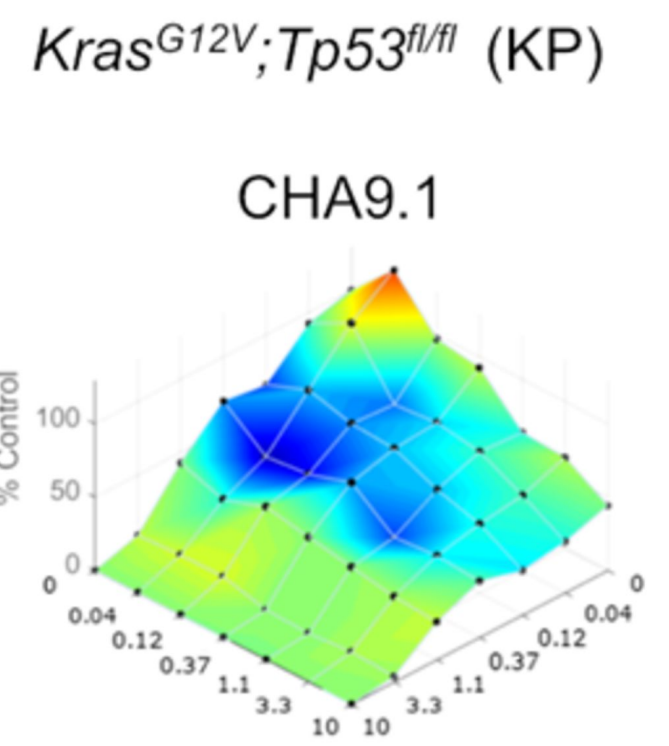

LY4996

Abema
CHA9.3

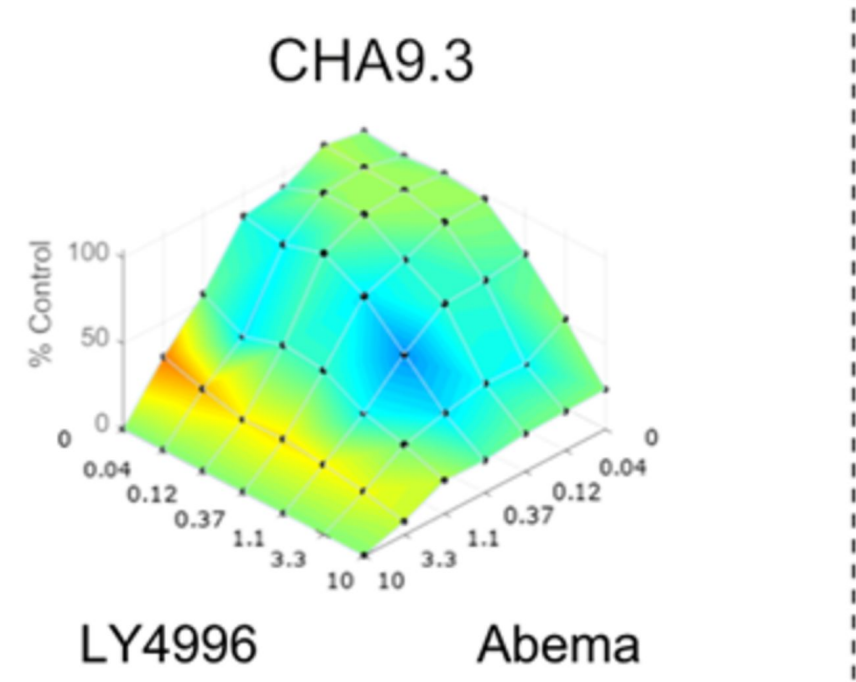

LY4996

Abema
$\operatorname{Kras}^{\mathrm{G} 12 V} ; T p 53^{f / f l} ; L k b 1^{f|f| f l}(\mathrm{KPL})$

CHA487

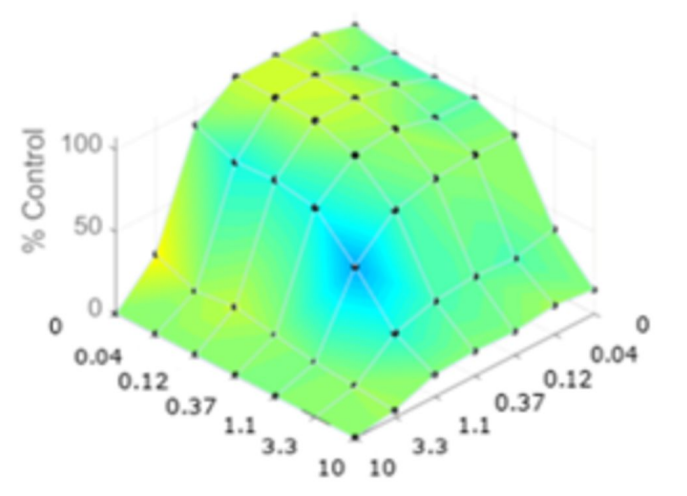

LY4996 Abema

CHA496

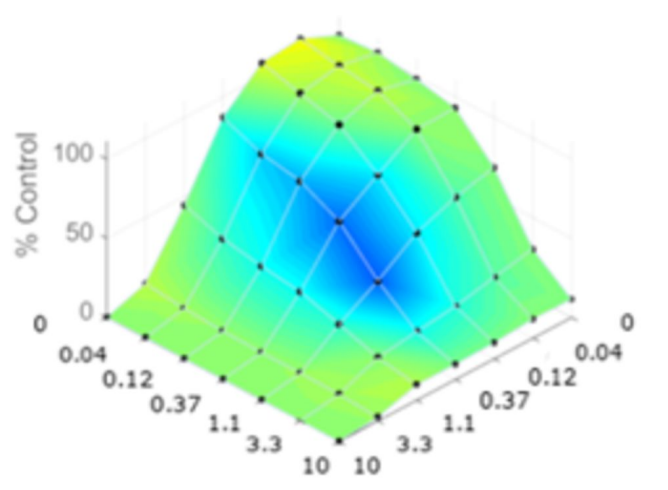

Antagonism

Synergism

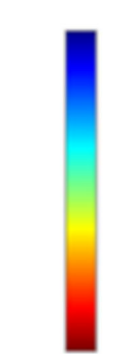



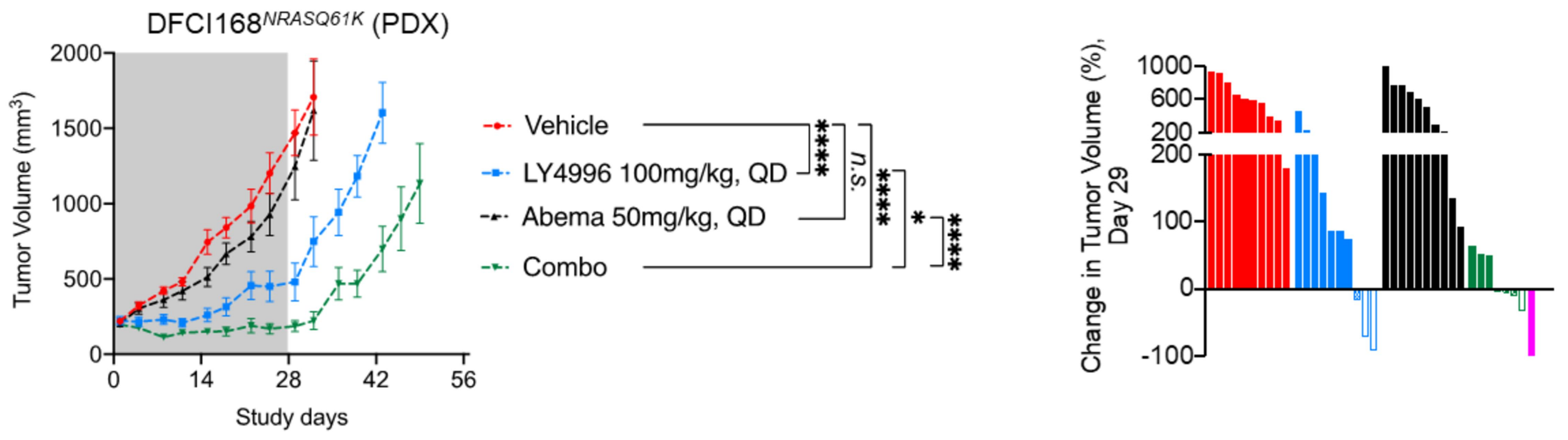

B
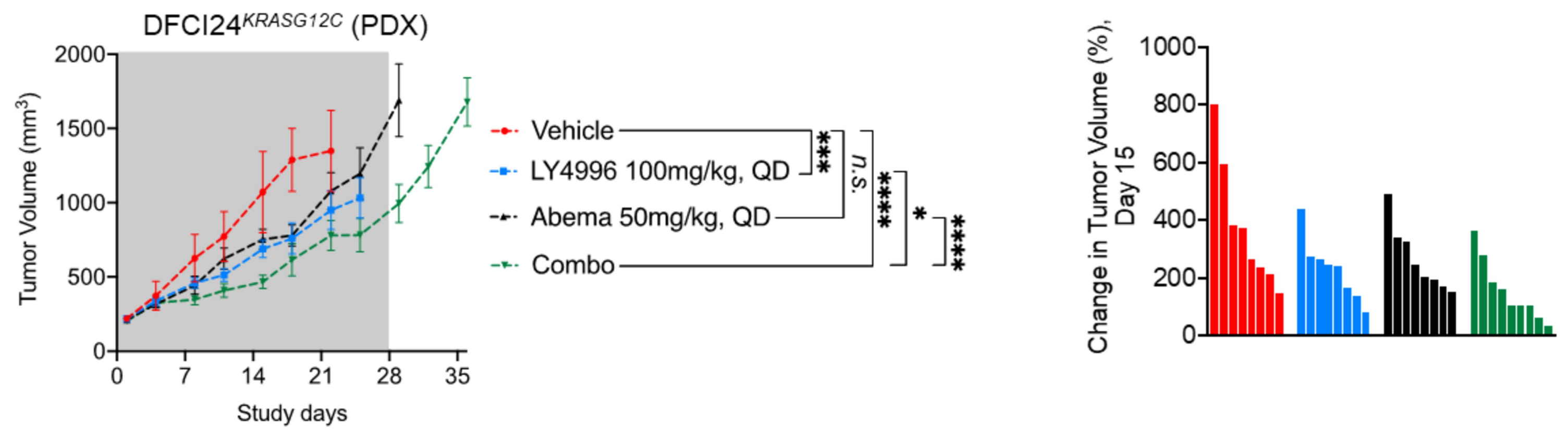

Vehicle

LY3214996

Abemaciclib

Combo

C

DFCI168NRASQ61K - Tumor growth delay

\begin{tabular}{|c|c|c|c|c|}
\hline $\begin{array}{l}\text { Catmaprablus } \\
\text { Author manuscripts }\end{array}$ & 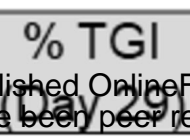 & 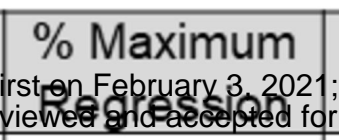 & 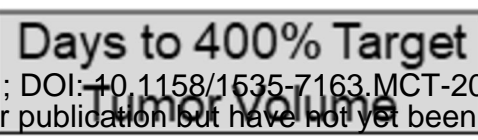 & $\begin{array}{c}T-C \\
\text { o5atalays) } \\
\text { dithoys }\end{array}$ \\
\hline Vehicle & - & - & 19.2 & - \\
\hline $\begin{array}{c}\text { LY3214996 } \\
\text { 100ma/kq. QD }\end{array}$ & 79.4 & 5.9 & 34.9 & 15.7 \\
\hline $\begin{array}{l}\text { Abemaciclib } \\
50 \mathrm{mg} / \mathrm{kg}, Q D\end{array}$ & 16.3 & 0.0 & 22.1 & 2.9 \\
\hline Combo & 100.0 & 37.8 & 44.0 & 24.8 \\
\hline
\end{tabular}

\begin{tabular}{|c|c|c|c|c|}
\hline Compound & $\begin{array}{c}\% \text { TGI } \\
\text { (Day 15) }\end{array}$ & $\begin{array}{c}\text { \% Maximum } \\
\text { Regression }\end{array}$ & $\begin{array}{c}\text { Days to 300\% Target } \\
\text { Tumor Volume }\end{array}$ & $\begin{array}{c}\text { T - C } \\
\text { (Days) }\end{array}$ \\
\hline Vehicle & - & - & 10.0 & - \\
\hline $\begin{array}{c}\text { LY3214996 } \\
\text { 100mg/kg, QD }\end{array}$ & 44.8 & 0.0 & 13.2 & 3.2 \\
\hline $\begin{array}{c}\text { Abemaciclib } \\
50 \mathrm{mg} / \mathrm{kg}, \text { QD }\end{array}$ & 36.7 & 0.0 & 13.1 & 3.1 \\
\hline Combo & 68.1 & 0.0 & 17.2 & 7.2 \\
\hline
\end{tabular}

DFCl168NRASQ61K PDX

F

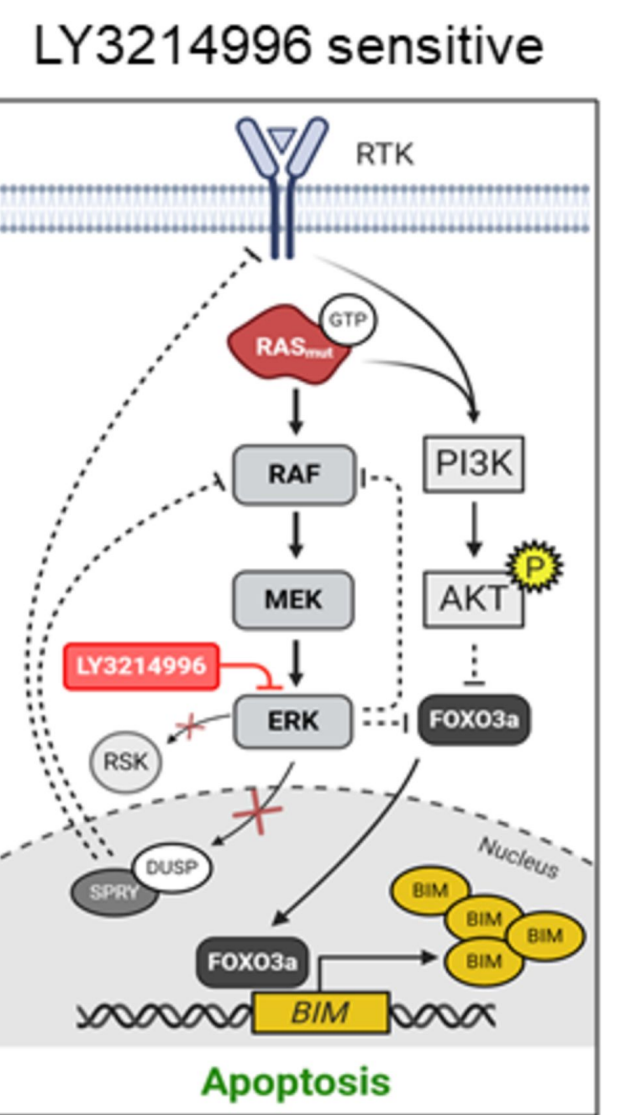

LY3214996 resistant

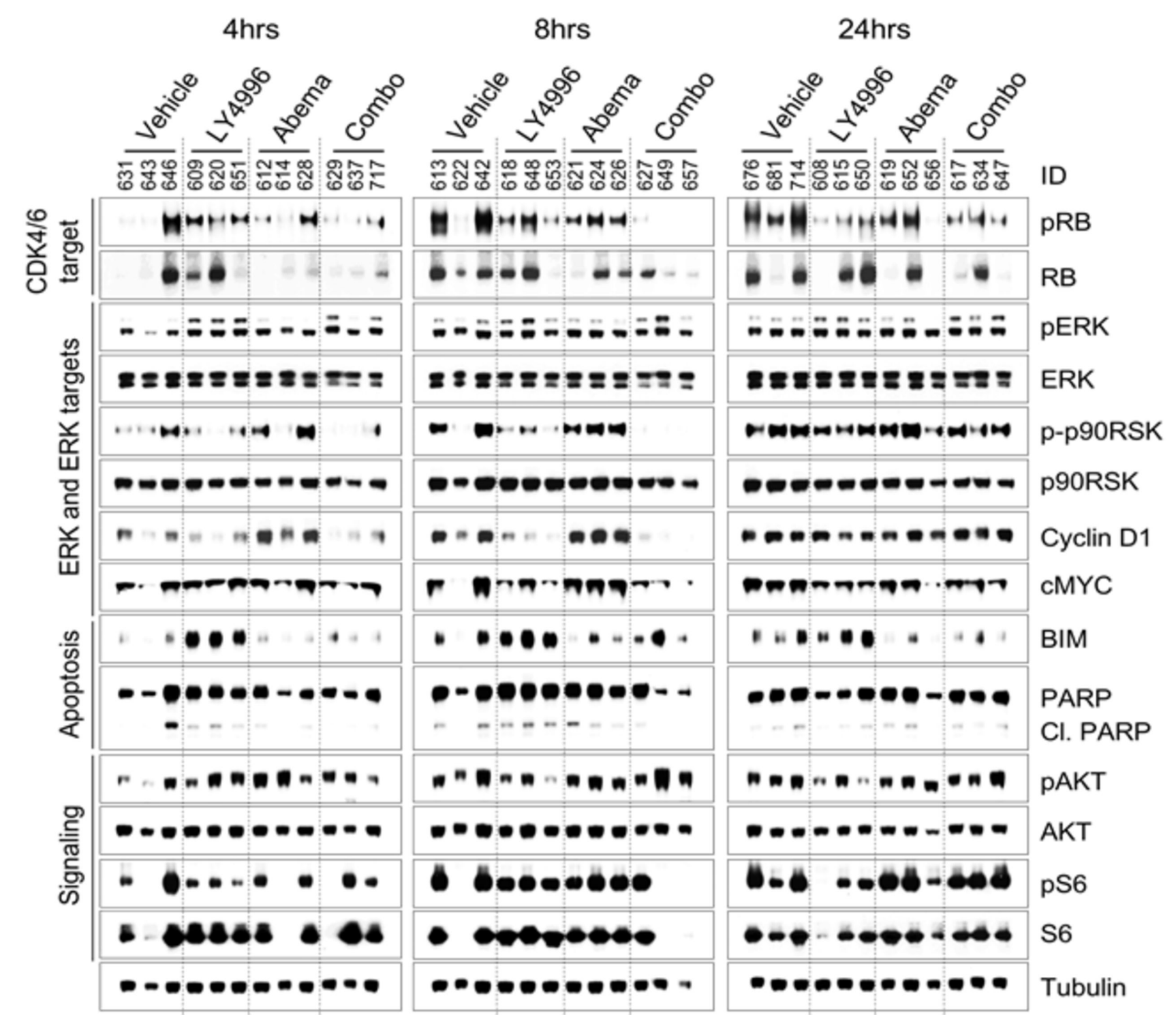

E

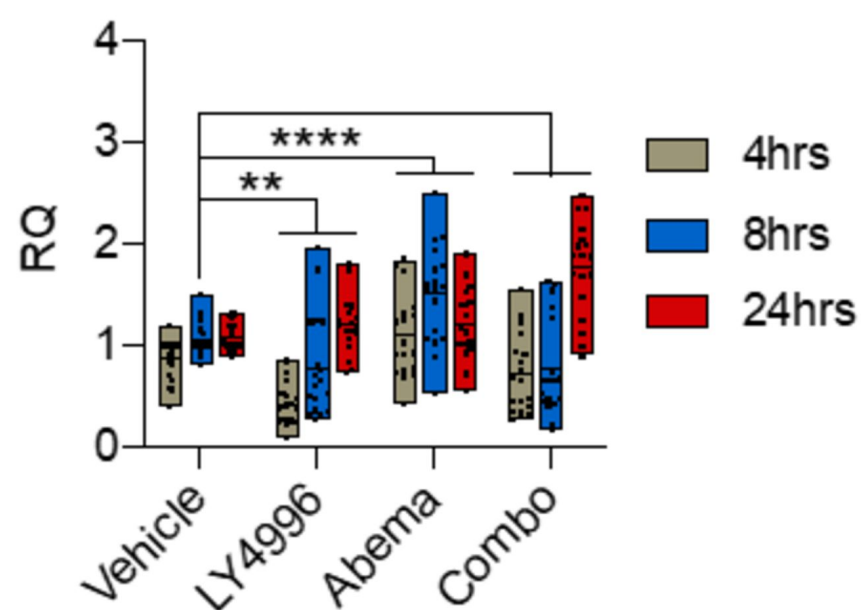

LY3214996 + LY3023414 LY3214996 + abemaciclib
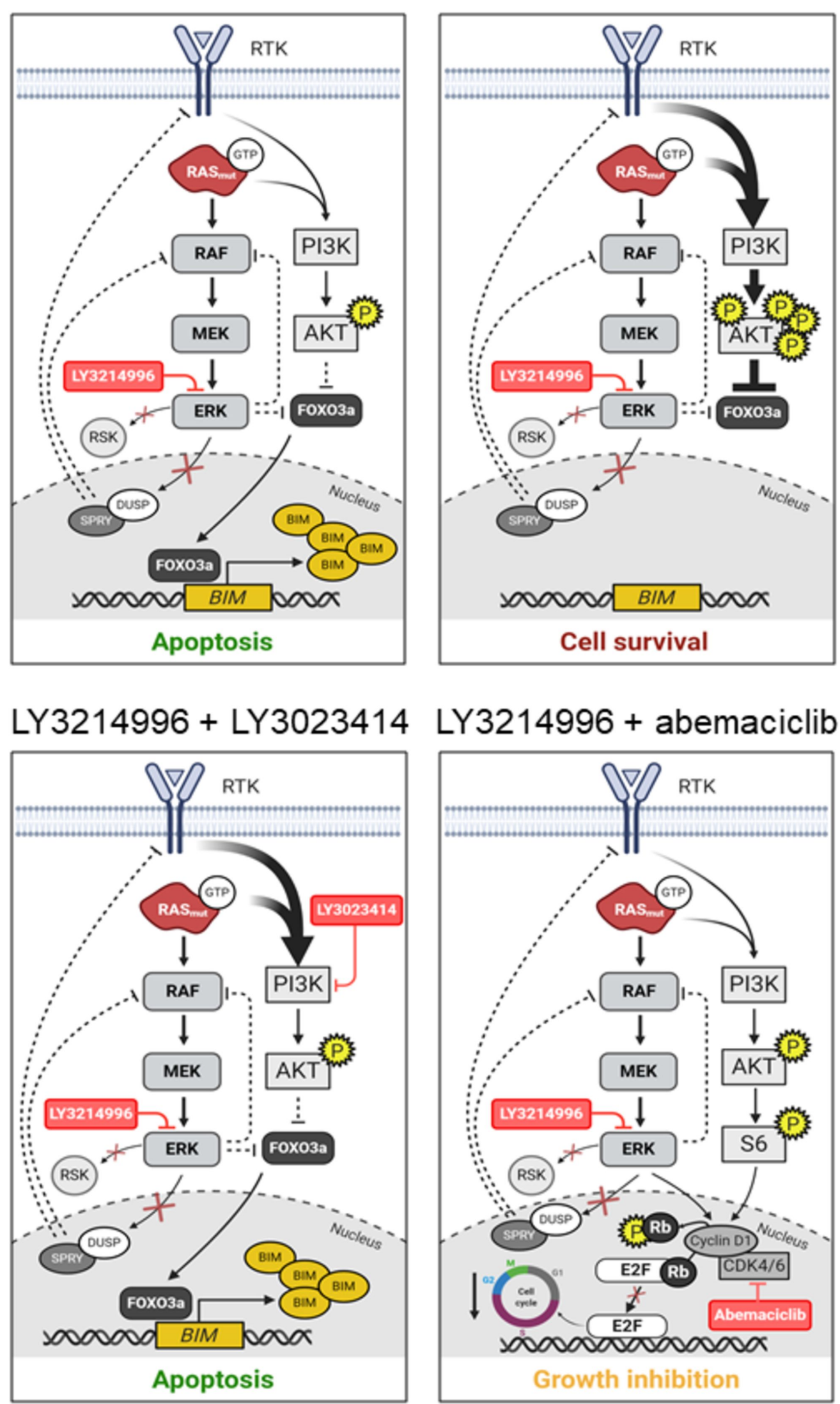

ERK-dependent transcriptional output (DFCl168 PDX)
Vehicle

LY3214996

Abemaciclib

Combo

DFCl24KRASG12C - Tumor growth delay 


\section{Molecular Cancer Therapeutics}

\section{ERK inhibitor LY3214996-based treatment strategies for RAS-driven lung cancer}

Jens Köhler, Yutong Zhao, Jiaqi Li, et al.

Mol Cancer Ther Published OnlineFirst February 3, 2021.

Updated version Access the most recent version of this article at: doi:10.1158/1535-7163.MCT-20-0531

Author Author manuscripts have been peer reviewed and accepted for publication but have not yet Manuscript been edited.

E-mail alerts Sign up to receive free email-alerts related to this article or journal.

Reprints and Subscriptions

Permissions
To order reprints of this article or to subscribe to the journal, contact the AACR Publications Department at pubs@aacr.org.

To request permission to re-use all or part of this article, use this link http://mct.aacrjournals.org/content/early/2021/02/03/1535-7163.MCT-20-0531.

Click on "Request Permissions" which will take you to the Copyright Clearance Center's (CCC) Rightslink site. 